\title{
Near Boundary Turbulence Characteristics among Stream Restorations of Varying Intensity
}

\author{
Sean M. Abel \\ West Virginia University
}

Follow this and additional works at: https://researchrepository.wvu.edu/etd

\section{Recommended Citation}

Abel, Sean M., "Near Boundary Turbulence Characteristics among Stream Restorations of Varying Intensity" (2012). Graduate Theses, Dissertations, and Problem Reports. 3377.

https://researchrepository.wvu.edu/etd/3377

This Thesis is protected by copyright and/or related rights. It has been brought to you by the The Research Repository @WVU with permission from the rights-holder(s). You are free to use this Thesis in any way that is permitted by the copyright and related rights legislation that applies to your use. For other uses you must obtain permission from the rights-holder(s) directly, unless additional rights are indicated by a Creative Commons license in the record and/ or on the work itself. This Thesis has been accepted for inclusion in WVU Graduate Theses, Dissertations, and Problem Reports collection by an authorized administrator of The Research Repository @ WVU. For more information, please contact researchrepository@mail.wvu.edu. 
Near Boundary Turbulence Characteristics among Stream Restorations of Varying Intensity

\author{
Sean M. Abel
}

Thesis submitted to the

Benjamin M. Statler College of Engineering and Mineral Resources at West Virginia University in partial fulfillment of the requirements for the degree of

\author{
Master of Science \\ in \\ Civil Engineering
}

Leslie C. Hopkinson, Ph.D., Chair

Donald D. Gray, Ph.D.

Angela S. Campbell

Department of Civil and Environmental Engineering

Morgantown, West Virginia

2012

Keywords: Stream restoration, near boundary turbulence

Copyright 2012 Sean M. Abel 


\title{
ABSTRACT \\ Near Boundary Turbulence Characteristics among Stream Restoration of Varying Intensity
}

\author{
Sean M. Abel
}

Stream restoration is estimated to be a multi-billion dollar industry and includes techniques such as planting vegetation, modifying channel form, and installing in-stream structures. These techniques potentially alter the velocity field and flow complexity. The specific objective of this research was to characterize near-boundary flow within the three restored reaches of varying intensities located in the Stream Research, Education, and Management (StREAM) Laboratory at Virginia Tech. Three restoration techniques were applied in 2009-10 to consecutive reaches of Stroubles Creek: 1$)$ cattle restriction only $(0.5 \mathrm{~km}) ; 2)$ cattle restriction, banks reshaped to 3:1 slope and re-vegetated $(0.6 \mathrm{~km})$; and, 3$)$ designed and installed a two-stage channel with inset floodplains and re-vegetated $(0.3 \mathrm{~km})$. Results were compared to an upstream reference reach $(\sim 0.35 \mathrm{~km})$ where cattle have been excluded for approximately 17 years. Two experimental sample locations, positioned in riffles, were identified within each section of restoration treatment and the reference reach. Velocity measurements, pebble counts, and topographic surveys were completed twice at each location. Three-dimensional velocities were measured with a 16-MHz acoustic Doppler velocimeter (MicroADV) at 49 points within a $30 \mathrm{~cm} \mathrm{x} 30 \mathrm{~cm}$ grid within each experimental sample location. Velocity was measured at a vertical distance of 7 $\mathrm{cm}$ from the streambed, and the MicroADV recorded velocity for $2 \mathrm{~min}$ at $50 \mathrm{~Hz}$ at each of the 49 points. All measurements were completed at baseflow. Stage and turbidity were measured continuously during velocity measurements utilizing existing monitoring equipment. Turbulent kinetic energy (TKE) and Reynolds shear stresses $\left(\tau_{\mathrm{xy}}\right.$ and $\left.\tau_{\mathrm{xz}}\right)$ were calculated for each velocity measurement. At baseflow the differences among restoration treatments did not directly result in differences in turbulence statistics. Overall velocity vector magnitudes were influenced by the flow depth and the channel width of the stream cross section at the location and time of the sample. With few exceptions, TKE and $\tau_{\mathrm{xz}}$ varied by sample date likely due to redistribution of bed sediment following storm events. TKE and $\tau_{\mathrm{xz}}$ were statistically different between the two sample locations within a common reach. A correlation can be seen between turbulence characteristics and the variation of flow depth within the measurement area. This correlation indicates that the streambeds with greater depth variability cause greater TKE and $\tau_{\mathrm{xz}}$. TKE and $\tau_{\mathrm{xz}}$ had similar spatial distributions. 


\section{Acknowledgements}

Partial support for this work was provided by the National Science Foundation's ADVANCE IT Program. I would like to thank NSF for making this research possible.

There are many people I would like to thank for their help and support which has made this thesis possible. First and foremost I would like to thank my advisor and committee chairperson, Dr. Leslie Hopkinson, for her advice, assistance and patience throughout the duration of this project. Without her guidance this thesis would not have been manageable. I would like to thank committee member Dr. Donald Gray for his knowledge and teaching, and for strengthening my interest in the field of hydro technical engineering. Thank you to Angela Campbell for giving her time to join the committee. I appreciate my fellow students at West Virginia University for making the years I spent there the best of my life. I would also like to express my gratitude to the faculty and staff of the Benjamin M. Statler College of Engineering and Mineral Resources at West Virginia University for their teaching and support over the years.

Two months of research for this project was conducted at Virginia Tech in Blacksburg, VA. I would like to thank Dr. W. Cully Hession and Laura Lehmann of the Virginia Tech Biological Systems Engineering Department. They provided endless assistance with facilities and equipment access at Stroubles Creek and I am very grateful for their help. I would also like to express my appreciation for the students of the BSE department for their assistance and hospitality during my summer stay; it was truly a great experience.

I would like to personally thank my Mother, Joyce Abel, and my Father, Robin Abel. Their love and guidance throughout my life has been tremendous. I am truly grateful for the support I have received from my family and friends over the years and I will never forget the help they have given me. 


\section{Grant Information}

Partial support for this work was provided by the National Science Foundation's ADVANCE IT Program under Award HRD-1007978. Any opinions, findings, and conclusions or recommendations expressed in this material are those of the author(s) and do not necessarily reflect the views of the National Science Foundation. 


\section{Table of Contents}

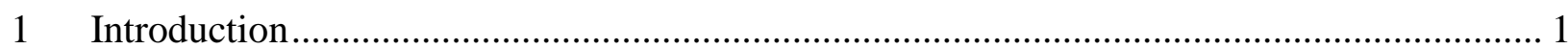

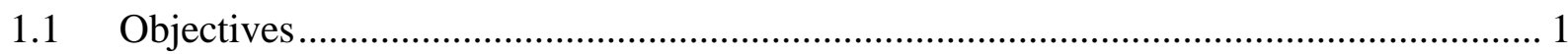

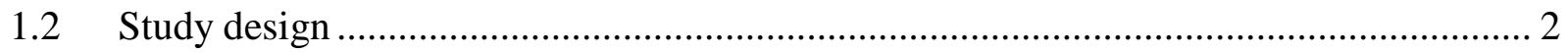

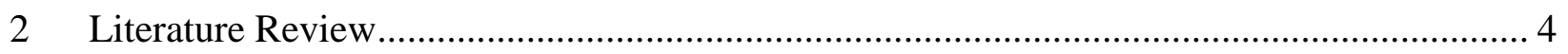

2.1 Stream Restoration in the United States.................................................................. 4

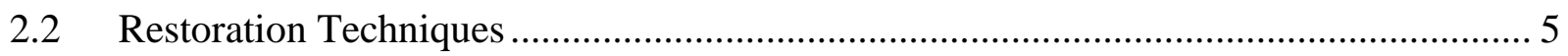

2.2.1 Vegetation .................................................................................................. 5

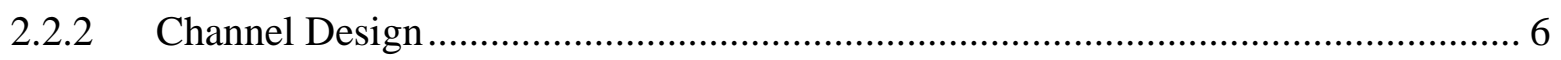

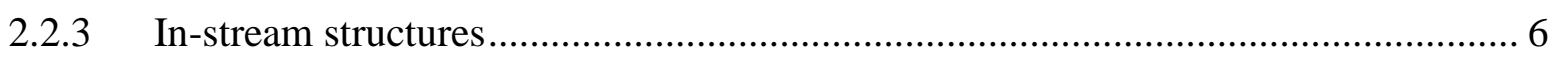

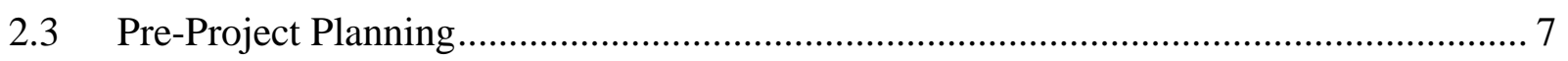

2.4 Post-Restoration Monitoring ...................................................................................... 7

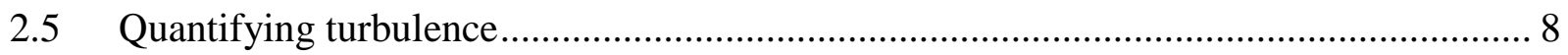

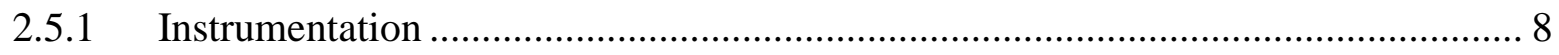

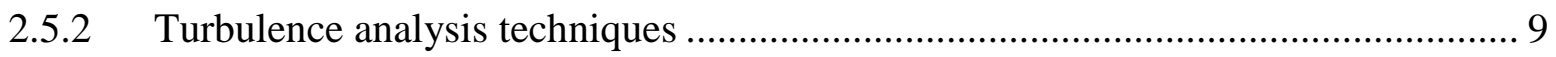

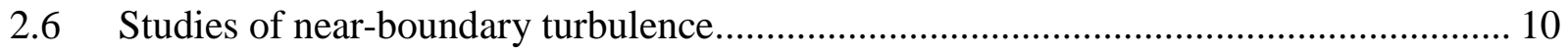

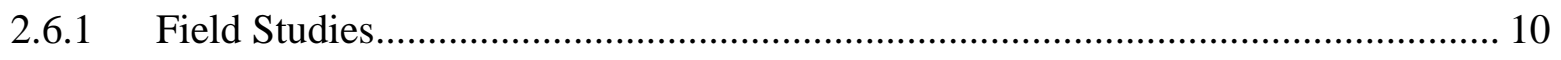

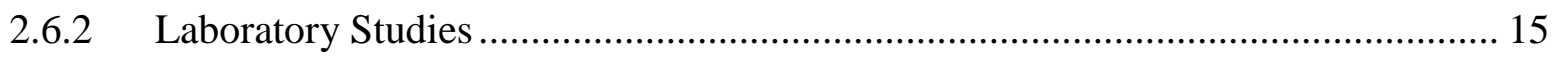

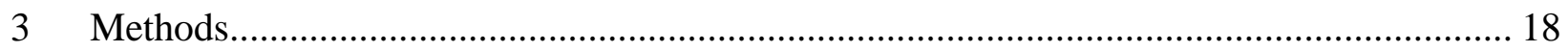

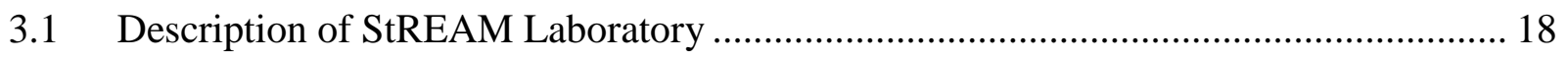

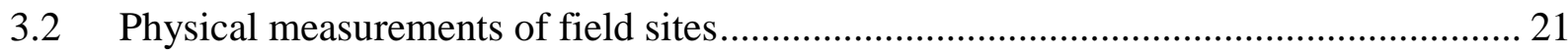

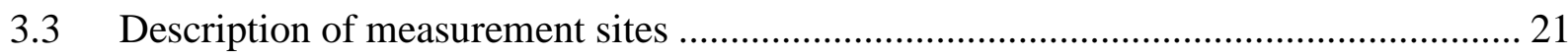

3.3.1 Reference Reach (R0): Cattle restriction for 17 years ............................................. 22

3.3.2 Reach 1 (R1): Cattle Restriction ....................................................................... 27

3.3.3 Reach 2 (R2): Cattle restriction, banks reshaped to 3:1 slope and re-vegetated..... 32 
3.3.4 Reach 3 (R3): Designed and installed a two-stage channel with inset floodplains

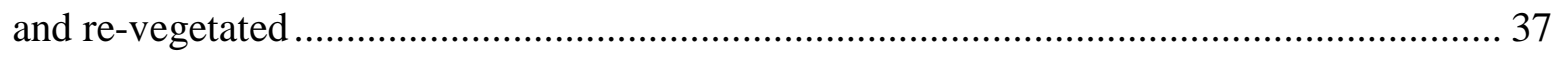

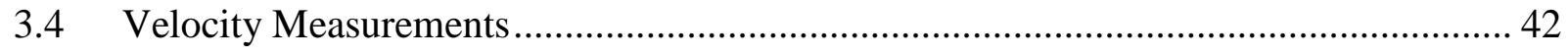

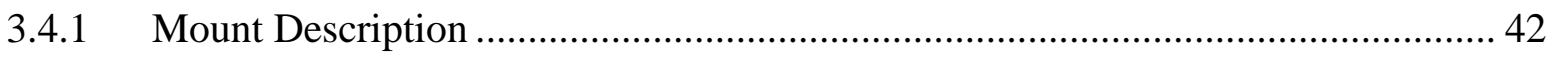

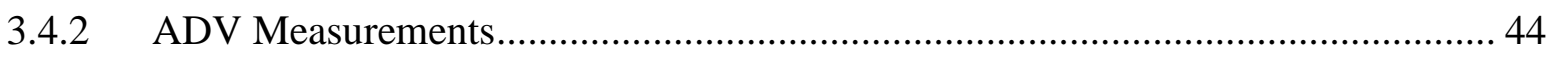

3.5 Data Analysis and Statistical Methods ………………............................................... 45

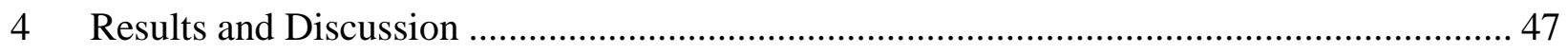

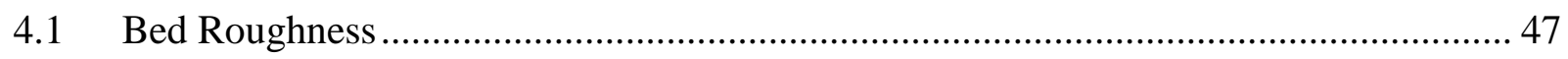

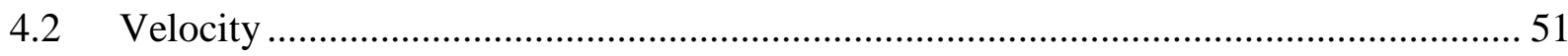

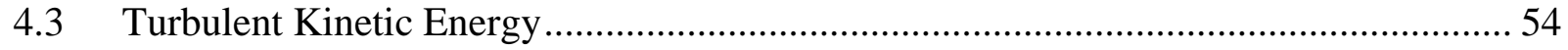

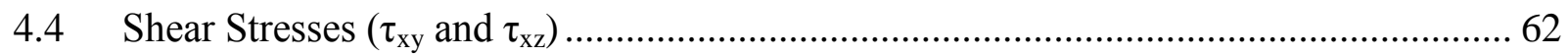

4.5 Comparison of Restoration Treatments...................................................................... 70

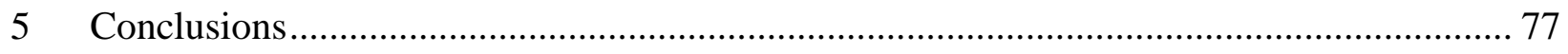

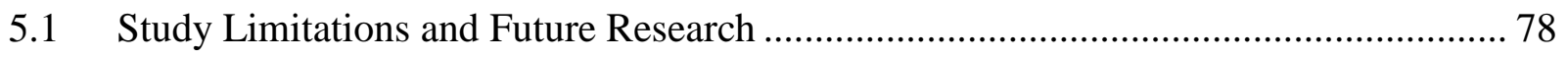

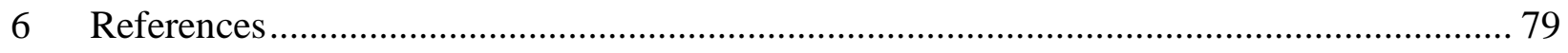

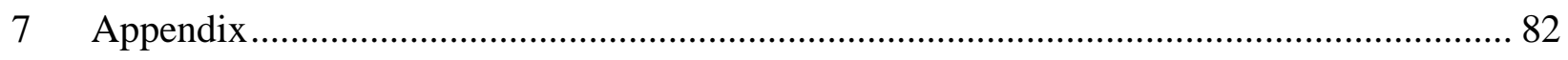




\section{Table of Figures}

Figure 1: Stroubles Creek with restoration reaches, multi-parameter sondes, and sample locations labeled. 3

Figure 2: Stroubles Creek with restoration reaches, multi-parameter sondes, and sample locations labeled.

Figure 3: Continuous discharge measurements for the two month sample period with vertical lines indicating time of velocity sampling. 23 Figure 4: a) Upstream, b) downstream, c) left bank, and d) right bank of sample location 1 within the reference reach (ROL1): cattle restriction for 17 years. 25

Figure 5: Cross section of location one in the reference reach (R0L1) with the water surface (blue) and the measurement area (red) marked.

Figure 6: a) Upstream, b) downstream, c) left bank, and d) right bank of sample location 2 within the reference reach (ROL2): cattle restriction for 17 years. 26 Figure 7: Cross section of location two in the reference reach (R0L2) with the water surface (blue) and the measurement area (red) marked.... 27

Figure 8: Continuous discharge measurements for the two month sample period with vertical lines indicating time of velocity sampling. 28 Figure 9: a) Upstream, b) downstream, c) left bank, and d) right bank of sample location 1 within the reach 1 (R1L1): cattle restriction. 29

Figure 10: Cross section of location one in reach one (R1L1) with the water surface (blue) and the measurement area (red) marked.

Figure 11: a) Upstream, b) downstream, c) left bank, and d) right bank of sample location 2 within reach 1 (R1L2): cattle restriction.

Figure 12: Cross section of location two in reach one (R1L2) with the water surface (blue) and the measurement area (red) marked.

Figure 13: Continuous discharge measurements for the two month sample period with vertical lines indicating time of velocity sampling.

Figure 14: a) Upstream, b) downstream, c) left bank, and d) right bank of sample location 2

within reach 2 (R2L1):cattle restriction, banks reshaped to 3:1 slope and re-vegetated. 34 Figure 15: Cross section of location one in reach two (R2L1) with the water surface (blue) and the measurement area (red) marked. 
Figure 16: a) Upstream, b) downstream, c) left bank, and d) right bank of sample location 2 within reach 2 (R2L2): cattle restriction, banks reshaped to 3:1 slope and re-vegetated............ 36 Figure 17: Cross section of location two in reach two (R2L2) with the water surface (blue) and the measurement area (red) marked. 36 Figure 18: Continuous discharge measurements for the two month sample period with vertical lines indicating time of velocity sampling. 38 Figure 19: a) Upstream, b) downstream, c) left bank, and d) right bank of sample location 1 within reach 3 (R3L1): cattle restriction, two-stage channel design with in-set floodplain and revegetated.

Figure 20: Cross section of location one in reach three (R3L1) with the water surface (blue) and the measurement area (red) marked. 40 Figure 21: a) Upstream, b) downstream, c) left bank, and d) right bank of sample location 2 within reach 3 (R3L2): cattle restriction, two-stage channel design with in-set floodplain and revegetated.

Figure 22: Cross section of location two in reach three (R3L2) with the water surface (blue) and the measurement area (red) marked. 41

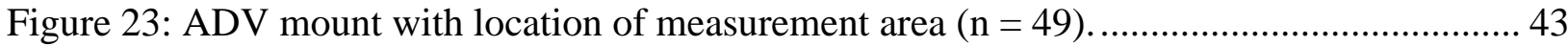

Figure 24: ADV mount deployed with ADV. 44

Figure 25: Continuous discharge measurements for the two month sample period with vertical lines indicating time of velocity sampling. 50

Figure 26: Distributions of TKE values for all samples. ................................................. 57

Figure 27: Spatial distributions of TKE for the first sample time at all locations..................... 58

Figure 28: Spatial distributions of TKE for the second sample time at all locations. ................. 59

Figure 29: Mean TKE versus standard deviations of flow depths for each sample. .................. 59

Figure 30: Comparison of grain size distributions to distributions of TKE values for all samples. 61

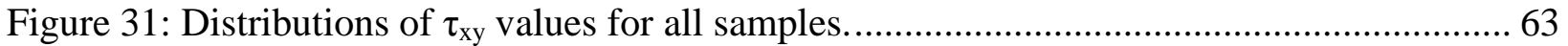

Figure 32: Spatial distributions of $\tau_{\mathrm{xy}}$ for the first sample time at all locations......................... 64

Figure 33: Spatial distributions of $\tau_{\mathrm{xy}}$ for the second sample time at all locations.................... 65

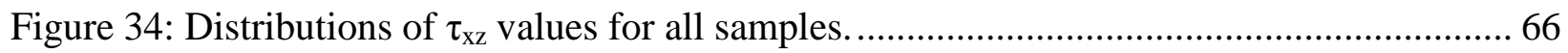

Figure 35: Spatial distributions of $\tau_{\mathrm{xz}}$ for the first sample time at all locations........................ 67 
Figure 36: Spatial distributions of $\tau_{\mathrm{xz}}$ for the second sample time at all locations.

Figure 37: Mean $\tau_{\mathrm{xz}}$ versus standard deviations of flow depths for each sample with linear trend

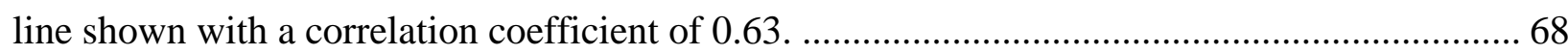

Figure 38: Comparison of grain size distributions to distributions of $\tau_{\mathrm{xz}}$ values for all samples. 69 Figure 39: Mean TKE versus mean $\tau_{\mathrm{xz}}$ for each sample.................................................... 70

Figure 40: Examples of bank failure in reach one (cattle restriction).................................... 72

Figure 41: Distributions of TKE values for all experimental reaches. .................................... 73

Figure 42: Distributions of $\tau_{\mathrm{xy}}$ values for all experimental reaches..................................... 74

Figure 43: Distributions of $\tau_{\mathrm{xz}}$ values for all experimental reaches....................................... 75

Figure 44: Continuous turbidity measurements for the two month sample period.................... 83 


\section{Table of Tables}

Table 1: Summary of field studies including site description, probe used, sample distance from streambed, time duration of samples, sample frequency, and reference. 14 Table 2: Summary of laboratory studies including flume description, probe used, sample distance from flume boundary, time duration of samples, sample frequency, and reference................... 17

Table 3: Grain size statistics for the reference reach (R0) (cattle restriction). ......................... 27

Table 4: Grain size statistics for reach one (R1) (cattle restriction). ....................................... 32

Table 5: Grain size statistics for reach two (R2) (cattle restriction, reshaping of banks to 3:1

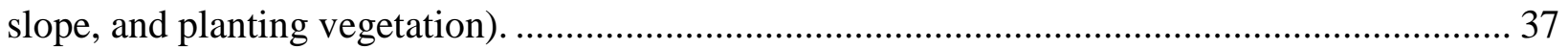

Table 6: Grain size statistics for reach three (R3) (cattle restriction and two-stage channel with inset floodplain)

Table 7: Bed roughness information collected from pebble counts after each velocity measurement and percent change between sample time one and sample time two.....

Table 8: Means and standard deviations (in italics) of streamwise $(\boldsymbol{u})$, lateral $(\boldsymbol{v})$, and vertical $(\boldsymbol{w})$ velocities for all samples and percent contribution to the velocity magnitude.

Table 9: Minimum, maximum, mean and standard deviations of water depth in sample area for each sample and baseflow channel width measurements of each location.

Table 10: Mean values of TKE, $\tau_{\mathrm{xy}}$, and $\tau_{\mathrm{xz}} ; \mathrm{p}$-values for t-tests between each sample time for a given location are italicized.

Table 11: Mean values and results of t-tests comparing TKE, $\tau_{\mathrm{xy}}$, and $\tau_{\mathrm{xz}}$ between two locations within a common reach. p-values of t-tests are in parenthesis. 56

Table 12: Mean values of TKE, $\tau_{\mathrm{xy}}$, and $\tau_{\mathrm{xz}}$ for each experimental reach. 76 Table 13: Results of pebble counts taken immediately following each velocity measurement. .. 82 


\section{Introduction}

The Natural Resources Conservation Service (2007) defines restoration as the act of returning an ecosystem to an approximation of its conditions prior to disturbance. It has been estimated that annual stream restoration expenditures in the United States exceed \$1 billion USD (Bernhardt et al. 2005). Costs of restoration projects in the Chesapeake Bay watershed alone averaged over \$300,000 per project during 1996-2006 (Hassett et al. 2007).

One main goal of stream restoration is to create physical stability. Restoration techniques may be passive (e.g. removal of livestock), moderate (e.g. reshaping the streambank and establishing riparian vegetation), or aggressive (e.g. natural channel design) (Natural Resources Conservation Service 2007). Before the restoration design process is started, site characteristics must be analyzed and goals for the project set. Setting specific goals previous to the design process is vital to choosing the appropriate restoration technique (Hassett et al. 2007; Rosgen 2001;Radspinner et al. 2010); however, few projects have these goals defined (Hassett et al. 2007). One problem with assessing the success of the restoration techniques is the lack of postconstruction monitoring of restoration projects. One report suggests that only $10 \%$ of projects include any form of assessment or monitoring (Bernhardt et al. 2005).

\subsection{Objectives}

The goal of this project was to examine the influence of stream restoration techniques on stream stability and in-stream turbulence. The specific objective was to characterize near-boundary flow within the three restored reaches of the Stroubles Creek Stream Research, Education, and Management (StREAM) Laboratory in Blacksburg, Virginia. Time-averaged velocity values as well as turbulence characteristics were examined, testing the following hypotheses:

- $H_{o}$ : Near-boundary time-averaged velocity values will not be influenced by the intensity of stream restoration.

- $H_{o}$ : Near-boundary turbulence will not be influenced by the intensity of stream restoration. 


\subsection{Study design}

Near-bed velocity measurements were collected at the StREAM Lab at Virginia Polytechnic Institute and State University in Blacksburg, Virginia. The laboratory is located on Stroubles Creek where three restoration techniques have been employed on consecutive sections of the creek: 1) cattle restriction only $(0.5 \mathrm{~km}) ; 2)$ cattle restriction, banks reshaped to $3: 1$ slope and revegetated $(0.6 \mathrm{~km})$; and 3) designed and installed a two-stage channel with inset floodplains and re-vegetated $(0.3 \mathrm{~km})$. These locations were compared to a reference reach which has had cattle restriction for 17 years $(\sim 0.35 \mathrm{~km})$ located upstream of reach one.

Two riffle sections were identified within each reach of restoration treatment for a total of eight sample locations (Figure 1). At each location measurements were conducted at two different sample times. A Sontek acoustic Doppler velocimeter (ADV) was used to measure threedimensional velocities at each of the eight experimental locations at baseflow.

Throughout this paper a naming convention will be used to refer to reaches, locations, and samples. R, $\mathrm{L}$ and $\mathrm{S}$ refer to the reach number, location number and sample number, respectively. For example, R0L2S1 refers to the first sample of location two in the reference reach and R3L1S2 refers to the second sample of location one in reach 3. 


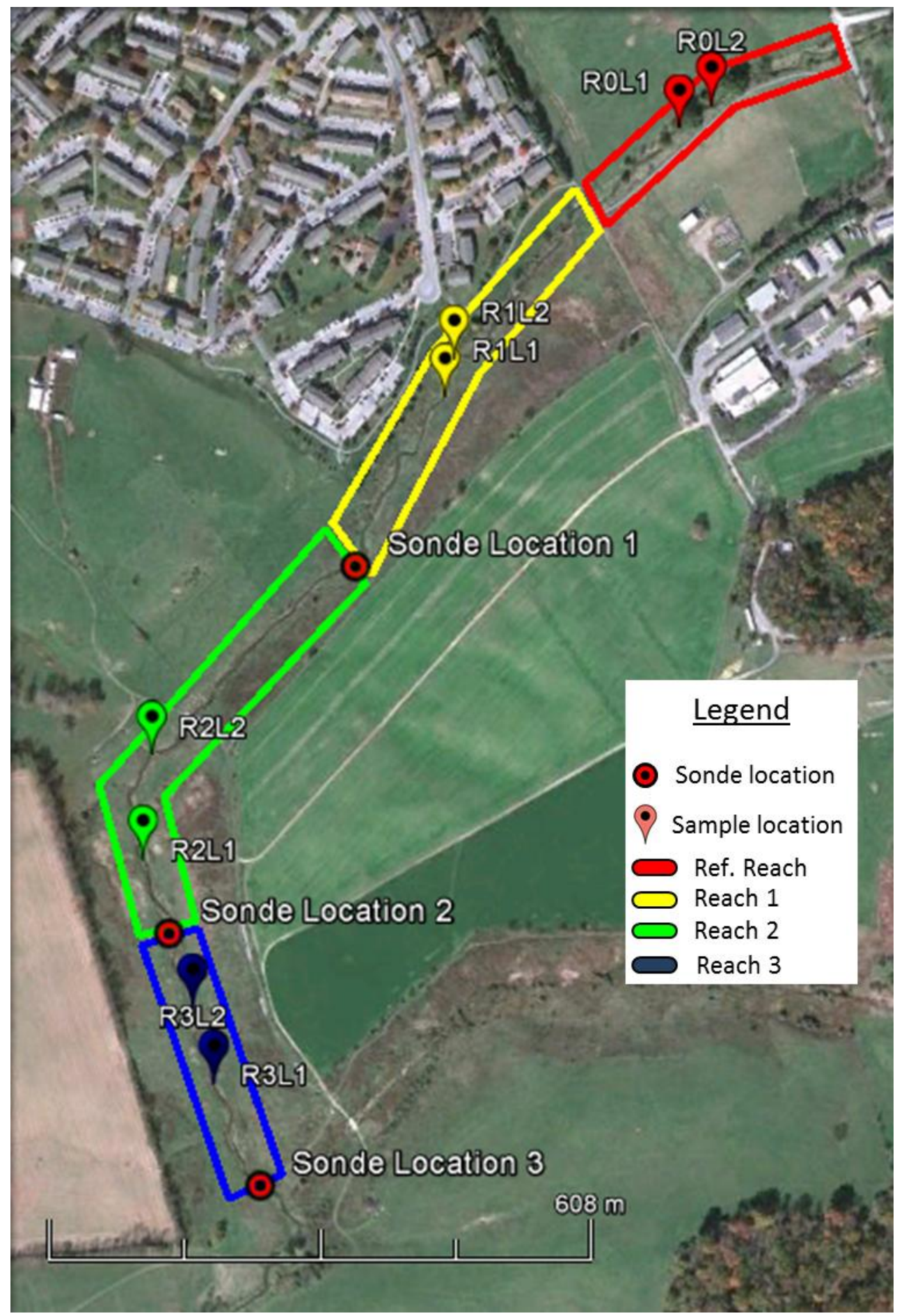

Figure 1: Stroubles Creek with restoration reaches, multi-parameter sondes, and sample locations labeled.

Restoration reaches outlined. Red: reference reach, cattle restriction for 15 years. Yellow: reach one, cattle restriction. Green: reach 2, reshaping banks to 3:1 slope and planting vegetation. Blue: reach 3 , cattle restriction and two-stage channel with inset floodplain. 


\section{Literature Review}

The objective of this literature review is to evaluate the success of stream restoration techniques applied to impaired waterways. Several articles and case studies are consulted to gather information on stream restoration projects in the United States with a focus on the techniques used and post-project improvement of stream stability. Techniques studied include the use of vegetation, in-stream flow control structures, and channel design techniques with a focus on the Rosgen method of natural channel design. All restoration techniques studied have proven successful in practice but gaps still remain in the design process. The Rosgen method of natural channel design has been subject to criticism for several inadequacies. Practitioners in the field have indicated a need for more comprehensive restoration guidelines. It has become evident that a successful stream restoration design must be tailored to the specific project based on site specific details. Research shows that effectiveness of individual techniques can be difficult to

quantify due to a lack of extensive post-restoration monitoring. It is important for future projects to include post-restoration monitoring to fully understand the success of individual stream restoration techniques.

\subsection{Stream Restoration in the United States}

Stream restoration refers to the physical alteration of a stream with the intent of reestablishing its natural health and stability (Natural Resources Conservation Service 2007). A stable channel is often defined as a channel where the "prevailing flow and sediment regimes do not lead to longterm aggregation or degradation (Natural Resources Conservation Service 2007). There are 3.5 million miles of rivers and streams in the United States (Environmental Protection Agency (U.S.) 2009). During the 2004 National Water Quality Inventory, conducted by the United States Environmental Protection Agency (2009), 44\% of the lengths of surveyed waters were classified as impaired. It has been estimated that annual stream restoration expenditures in the United States exceed \$1 billion USD (Bernhardt et al. 2005). Restoration projects in the Chesapeake Bay watershed alone averaged over \$300,000 per project during 1996-2006 (Hassett et al. 2007). The most common goals of restoration in the United States are improved water quality and instream habitat, management of riparian zones, fish passage, and bank stabilization (Bernhardt et al. 2005). 
Streambank erosion is a common cause of the degradation of stream stability. Stream instability, aggregation and degradation, scour, and erosion have been the key cause of $60 \%$ of U.S. highway bridge failures (Lagasse and Thompson 1995). These failures can result in a loss of life and millions of dollars each year for replacement of structures as well as the disruption of infrastructure (Lagasse and Thompson 1995). Moderate restoration designs could include reshaping the streambank and replanting of vegetation. More aggressive techniques include deployment of an in-stream structure or the reshaping of the channel cross section (Natural Resources Conservation Service 2007).

\subsection{Restoration Techniques}

\subsubsection{Vegetation}

Planting vegetation along streambanks is a popular technique used to prevent streambank erosion and sediment transport. Grasses have proven to protect the streambank by folding and reducing shear stresses near the bank which generally cause erosion of sediment (Hopkinson and Wynn 2009). Sukhodolov and Sukhodolov (2010) showed that submerged aquatic vegetation significantly reduced near bed velocity, turbulent kinetic energy, and dissipation rate in a lowland river. Pujol et al. (2010) found similar results in a laboratory study which simulated wind-generated turbulence with an oscillating grid and measured the effects of submerged aquatic vegetation on this turbulence. While this study mimics the effects of wind generated turbulence it offers insight into effect of vegetation on all forms of turbulence. The study included analysis among different plant species as well as varying canopy models (rigid and semi rigid) with varying solid plant fractions, stem diameters, and grid oscillation frequencies. The solid plant fractions were calculated as:

$$
S P F=\frac{n \pi\left(\frac{d}{2}\right)^{2}}{A}
$$

where $\mathrm{n}$ is the number of plants, $\mathrm{d}$ is the diameter of the plant and $\mathrm{A}$ is the total area studied. Results showed that turbulent kinetic energy was increased through the midsection of the vegetation and above the vegetation as compared to studies without vegetation. However, there was a decrease in turbulent kinetic energy in the near-bed zone. This phenomenon is referred to as sheltering or dampening. This effect was found to more effectively reduce turbulent kinetic 
energies when the plant diameter was decreased and the solid plant fraction was increased (Pujol et al. 2010). These studies, as well as many others with related goals, prove that vegetation is effective in countering the flow characteristics which cause sediment movement.

\subsubsection{Channel Design}

When the more passive techniques of restoring a waterway do not cause the necessary change, practitioners will sometimes turn to channel design in order to establish a stable channel. Channel design often aims to mimic the shape of a natural channel, defined as a river, stream, creek, or swale that has existed long enough and without significant alteration to establish a dynamically stable route (Natural Resources Conservation Service 2007). While this technique may be more radical, it can often reduce or eliminate the need for future maintenance or repair (Natural Resources Conservation Service 2007). There are many methods associated with channel design including the threshold channel design, alluvial channel design, two-stage channel design, and the Rosgen geomorphic channel design (Natural Resources Conservation Service 2007; Doll et al. 2003). Threshold channel designs are used for rigid boundary systems where little or no movement of the boundary occurs at design flows. Alluvial channel designs are for moveable boundary systems. These designs require pre-project assessment of bed material and channel performance for multiple flow conditions. The Rosgen method includes the Rosgen stream-classification system which sorts streams based on channel morphology. This allows for consistent descriptions which are quantitative (Rosgen 2001).

The two-stage channel design is popular for use on agricultural land in the United States as an alternative to the typical trapezoidal shape. Trapezoidal ditches are designed using threshold design techniques which are suitable in some cases but can often require frequent, expensive maintenance. The two-stage channel system attempts to take into consideration the ecological functions of the channel. This system utilizes benches which act as flood plains to create natural alluvial processes (Natural Resources Conservation Service 2007). The two-stage channel design technique was implemented at Stroubles Creek.

\subsubsection{In-stream structures}

Stream instability can also be prevented with the use of structures (e.g. w-weir, j-hook vane, constructed riffles, etc.) which control natural stream occurrences such as sediment erosion and 
deposition, scour, and effects of natural currents (Radspinner et al. 2010). Often referred to as river training, these structures affect the flow regimes in streams to restore stability. This type of restoration is also referred to as a "hard" control measure. While these structures can prove successful in restoring streams, they are often opposed by general public as they often turn a natural channel into a man-made canal (Radspinner et al. 2010). The stream studied in this project does not utilize in-stream structures so this technique will not be discussed any further.

\subsection{Pre-Project Planning}

Each stream restoration technique discussed in the previous sections has proven beneficial experimentally and in practice. However, it is important to understand that stream restoration projects should have specific goals previous to design in order to choose the most applicable technique (Hassett et al. 2007; Rosgen 2001; Radspinner et al. 2010). Interviewed practitioners in the Chesapeake Bay watershed indicated that few of the projects they worked on stated quantifiable goals in the project design (Hasset 2007). Without specific goals the design process can become difficult and leave many questions unanswered in the design process. The method proposed by Rosgen (2001) places emphasis on gathering site specific characteristics previous to design. Radspinner (2010) discussed ambiguity in the construction and maintenance of instream structures due to a lack of comprehensive theory. Certain in-stream structure practices are more popular in a given region than in others (Radspinner et al. 2010). Radspinner (2010) suggests that while this distribution of use of structures could be due to the specific stream conditions in the given area it could also be due to a lack of design guidelines. An engineer may be more likely to apply a practice which they are familiar with rather than the most appropriate practice if guidelines on that practice are not readily available. With a more universal source of restoration practices (i.e. design handbooks); pre-project planning could be an easier process.

\subsection{Post-Restoration Monitoring}

One large obstacle in tracking the progress of restoration efforts is the lack of monitoring of sites after restoration efforts (Bernhardt et al. 2005; Hassett et al. 2007; Radspinner et al. 2010). Bernhardt et al. (2005) found that the percentage of projects which included monitoring techniques varied by region. Greater than $20 \%$ of projects in the southwest, southeast, and central United States included some form of monitoring. In the Chesapeake Bay area, records 
show that only $6 \%$ of projects included monitoring (Bernhardt et al. 2005). While a more recent report suggests that more projects in the Chesapeake Bay watershed include monitoring, many of the practitioners surveyed by Hasset et al. (2007) commented on the importance and need to fund project monitoring. Radspinner (2010) discussed the low number of projects which included some sort of monitoring which makes judging the success of a restoration technique a very difficult task.

The final phase of the Rosgen (2001) natural channel design method specifically calls for monitoring of channels after the design has been implemented. While this methodology of channel design has been criticized (Simon et al. 2007), the importance of post-construction monitoring is widely accepted. A larger collection of information regarding the monitoring of restoration projects would allow for a more expansive understanding of stream restoration progress in the Unites States.

\subsection{Quantifying turbulence}

\subsubsection{Instrumentation}

To analyze turbulence characteristics, it is necessary to gather high frequency three-dimensional velocity data. Two instruments commonly used to accomplish this are the acoustic Doppler velocimeter (ADV) and the laser Doppler velocimeter (LDV).

\section{$\underline{\mathrm{LDV}}$}

The LDV is an instrument which is widely used for studies of fluid dynamics in both liquids and gases. LDVs are particularly useful for measuring three dimensional velocities in water with a variety of flow characteristics (Nezu and Rodi 1986). LDVs offer non-intrusive measurements with high spatial and temporal resolution without the need for calibration (Dantec Dynamics A/S 2012). A typical LDV system contains a continuous wave laser, transmitting optics, receiving optics, signal conditioner and a signal processor (Dantec Dynamics A/S 2012). Due to the size and issues with maneuverability of LDV systems this instrument is not fit for the field uses in this study. 
An ADV is a three-dimensional velocity sensor which operates on the Doppler shift effect (Voulgaris and Trowbridge 1998). The Sontek $16 \mathrm{MHz}$ MicroADV used for this study is capable of measurement at as low as $0.1 \mathrm{~Hz}$ and up to $50 \mathrm{~Hz}$ (SonTek 2008). The instrument has a velocity resolution of $0.01 \mathrm{~cm} / \mathrm{s}$ and a programmed flow velocity range of \pm 3 to $\pm 250 \mathrm{~cm} / \mathrm{s}$. The accuracy of the instrument measurements is $1 \%$ of the programmed flow velocity range. The ADV system consists of a probe, a signal conditioning module, and a processor. The probe is down-looking and consists of a central transmitter and three receivers which are arranged at $120^{\circ}$ in a circle around the transmitter. The receivers are angled inward to focus on the sample volume $5 \mathrm{~cm}$ from the tip of the probe. The sampling volume of the ADV model used in this study is $0.09 \mathrm{~cm}^{3}$ (SonTek 2008). The ADV is easy to set up and record measurements in a field setting.

\subsubsection{Turbulence analysis techniques}

Turbulence characteristics can be evaluated by examining turbulent kinetic energy (TKE) and Reynolds stresses.

\section{$\underline{\text { TKE }}$}

Turbulent Kinetic Energy is a value used to estimate the average turbulence (Tennekes and Lumley 1972). It is a measurement of the energy from the turbulent portion of flow as opposed to the mean flow. TKE is often quantified by the mean of the turbulent normal stresses.

$$
T K E=\frac{\rho\left(\overline{u^{\prime 2}+v^{\prime 2}+w^{\prime 2}}\right)}{2}
$$

As with Reynolds stresses, Reynolds decomposition is used to find the fluctuating components of velocity (Tennekes and Lumley 1972).

\section{$\underline{\text { Reynolds stresses }}$}

For incompressible flows, the velocity can be split into two components: the mean (time average) velocity component and the time-dependent (fluctuating) component of velocity (Tennekes and Lumley 1972). This process is referred to as Reynolds decomposition. The velocity fluctuations generate momentum fluxes. Turbulent momentum fluxes referred to as 
Reynolds stresses are important to the theory of mean momentum transfer by turbulent motion (Tennekes and Lumley 1972). The diagonal components of the stress tensor are normal stresses and the off-diagonal components are shear stresses. This research will cover the vertical and lateral components of Reynolds shear stresses represented as $\tau_{\mathrm{xz}}$ and $\tau_{\mathrm{xy}}$, respectively. The shear stress is symmetrical: $\tau_{\mathrm{xz}}=\tau_{\mathrm{zx}}$.

$$
\begin{aligned}
& \tau_{x z}=-\rho \overline{u^{\prime} w^{\prime}} \\
& \tau_{x y}=-\rho \overline{u^{\prime} v^{\prime}}
\end{aligned}
$$

\section{$\underline{\text { Lateral Velocities }}$}

Lateral velocities are those which are normal to the primary flow and are distinctly different than cross-stream flows which are normal to the tangent of the streambank. This distinction is most important near stream bends where transverse flow can be considered a circulation (Crowder and Diplas 2002). These circulations can lead to sediment transportation. Several sample locations selected in this study are near bends and the effects of these bends on lateral velocities will be discussed.

\subsection{Studies of near-boundary turbulence}

Turbulence characteristics are often analyzed as an indicator of stream stability due to the tendency of turbulence to cause scour, erosion, and other phenomenon detrimental to stream stability. To create a stable channel it is important to stop long term aggregation or degradation (Natural Resources Conservation Service 2007). The importance or turbulent flow in supporting stream habitat has been subject or research in the past (Crowder and Diplas 2002). While these turbulence characteristics can cause erosion and scour, they also have been proven to improve instream habitat. One study showed a constructed riffle tripled fish population in a deeply incised sand-bed channel (Shields et al. 1995). The riffle sections selected in this study are important to maintaining a healthy stream habitat for aquatic life.

\subsubsection{Field Studies}

Velocity probes have been used to examine in-stream turbulence generation. The following discussion describes recent research contributions as summarized in Table 1. 
Wilcox and Wohl (2007) completed a study located in a step-pool channel in the Colorado Rockies. Measurements were taken near sections characteristic of a steep channel along a $30 \mathrm{~m}$ reach. Velocity measurements were taken at each location during five different discharge periods. Measurements were taken along a thalweg velocity profile consisting of three points in the water column for moderately high-flow and four to eight for all other field efforts. A SonTek Flowtracker Handheld ADV operated at $1 \mathrm{~Hz}$ measured velocity. Measurements were taken for 180s for moderate high and moderate flows and $90 \mathrm{~s}$ for all other flows. The measurement time and frequency were chosen based on finding from Buffin-Belanger and Roy (2005) which recommends time series of $60-90 \mathrm{~s}$ for $20-25 \mathrm{~Hz}$. The record lengths chosen would be a compromise given the low frequency of their measurement device. The Flowtracker was chosen for measurements over other ADVs due to ease of use in the field and its ability to take measurements near boundary because the side-looking probe. The study found that the flow was more three dimensional in step-pool channels than in lower-gradient systems.

A study completed by Lacey and Roy (2007) involved taking near boundary velocity measurements with and without a pebble cluster and investigated the special patterns of turbulence around this cluster. The pebble cluster consisted of six imbricated stones with a maximum protrusion of $0.1 \mathrm{~m}$. Four SonTek ADVs were used to take measurements. One stayed stationary while the other three were moved to 70 locations in a predetermined grid. The two heights sampled at each grid point were chosen to characterize the inner and intermediate flow regions. The frequency $(12 \mathrm{~Hz})$ was selected due to the limitations of the data transfer capabilities of the system. The sample time $(3.5 \mathrm{~min})$ resulted in 2500 measurements per time series which the authors note is more conservative than suggested by Buffin-Belanger and Roy (2005). Data was filtered based on correlation ( $<70 \%$ rejected). The slope of the power spectra within the inertial subrange was compared to Kolmogorov $-5 / 3$ law and noisy signals which had generally flat slopes were removed. Phase-space thresholding filtering (Goring and Nikora 2002) was also used. The study concludes there was a twofold increase in TKE with the pebble cluster compared to without it. One ADV probe took measurements upstream of the pebble cluster while the remaining three probes measured at 70 specific grid locations downstream of the pebble cluster. 
Franca et al. (2008) sampled two (hydraulically rough) rivers are composed of coarse gravel with 3D acoustic Doppler velocity profilers (ADVP) which were custom developed. The instrument was a non-intrusive ultrasonic measuring device capable measuring $3 \mathrm{D}$ velocities over the entire flow depth. These ADVPs allowed for samples to be taken very close to the streambed. Measurements were taken along vertical profiles spaced across the river cross section at 5-12.5 $\mathrm{cm}$ spacing. Vertical resolution was approximately $0.5 \mathrm{~cm}$ allowing for measurement densities of 693 and 884 points $/ \mathrm{m}^{2}$. This system also allowed for control of data quality by oscilloscope to assure optimal configuration. A dealiasing algorithm was applied to the data and, along with a multistatic configuration, allowed for noise-free measurements. The bed of the rivers was sampled as suggested by Wolman (1954) for coarse rivers. Median grain sizes were 40 and 49 $\mathrm{mm}$ for the two rivers.

Roy et al. (2010) investigates the relationship between standard habitat variables and turbulent properties. Measurements are taken in two pools and two riffles of a shallow gravel-bed river. The velocity measurements were taken at $10 \mathrm{~cm}$ from the bed with SonTek ADVs which were attached to wading rods and leveled by two operators previous to each measurement. The distance from bed was chosen due to the difficulty to obtain quality data quickly closer to the bed. Measurements were taken every $25 \mathrm{~cm}$ on a grid $\left(16\right.$ points $\left./ \mathrm{m}^{2}\right)$ for a total of 1932 individual velocity measurements. The measurement time $(80 \mathrm{~s})$ and frequency $(25 \mathrm{~Hz})$ allowed for 2000 measurements in each time series. The data were filtered for correlations less than $70 \%$ as suggested by Lane et al (1998). The slope of the power spectra within the inertial subrange was compared to the Kolmogorov -5/3 law and low correlations were detected with phase-space threshold filter (Goring and Nikora 2002). The results suggest that the ability of standard habitat variables to explain turbulent properties was low.

Sukhodolov and Sukhodolov (2010) investigated the effect of vegetation on turbulence structure. Measurements were completed in a lowland river at two times; once when vegetation was present in a patchy mosaic and again when the vegetation was not present. Measurements were taken at 15 vertical profiles distributed along the river cross section. Each vertical profile contained 11 points evenly distributed along the water column. ADVs were used to sample 3D velocities for $4 \mathrm{~min}$ at $25 \mathrm{~Hz}$. The measurements were compared to analytical models and 
showed that these models are sufficiently accurate. The results suggest plants change the flow from relatively 2-dimensional to a complex 3-dimensional flow. 
Table 1: Summary of field studies including site description, probe used, sample distance from streambed, time duration of samples, sample frequency, and reference.

\begin{tabular}{|c|c|c|c|c|c|}
\hline Site Description & Probe & Sample Distance & Sample Time & Freq. & Reference \\
\hline $\begin{array}{l}\text { Step-pool channel } \\
\text { East St. Louis Creek in the } \\
\text { Colorado Rockies }\end{array}$ & $\begin{array}{c}\text { SonTek } \\
\text { FlowTracker } \\
\text { Handheld ADV }\end{array}$ & $\begin{array}{c}\mathrm{z} / \mathrm{h}=0.2,0.6 \text { and } 0.8 \text { (high } \\
\text { flow data) } \\
\text { 4-8 data points (vertical } \\
\text { profile) } 0.1 \mathrm{~h}-0.2 \mathrm{~h}\end{array}$ & $\begin{array}{l}180 \text { s (mod. high- } \\
\text { mod. flow) } \\
90 \text { s (all other } \\
\text { periods) }\end{array}$ & $1 \mathrm{~Hz}$ & $\begin{array}{l}\text { (Wilcox and } \\
\text { Wohl 2006) }\end{array}$ \\
\hline $\begin{array}{l}\text { With and without a pebble } \\
\text { cluster } \\
\text { Eaton North River, Eastern } \\
\text { townships, Québec, } \\
\text { Canada }\end{array}$ & 4 Sontek ADVs & $\begin{array}{c}\text { Lower relative height: } \mathrm{z} / \mathrm{Z}= \\
0.2 \\
\text { Upper relative height: } \mathrm{z} / \mathrm{Z}= \\
0.4\end{array}$ & $210 s$ & $12 \mathrm{~Hz}$ & $\begin{array}{l}\text { (Lacey and } \\
\text { Roy 2007) }\end{array}$ \\
\hline $\begin{array}{c}\text { Lowland rivers } \\
\text { Rivers Vinoge and } \\
\text { Chamberonne in the canton } \\
\text { of Vaud, Switzerland }\end{array}$ & 3 ADVPs* & $\begin{array}{l}\text { ADVP measures over entire } \\
\text { flow depth }\end{array}$ & $300 \mathrm{~s}$ & $\begin{array}{c}62.5 \\
\mathrm{~Hz}\end{array}$ & $\begin{array}{l}\text { (Franca et } \\
\text { al. 2008) }\end{array}$ \\
\hline $\begin{array}{l}\text { Two pools and two riffles } \\
\text { Eaton North River, Eastern } \\
\text { townships, Québec, } \\
\text { Canada }\end{array}$ & 2 Sontek ADVs & $10 \mathrm{~cm}$ from the bed & $80 \mathrm{~s}$ & $25 \mathrm{~Hz}$ & $\begin{array}{l}\text { (Roy et al. } \\
\text { 2009) }\end{array}$ \\
\hline $\begin{array}{c}\text { Lowland river } \\
\text { Spree river near Berlin, } \\
\text { Germany }\end{array}$ & ADVs & $\begin{array}{l}11 \text { points evenly distributed } \\
\text { in each vertical profile }\end{array}$ & $240 \mathrm{~s}$ & $25 \mathrm{~Hz}$ & $\begin{array}{l}\text { (Sukhodolov } \\
\text { and } \\
\text { Sukhodolov } \\
\text { 2010) }\end{array}$ \\
\hline
\end{tabular}

Note: Where $\mathrm{z}$ is the vertical position in the water column, $h$ is the local flow depth, and $\mathrm{Z}$ is the mean water depth within the sample area.

*ADVPs developed at the Laboratoire d'Hydraulique Environnementale, École Polytechnique Fédérale de Lausanne (LHE). 


\subsubsection{Laboratory Studies}

Controlled lab experiments have helped to define field techniques. The following discussion describes recent research contributions as summarized in (Table 2).

Voulgaris and Trowbridge (1989) evaluated turbulence measurements with an ADV compared to those made with an LDV. The flow characteristics from these instruments were compared to "true" flow characteristics predicted by semiempirical models for open-channel flow. It was found that at distances less than $3 \mathrm{~cm}$ from the boundary the measured Reynolds stresses deviated from those predicted by the model. The instruments were first tested in still water to determine the sample error which was found to be adequate for field testing. Measurements were run in the flume for $6 \mathrm{~min}$ at $25 \mathrm{~Hz}$ for both instruments. The measurements were taken at several distances from the boundary during different flow conditions and ADV velocity range settings. Turbulence measurements made with the two instruments were in general agreement, and the study supports the accuracy of the ADV when used to measure turbulence.

Hopkinson and Wynn (2009) used an ADV to measure the effects of vegetation on three dimensional velocity structures and near bank turbulence characteristics. Tree, shrub and grass vegetation were modeled in a flume and compared to a control which had only grain roughness. Three-dimensional velocity measurements were taken along the simulated streambed and bank. Data were filtered which had correlation values less than $70 \%$ or average signal to noise ratio less than 15. The remaining data were used to evaluate the three dimensional flow structure and to calculate the turbulence characteristics. The streamwise velocity was increased by the addition of vegetation along the banks. The vegetation decreased the streamwise velocity near the banks. Turbulence characteristics with trees were similar to those with a bare bank. TKE and Reynolds shear stresses were increased near the streambank with the addition of shrubs. The grasses folded and protected the banks from the shear stresses.

Pujol et al. (2010) studied the effects of vegetation on turbulence induced by an oscillating grid to mimic the turbulence generated by wind in a wetland. Turbulence characteristics were measured with an ADV for several different canopy models, solid plant fractions, stem diameters, oscillating grid frequencies, and plant species. With the given sample time (5 min) and frequency $(10 \mathrm{~Hz})$ of the ADV measurements, a total of 3000 records were made in each 
time series. Measurements with correlation less than $80 \%$ were removed. At the lower elevations near the bed the turbulence was found to be greater without plants compared to that with vegetation. This result suggests the plants redistribute the TKE. 
Table 2: Summary of laboratory studies including flume description, probe used, sample distance from flume boundary, time duration of samples, sample frequency, and reference.

\begin{tabular}{|c|c|c|c|c|c|}
\hline Flume & Probe & Sample Distance & $\begin{array}{c}\text { Sample } \\
\text { Time }\end{array}$ & Freq. & Reference \\
\hline $\begin{array}{c}17 \mathrm{~m} \text { long, } 60 \mathrm{~cm} \text { wide, } 30 \mathrm{~cm} \\
\text { deep }(16.2 \mathrm{~cm} \text { mean flow } \\
\text { depth })\end{array}$ & $\begin{array}{l}\text { Comparing ADV and } \\
\text { Laser Doppler } \\
\text { Velocimeter (LDV) }\end{array}$ & $0.76-4.7 \mathrm{~cm}$ above bed & $6 \mathrm{~min}$ & $25 \mathrm{~Hz}$ & $\begin{array}{c}\text { (Voulgaris and } \\
\text { Trowbridge 1998) }\end{array}$ \\
\hline $6 \mathrm{~m}$ long, $1 \mathrm{~m}$ wide, $40 \mathrm{~cm}$ deep & $\begin{array}{c}\text { 16MHz SonTek } \\
\text { sidelooking MicroADV }\end{array}$ & $0.5 \mathrm{~cm}$ from bank & $1 \mathrm{~min}$ & $25 \mathrm{~Hz}$ & $\begin{array}{c}\text { (Hopkinson and Wynn } \\
\text { 2009) }\end{array}$ \\
\hline $28 \mathrm{~cm} \times 28 \mathrm{~cm} \mathrm{x} 49 \mathrm{~cm}$ tank & $\begin{array}{l}\text { 16MHz SonTek } \\
\text { MicroADV }\end{array}$ & $\begin{array}{l}5-25 \mathrm{~cm} \text { with } 13 \\
\text { positions from bottom } \\
\text { of tank }\end{array}$ & $5 \mathrm{~min}$ & $10 \mathrm{~Hz}$ & (Pujol et al. 2010) \\
\hline
\end{tabular}




\section{Methods}

Measurements were completed in June and July 2012 at the Virginia Tech Stream Research, Education, and Management (StREAM) Laboratory. Four experimental reaches were identified with two locations chosen within each reach for a total of eight experimental locations. Physical measurements of each sample location were completed including a topographic survey and modified Wolman pebble counts. Pebble counts and velocity and flow depth measurements were taken at two sample times at each location. Continuous data including turbidity and stage height were collected for the full two month period.

\subsection{Description of StREAM Laboratory}

The Stream Research, Education, and Management (StREAM) Laboratory is located on Stroubles Creek in Blacksburg, Virginia and managed by the Virginia Polytechnic and State University Department of Biological Systems Engineering (Thompson et al. 2012) $\left(37^{\circ} 12^{\prime} 42.48^{\prime \prime} \mathrm{N}, 80^{\circ} 26^{\prime} 38.34^{\prime \prime} \mathrm{W}\right)$. The Stroubles Creek watershed (5,802 hectare) includes the Virginia Tech campus and most of the town of Blacksburg. This watershed is located within the New River watershed in southwest Virginia. The Stroubles Creek watershed land is $46 \%$ urban and residential, $28 \%$ forested, and 26\% agriculture (Stroubles Creek IP Steering Committee et al. 2006). The land surrounding the experimental reaches was once used for cattle grazing. The cattle had unlimited access to the stream which led to stream water pollution and streambank instability. Stroubles Creek was listed on the 303(d) TMDL priority list in 1996 for aquatic life use impairment. According to the report, sediment was the primary stressor and the stream was experiencing severe bank retreat. Due to urban development in the Stroubles Creek watershed, discharge changes occur rapidly after large storm events.

Three restoration techniques were applied in 2009-10 to consecutive reaches of Stroubles Creek (Figure 2):

R1) cattle restriction only $(0.5 \mathrm{~km})$;

R2) cattle restriction, banks reshaped to 3:1 slope and re-vegetated $(0.6 \mathrm{~km})$; 
R3) designed and installed a two-stage channel with inset floodplains and re-vegetated $(0.3 \mathrm{~km})$.

In this study, results were compared to an upstream reference reach $(\mathrm{R} 0 ; \sim 0.35 \mathrm{~km})$ where cattle have been restricted for approximately 17 years (StREAM 2011).

Sample bridges are located at the end of each of reach one, reach two, and reach three and hold multi parameter sondes which record continuous data including conductivity, dissolved oxygen, temperature, $\mathrm{pH}$, and turbidity (Figure 2). 


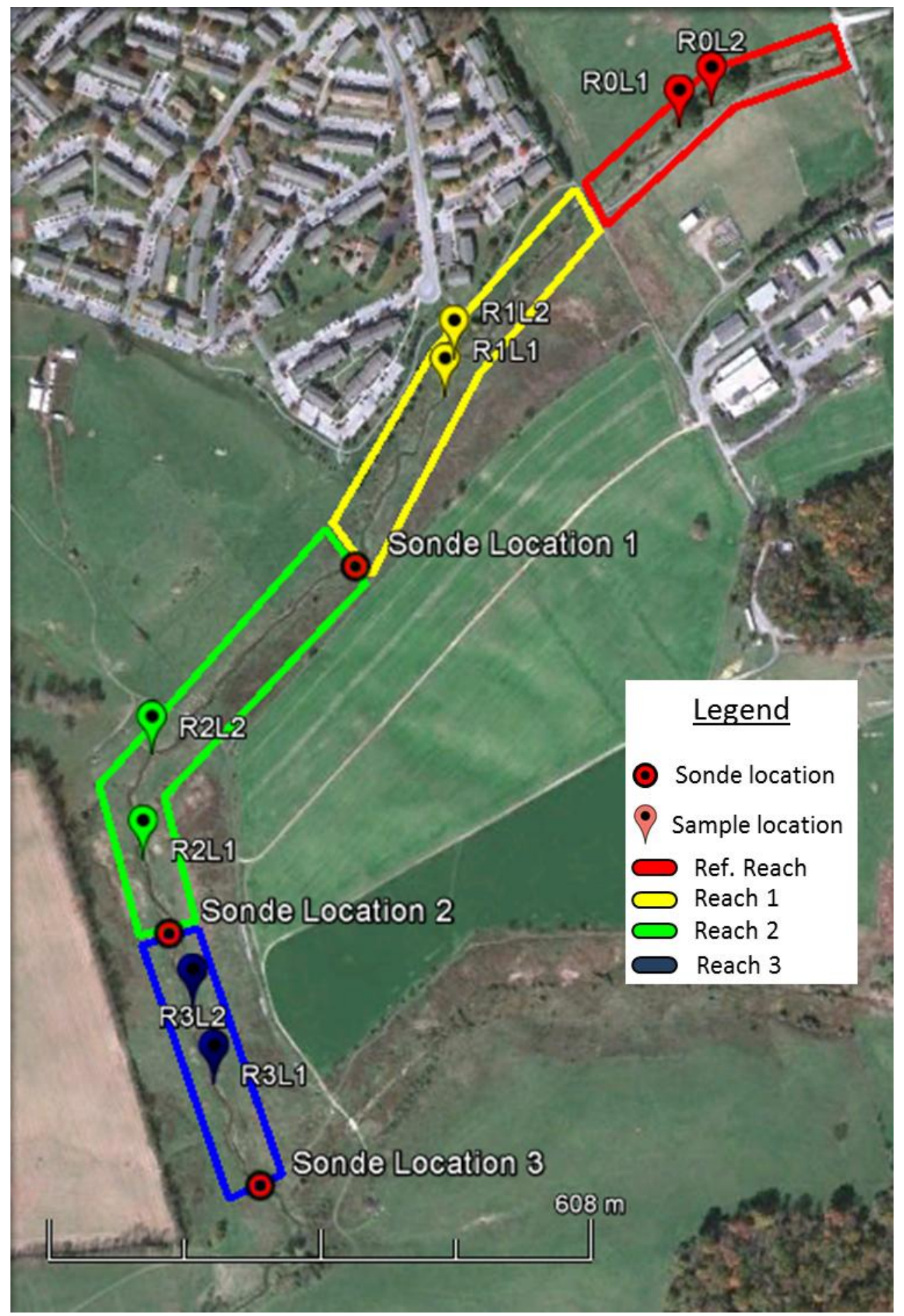

Figure 2: Stroubles Creek with restoration reaches, multi-parameter sondes, and sample locations labeled.

Restoration reaches outlined. Red: reference reach, cattle restriction for $\mathbf{1 5}$ years. Yellow: reach one, cattle restriction. Green: reach 2, reshaping banks to 3:1 slope and planting vegetation. Blue: reach 3 , cattle restriction and two-stage channel with inset floodplain. 


\subsection{Physical measurements of field sites}

A survey with a TopConn GR-3 (Topcon Positioning Systems, Inc. Livermore, CA, USA) was completed at seven of the sample locations. Due to poor signal with the GR-3 unit at location one of the reference reach (R0L1; cattle restriction for 17 years), a laser level was used for the cross section survey. Survey procedures followed those suggested by Harrelson et al. (1994). The channel cross sections were surveyed to determine dimensions and the baseflow channel widths. A rebar monument previously placed near the stream served as a benchmark with a known location for the surveys. One piece of rebar was driven into each streambank to serve as a monument for the cross section surveys as suggested by Harrelson et al. (1994). These monuments assisted with the placement of the ADV mount for each sample as well.

Modified Wolman pebble counts were completed after each velocity measurement (Wolman 1954). The sample grid for these counts was a $60 \mathrm{~cm} \times 60 \mathrm{~cm}$ area encompassing the measurement grid.

Stage height and turbidity were measured continuously during the two month sampling period. In place at the measurement bridges were YSI 6600V2 model sondes with an YSI 6136 turbidity probe. These data were used to compare the stream conditions during each velocity measurement.

\subsection{Description of measurement sites}

Two sample locations were selected within each restoration reach as well as in the reference reach, resulting in a total of eight experimental locations. The physical properties including topography and grain roughness were measured at each of the two experimental locations in each restoration reach.

Each measurement location was visually inspected and photographed prior to velocity measurements. Measurement locations were chosen based on adequate water depth and similar morphology characteristics as best as could be done with the given reaches. The following section describes the two experimental measurement locations within each reach (Figure 2):

- Reference Reach (cattle restriction for 17 years): R0L1 and R0L2; 
- Reach 1 (cattle restriction): R1L1 and R1L2;

- Reach 2 (cattle restriction, banks reshaped to 3:1 slope and re-vegetated): R2L1 and R2L2; and,

- Reach 3 (cattle restriction, two-stage channel design with inset floodplain and revegetated): R3L1 and R3L2.

\subsubsection{Reference Reach (R0): Cattle restriction for 17 years}

The cattle have been restricted from the reference reach of the stream for 17 years. The reference reach is located upstream of reach one as seen in Figure $2(\sim 0.35 \mathrm{~km})$. The vegetation cover consists of grassy vegetation and shrubs lining most banks and large trees shading a majority of the stream reach (Thompson et al. 2012). Location one (R0L1) is downstream of location two (R0L2). The time of samples in this reach are labeled on the discharge plot in Figure 3. Data from pebble counts conducted after each velocity sample are presented in Table 3. 


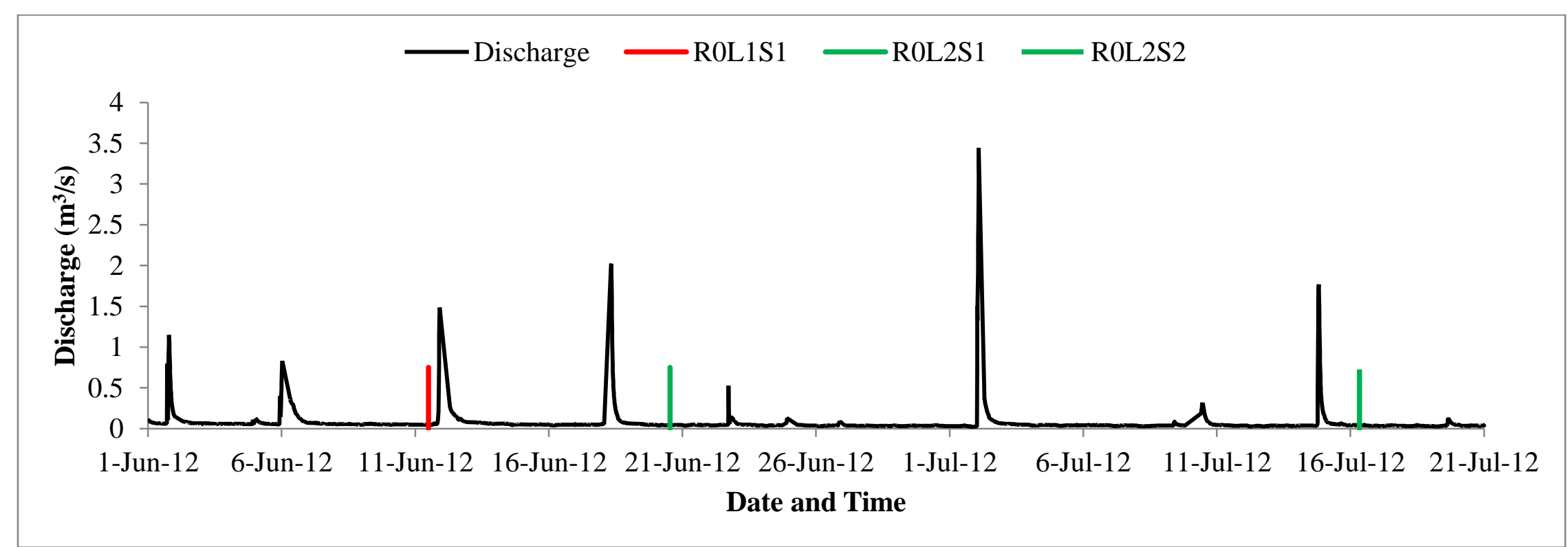

Figure 3: Continuous discharge measurements for the two month sample period with vertical lines indicating time of velocity sampling.

Note: $R, L$, and $S$ indicate reach number, location number, and sample time, respectively. R0: reference reach, cattle restriction. A second sample of ROL1 could not be taken due to low water depths and instrument limitations. 


\section{$\underline{\text { R0L1: }}$}

The stream flows through a bend upstream of the measurement area. A majority of the flow was directed toward the right bank (Figure 4a). Just downstream of the measurement area $(\sim 1 \mathrm{~m})$ was a small pool near the right bank after which the flow became more evenly distributed across the cross section (Figure 4b). The right bank was steep and covered with grassy vegetation and some woody debris (Figure 4c). The left bank was a relatively flat, pebble covered beach (Figure $4 \mathrm{~d}$ ). $\mathrm{D}_{50}$ at this location was $9.4 \mathrm{~mm}$ for sample one. A second pebble count and velocity sample was not taken due to low flow depth and ADV instrument limitations. The location of the velocity measurement area is identified in Figure 5. 

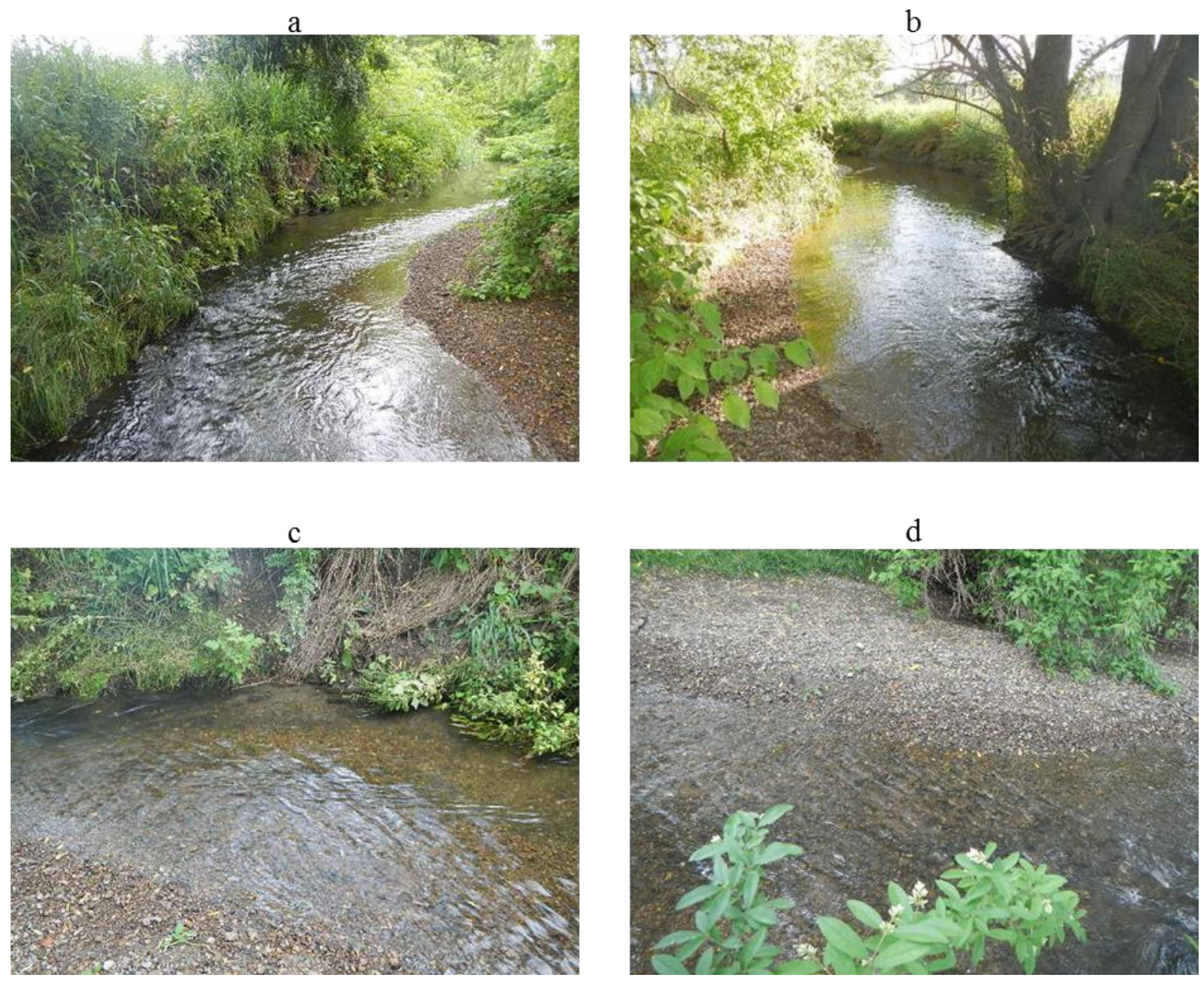

Figure 4: a) Upstream, b) downstream, c) left bank, and d) right bank of sample location 1 within the reference reach (ROL1): cattle restriction for 17 years.

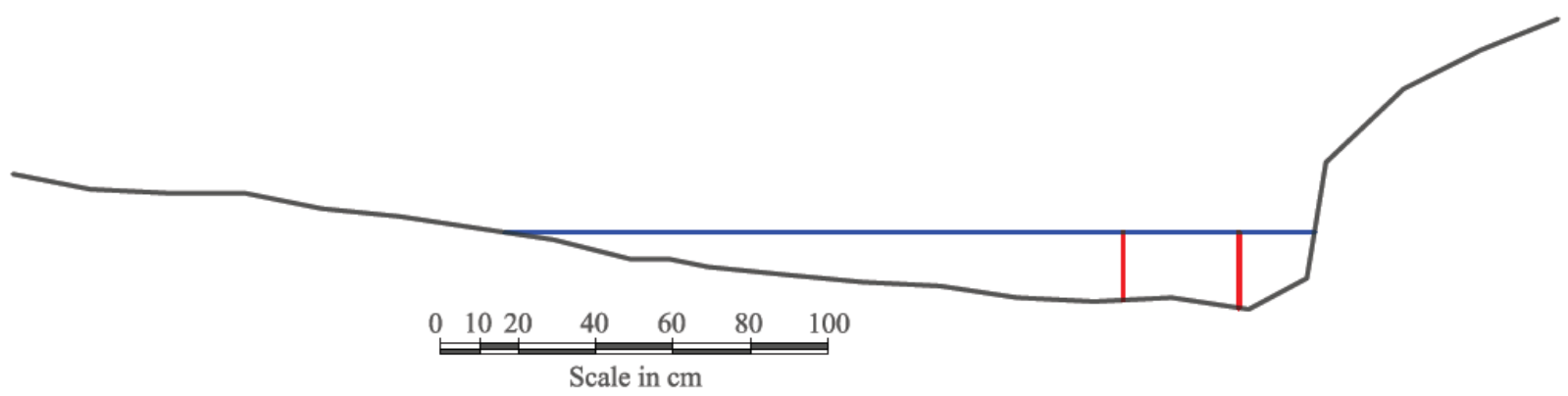

Figure 5: Cross section of location one in the reference reach (ROL1) with the water surface (blue) and the measurement area (red) marked. 
R0L2:

The measurement area was downstream of a long straight section of the stream $(\sim 20 \mathrm{~m})$ with steep banks on both sides covered with thick grassy vegetation which continued through the measurement area (Figure $6 \mathrm{a}, \mathrm{c}, \mathrm{d})$. Downstream of the measurement area $(\sim 1 \mathrm{~m})$ was a slight bend with large boulders on the left bank and large cobles and gravel on the streambed (Figure 6 b). $\mathrm{D}_{50}$ at this location was $12 \mathrm{~mm}$ and $11 \mathrm{~mm}$ for sample one and sample two, respectively (Table 3). The location of the velocity measurement area is identified in Figure 7.
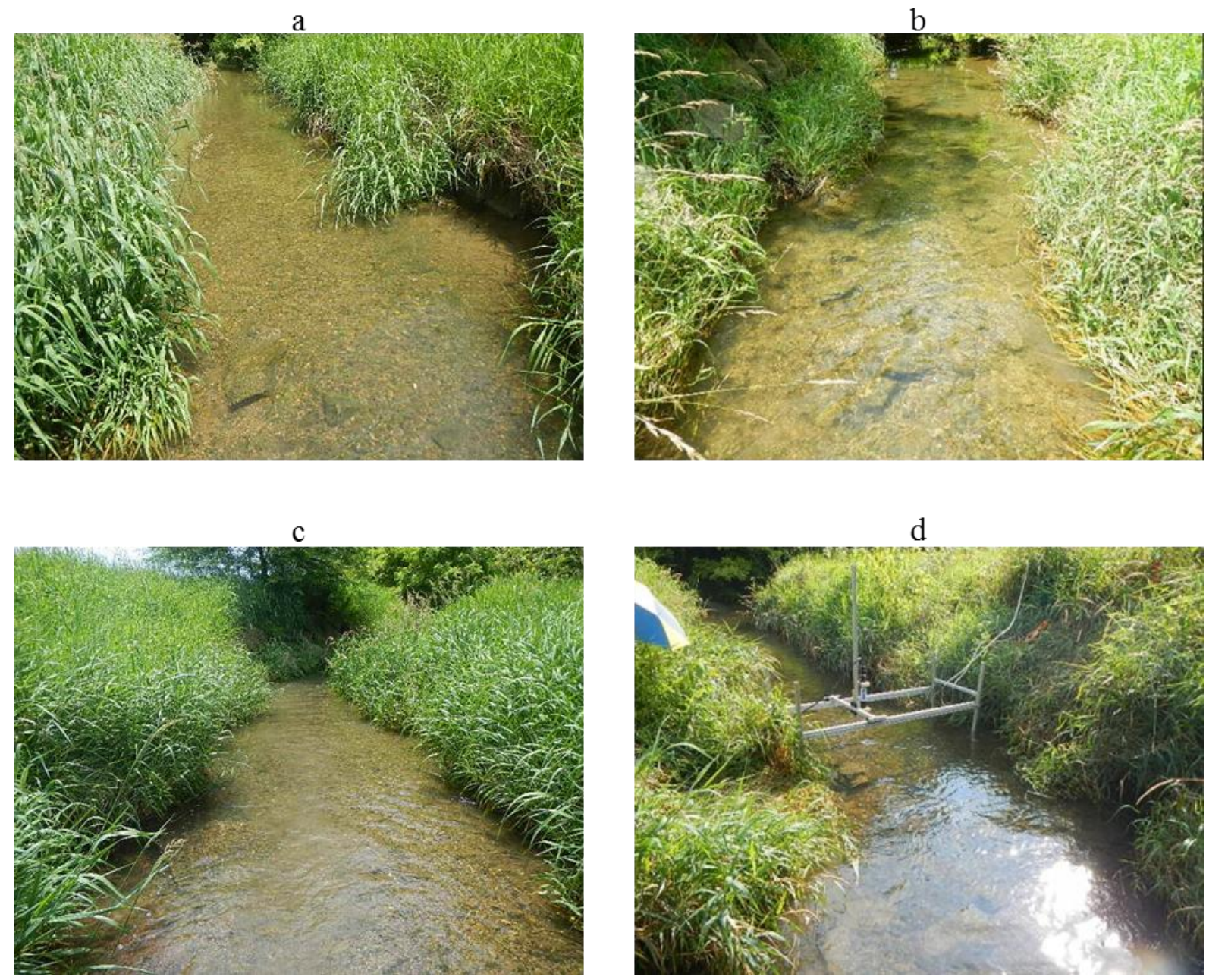

Figure 6: a) Upstream, b) downstream, c) left bank, and d) right bank of sample location 2 within the reference reach (ROL2): cattle restriction for 17 years. 

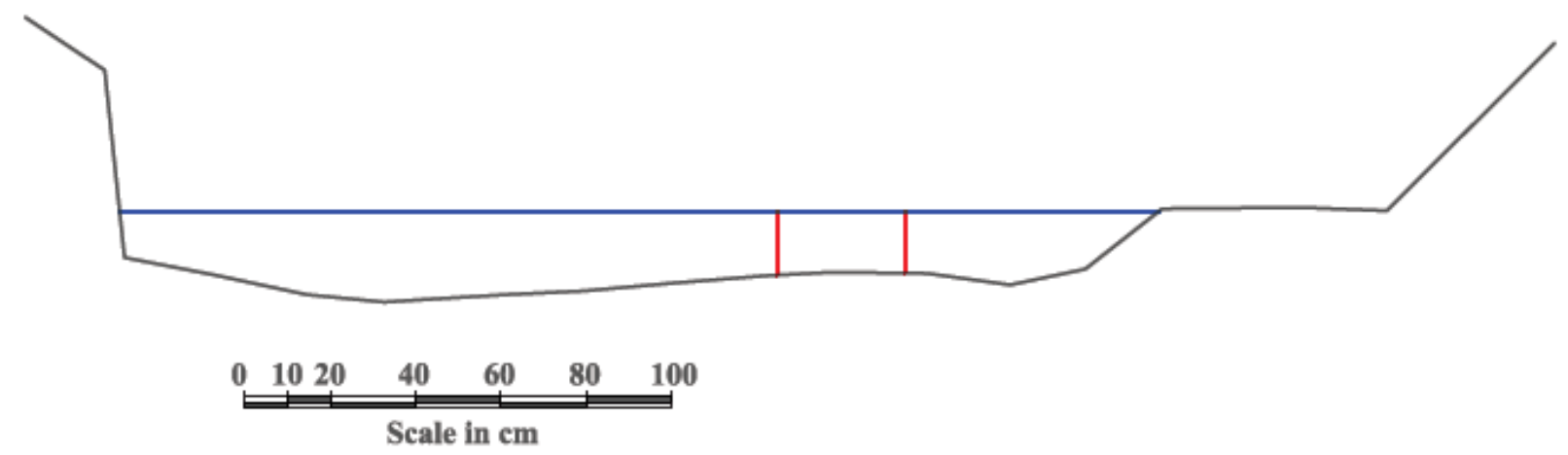

Figure 7: Cross section of location two in the reference reach (ROL2) with the water surface (blue) and the measurement area (red) marked.

Table 3: Grain size statistics for the reference reach (R0) (cattle restriction). R0L1 ROL2

\begin{tabular}{lcccc} 
& Sample 1 & Sample 2 & Sample 1 & Sample 2 \\
\hline D16 (mm) & 4.8 & NA* & 4.9 & 6.1 \\
D50 (mm) & 9.4 & NA & 12 & 11 \\
D84 (mm) & 16 & NA & 26 & 26
\end{tabular}

$R$ and $L$ indicate reach number and location number, respectively.

*A second sample of location one could not be taken due to low water depths and instrument limitations.

\subsubsection{Reach 1 (R1): Cattle Restriction}

Within this reach cattle access to the stream was restricted and natural re-vegetating occurred $(0.5 \mathrm{~km})$. Thick grassy vegetation grows on both sides of the stream but the streambanks, especially those on the outside of the bends, were typically steep and void of vegetation (Thompson et al. 2012). Location one (R1L1) is downstream of location two (R1L2). The time of samples in this reach are labeled on the discharge plot in Figure 8. Data from pebble counts conducted after each velocity sample are presented in Table 4. 


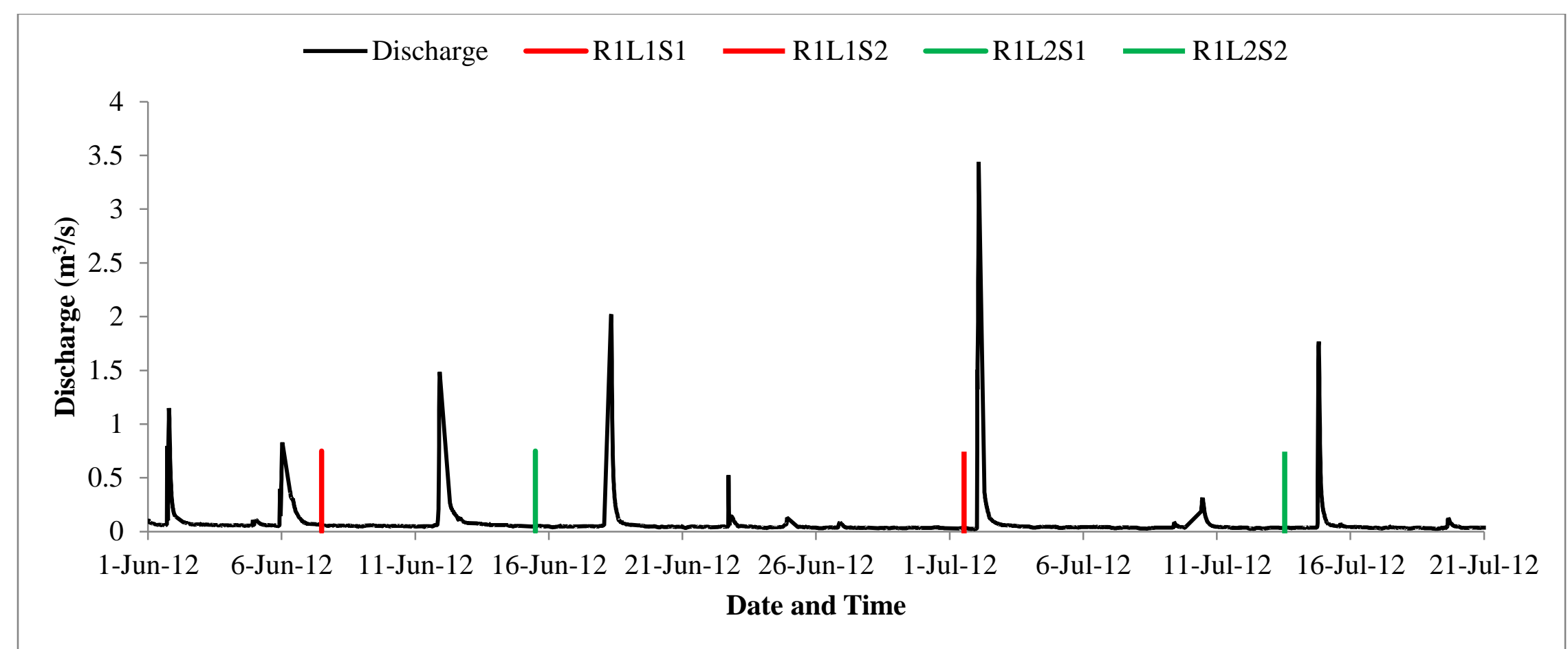

Figure 8: Continuous discharge measurements for the two month sample period with vertical lines indicating time of velocity sampling.

Note: $R, L$, and $S$ indicate reach number, location number, and sample time, respectively. $R 1$ : cattle restriction. 


\section{$\underline{\text { R1L1: }}$}

Upstream of the measurement area was a straight section of stream $(\sim 15 \mathrm{~m})$ with vegetation on both banks (Figure 9a). Approximately $5 \mathrm{~m}$ downstream of the measurement area the stream bends to the right (Figure 9b). The left bank has a $0.7 \mathrm{~m}$ vertical bank with no vegetation on the vertical section and grassy vegetation on the top (Figure 9c). The right bank was gradually sloped and covered with thick grassy vegetation (Figure $9 \mathrm{~d}$ ). $\mathrm{D}_{50}$ at this location was $15 \mathrm{~mm}$ and $12 \mathrm{~mm}$ for sample one and sample two, respectively (Table 4). The location of the velocity measurement area is identified in Figure 10.

a

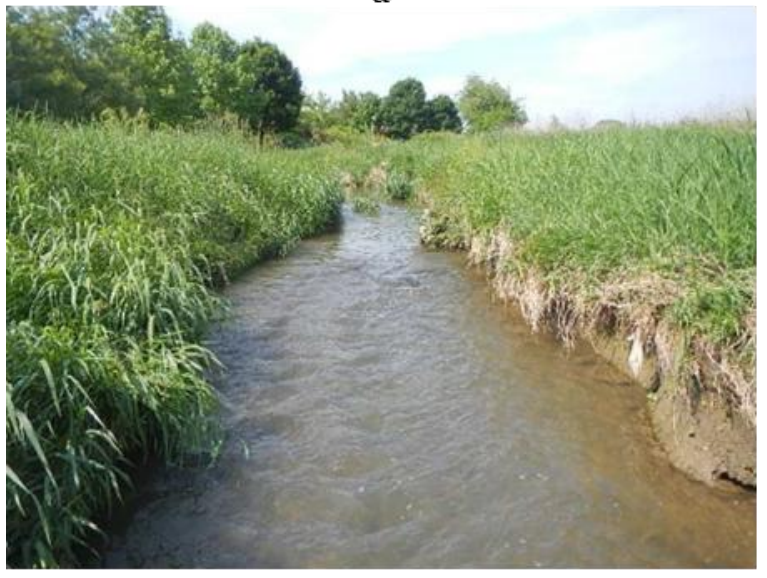

C

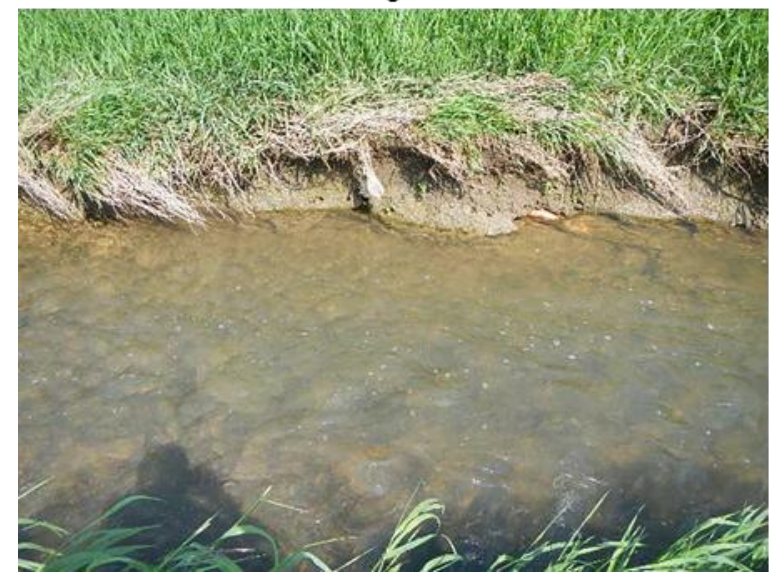

$\mathrm{b}$

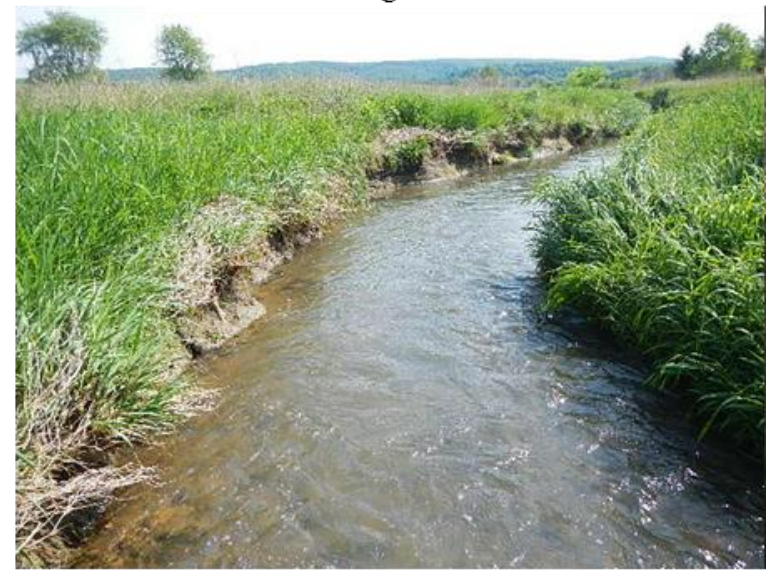

d

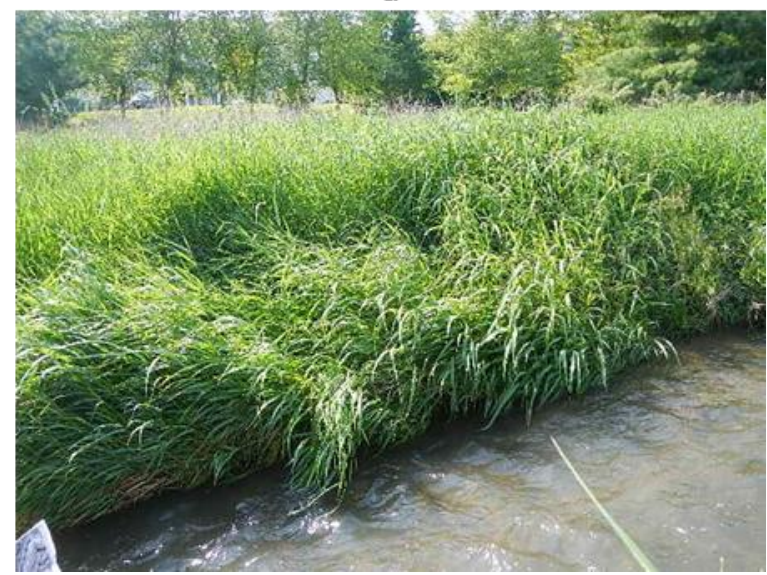

Figure 9: a) Upstream, b) downstream, c) left bank, and d) right bank of sample location 1 within the reach 1 (R1L1): cattle restriction. 


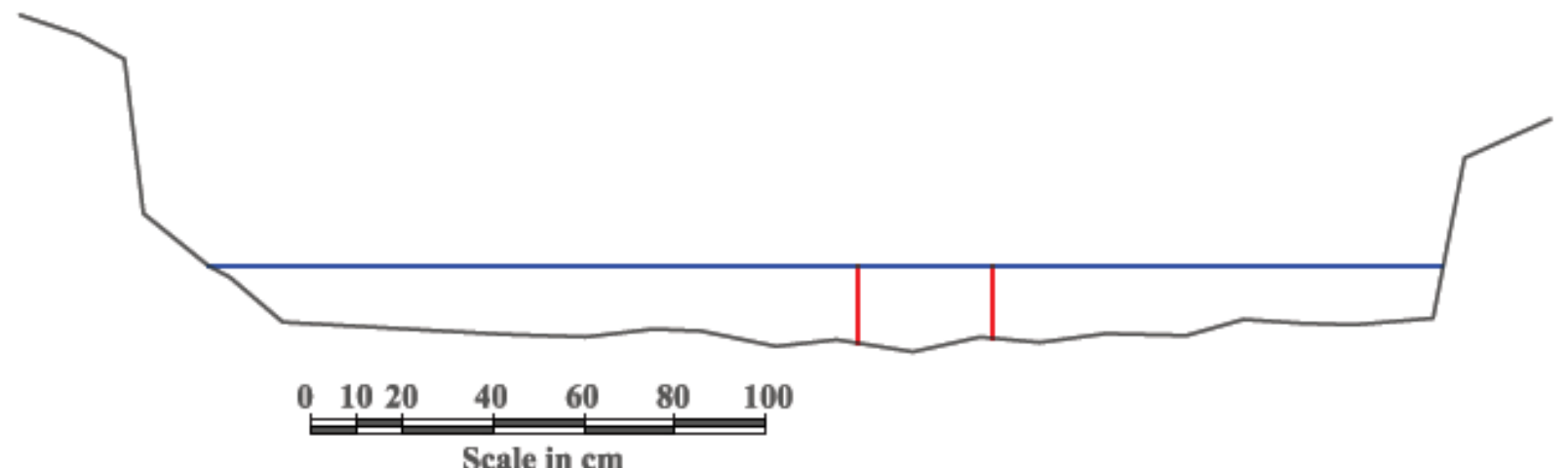

Figure 10: Cross section of location one in reach one (R1L1) with the water surface (blue) and the measurement area (red) marked.

Note: Scale is not distorted.

\section{R1L 2:}

Just upstream of the measurement area $(\sim 1 \mathrm{~m})$ was a bend where the flow was constricted by the banks on either side, reducing the bankfull width (Figure 8a). Downstream of the measurement area was a straight section of stream with some large cobbles which impede the flow (Figure $8 b$ ). The left bank was covered with thick grassy vegetation (Figure 8c). The right bank was steep, without vegetation and observations suggest recent erosion (Figure $8 d$ ). $D_{50}$ at this location was $28 \mathrm{~mm}$ and $18 \mathrm{~mm}$ for sample one and sample two, respectively (Table 4). The location of the velocity measurement area is identified in Figure 12. 
a

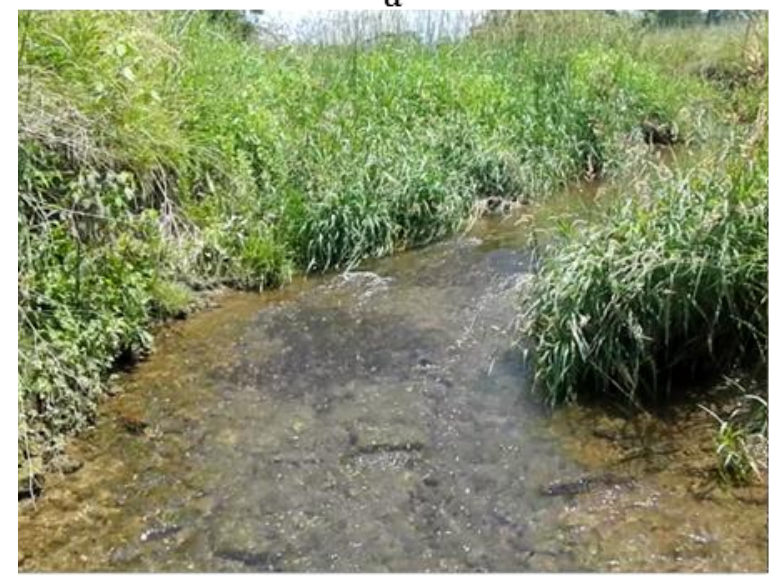

C

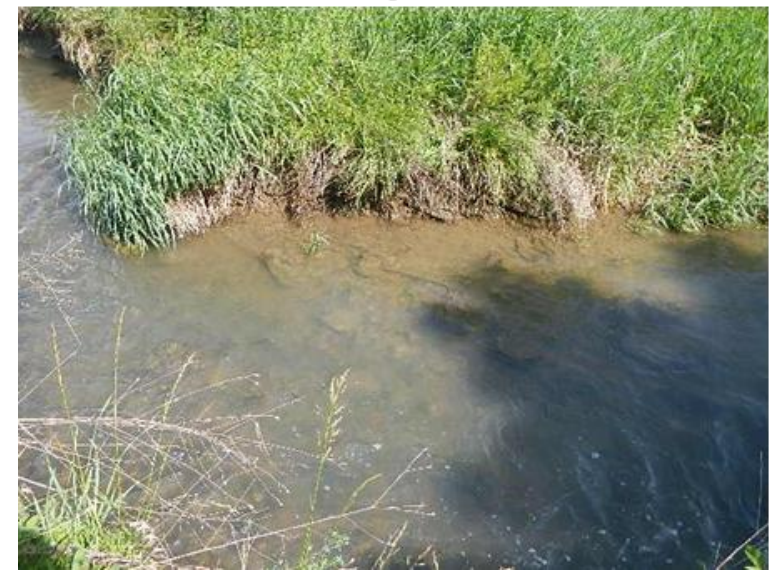

$\mathrm{b}$

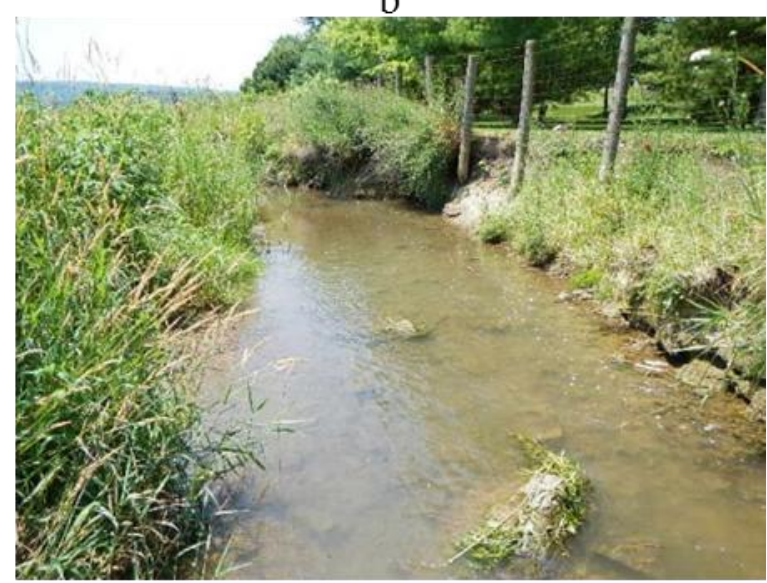

d

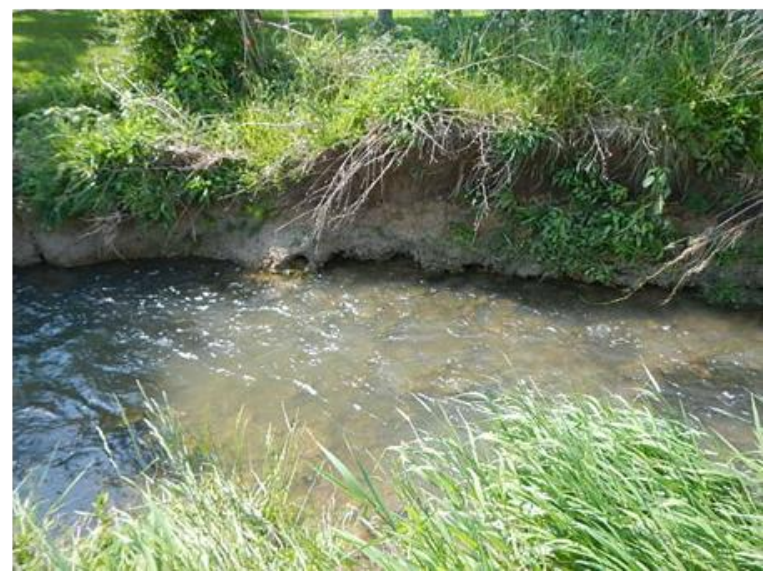

Figure 11: a) Upstream, b) downstream, c) left bank, and d) right bank of sample location 2 within reach 1 (R1L2): cattle restriction.

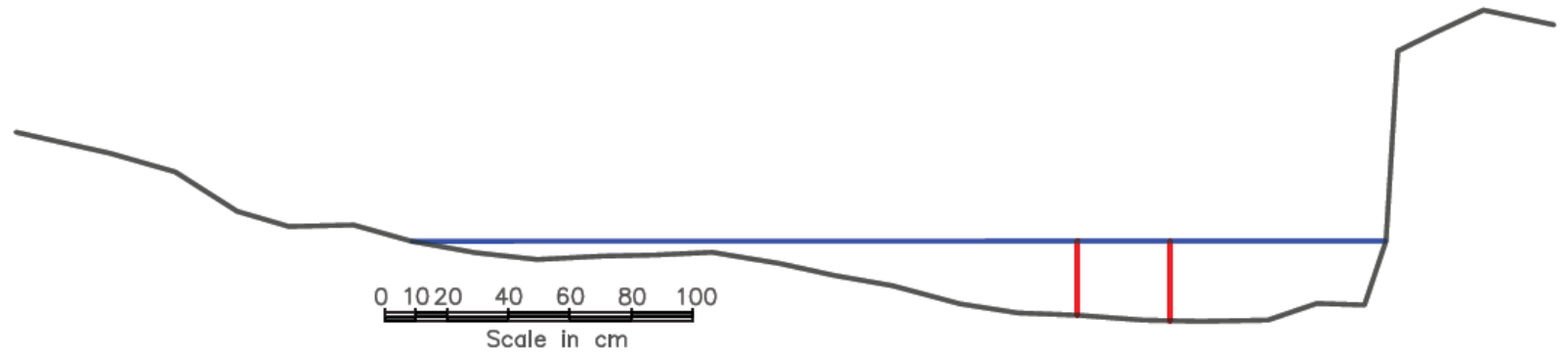

Figure 12: Cross section of location two in reach one (R1L2) with the water surface (blue) and the measurement area (red) marked.

Note: Scale is not distorted. 
Table 4: Grain size statistics for reach one (R1) (cattle restriction).

R1L1 R1L2

Sample 1 Sample 2 Sample 1 Sample 2

\begin{tabular}{lllll}
\hline D16 (mm) & 7.1 & 4.5 & 10 & 6.6 \\
D50 (mm) & 15 & 12 & 28 & 18 \\
D84 (mm) & 28 & 34 & 73 & 44 \\
\hline
\end{tabular}

\subsubsection{Reach 2 (R2): Cattle restriction, banks reshaped to 3:1 slope and re-vegetated}

In addition to cattle restriction, within this reach the banks were reshaped to a 3:1 slope and vegetation was planted along these banks $(0.6 \mathrm{~km})$. Most of the banks have maintained this slope and grassy vegetation and small shrubs grow thick along the banks and riparian zone (Thompson et al. 2012). Location one (R2L1) is downstream of location two (R2L2). The time of samples in this reach are labeled on the discharge plot in Figure 13. Data from pebble counts conducted after each velocity sample are presented in Table 5. 


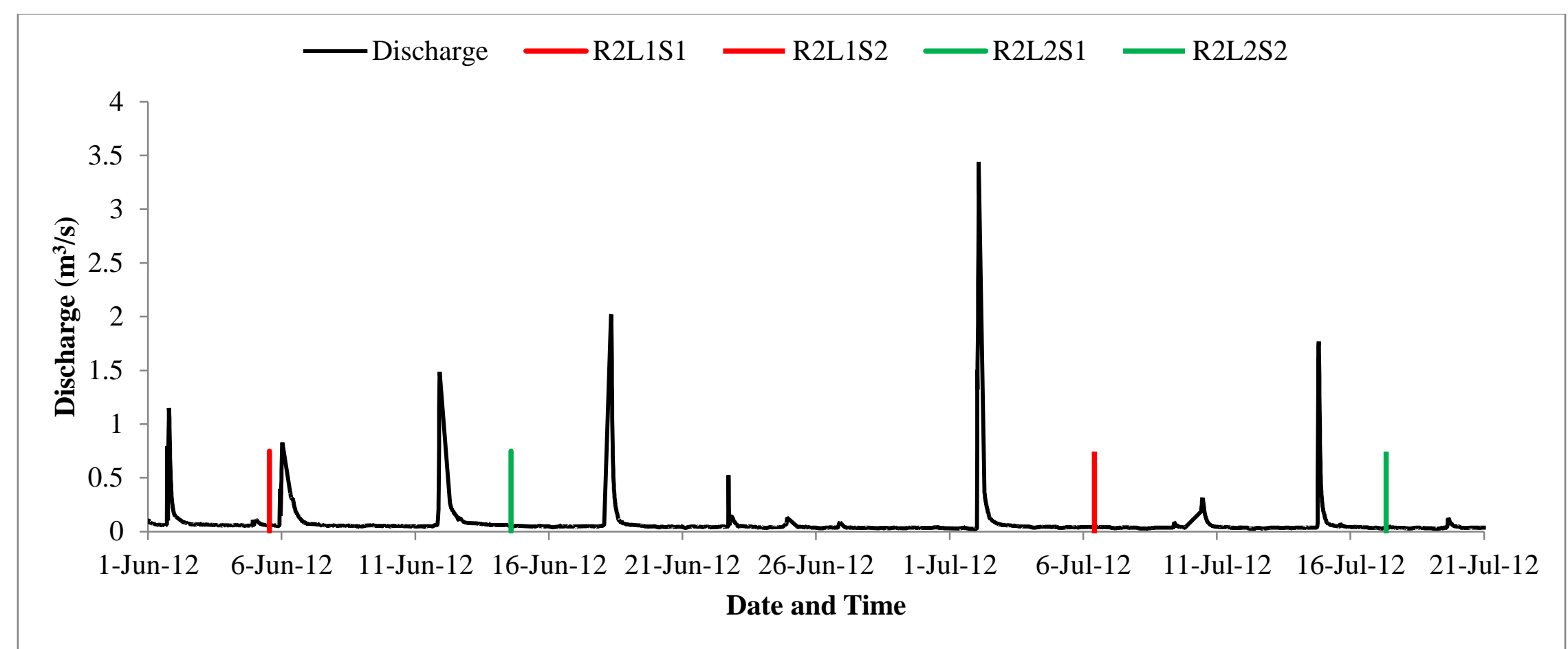

Figure 13: Continuous discharge measurements for the two month sample period with vertical lines indicating time of velocity sampling.

Note: $R, L$, and $S$ indicate reach number, location number, and sample time, respectively. $R 2$ : cattle restriction and reshape banks to 3:1 slope. 


\section{R2L1:}

Upstream of the measurement area was a straight section of stream with vegetation on both banks and patches of vegetation on the stream bed (Figure 14a). At the measurement area the stream begins to widen into the straight reach downstream where the flow was concentrated toward the right bank and the streambed consists of cobbles, gravel, sand and a patch of vegetation near the left bank (Figure 14b). At the measurement area the left and right banks were covered with grassy vegetation and the bed was mostly comprised of large cobbles with some sand and gravel. $\mathrm{D}_{50}$ at this location was $24 \mathrm{~mm}$ and $29 \mathrm{~mm}$ for sample one and sample two, respectively (Table 5). The location of the velocity measurement area is identified in Figure 15.
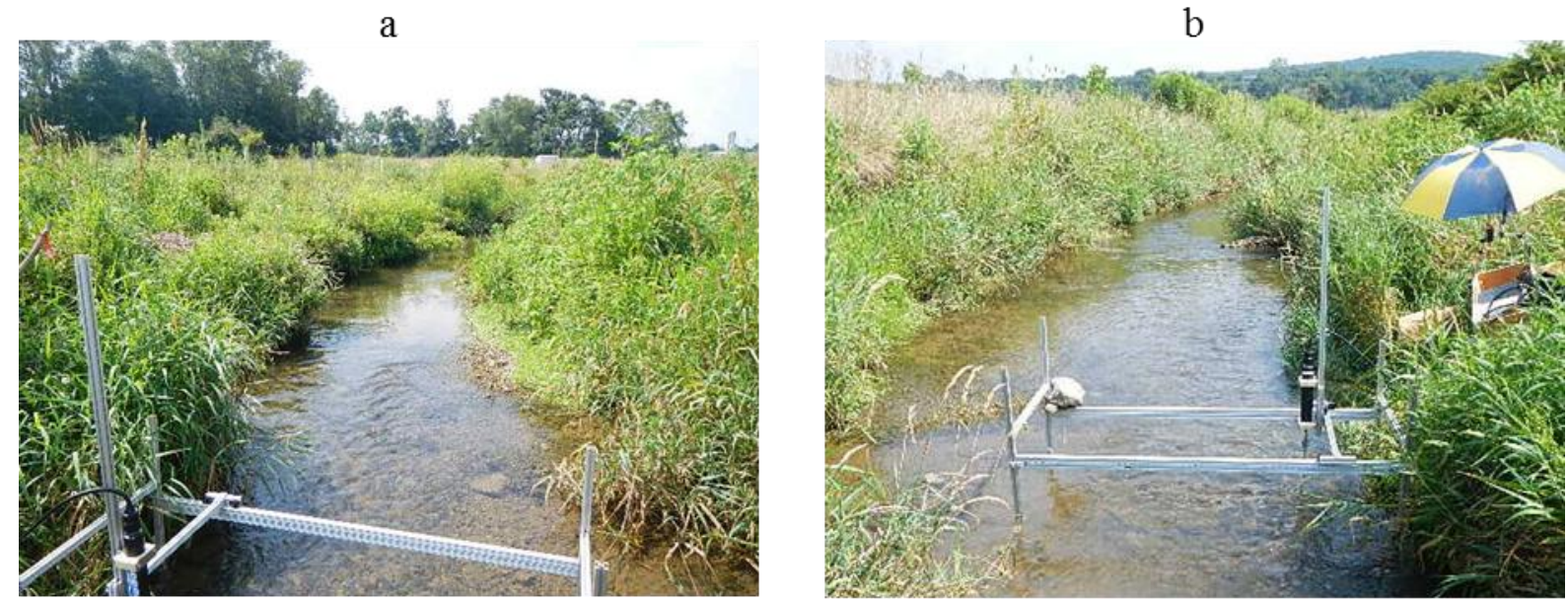

C

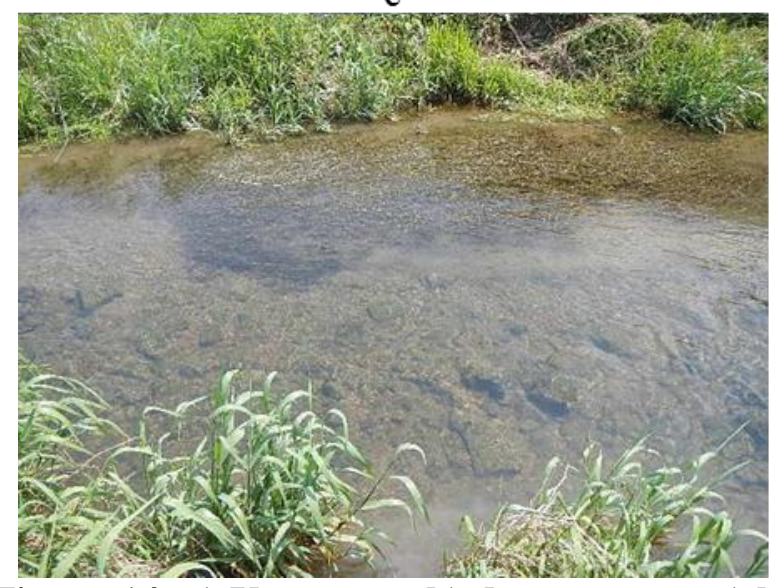

d

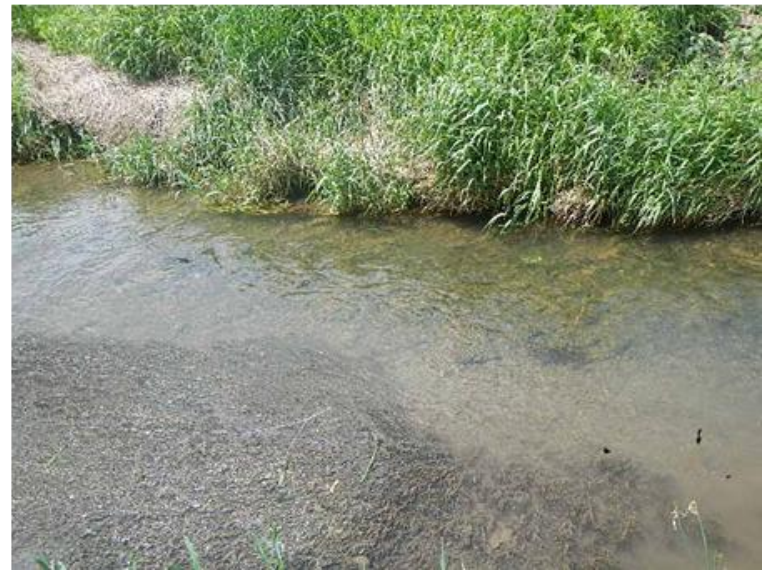

Figure 14: a) Upstream, b) downstream, c) left bank, and d) right bank of sample location 2 within reach 2 (R2L1):cattle restriction, banks reshaped to 3:1 slope and re-vegetated. 


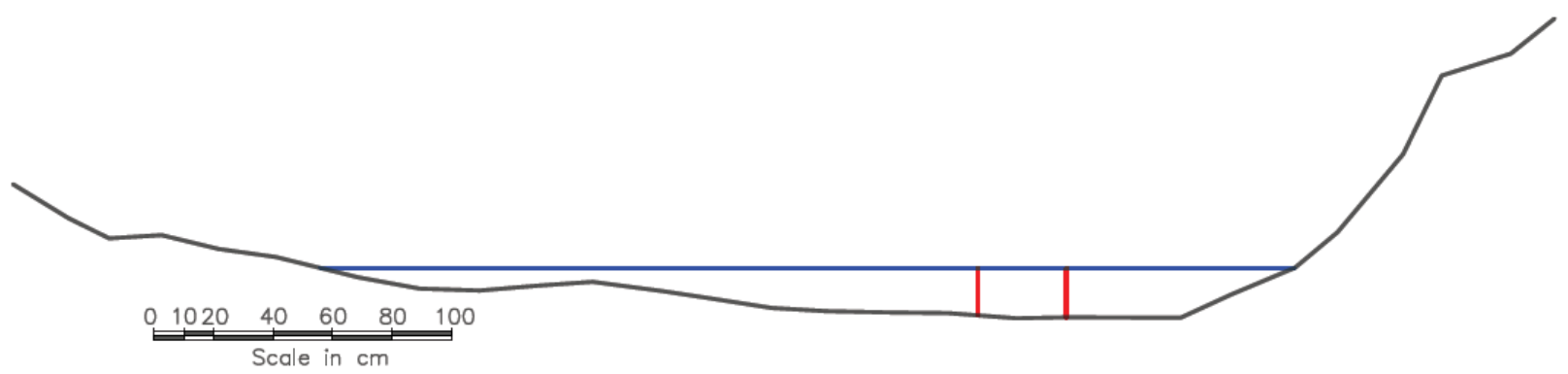

Figure 15: Cross section of location one in reach two (R2L1) with the water surface (blue) and the measurement area (red) marked.

Note: Scale is not distorted.

\section{R2L2:}

Upstream of the measurement area ( 4 $\mathrm{m})$ was a bend in the stream and two masses of vegetation in the stream which reduce the flow area. Most of the flow was directed toward the right bank (Figure 16a). Downstream of the measurement area the stream widened and depth increased. The streambed was mostly comprised of gravel and sand (Figure 16b). The right and left banks at the measurement area were gradually sloped and covered with grassy vegetation (Figure 16c, d). $\mathrm{D}_{50}$ at this location was $12 \mathrm{~mm}$ for both sample times (Table 5). The location of the velocity measurement area is identified in Figure 17. 
a

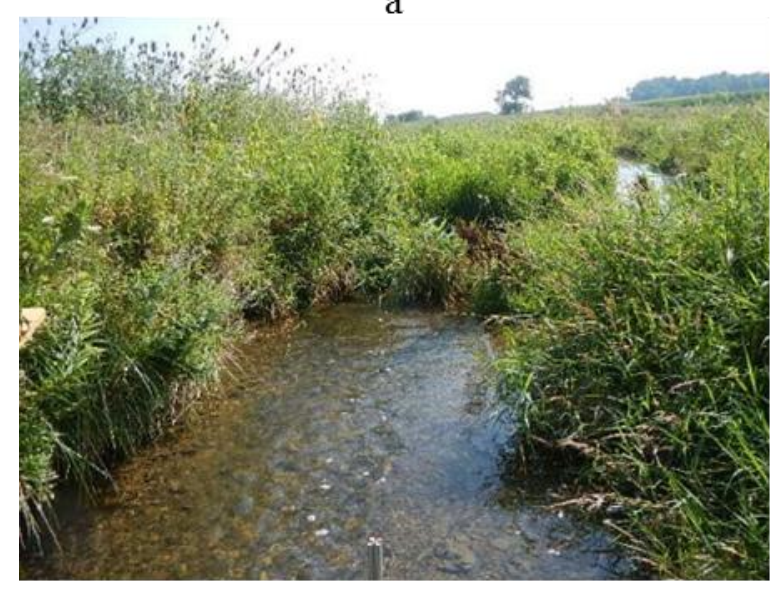

C

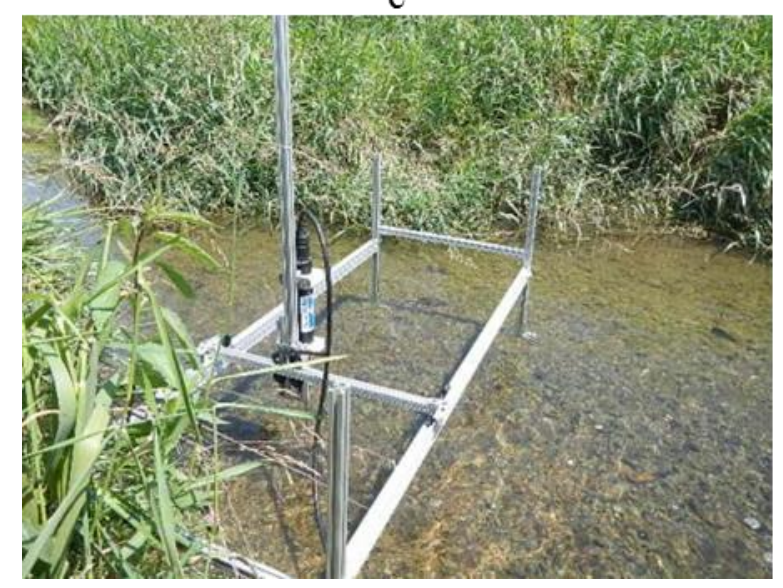

b

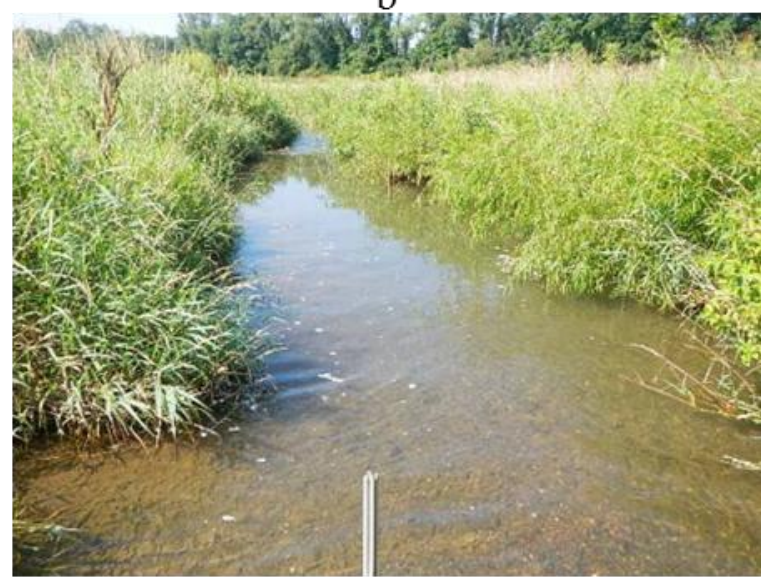

d

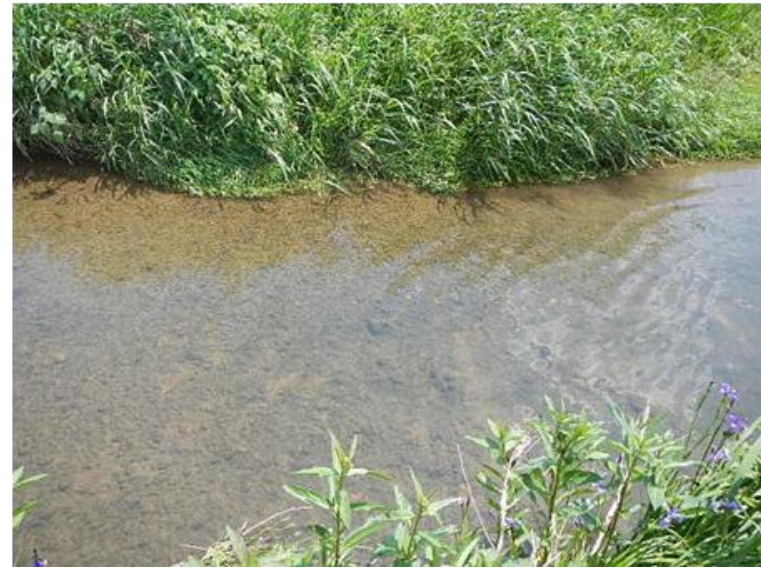

Figure 16: a) Upstream, b) downstream, c) left bank, and d) right bank of sample location 2 within reach 2 (R2L2): cattle restriction, banks reshaped to 3:1 slope and re-vegetated.

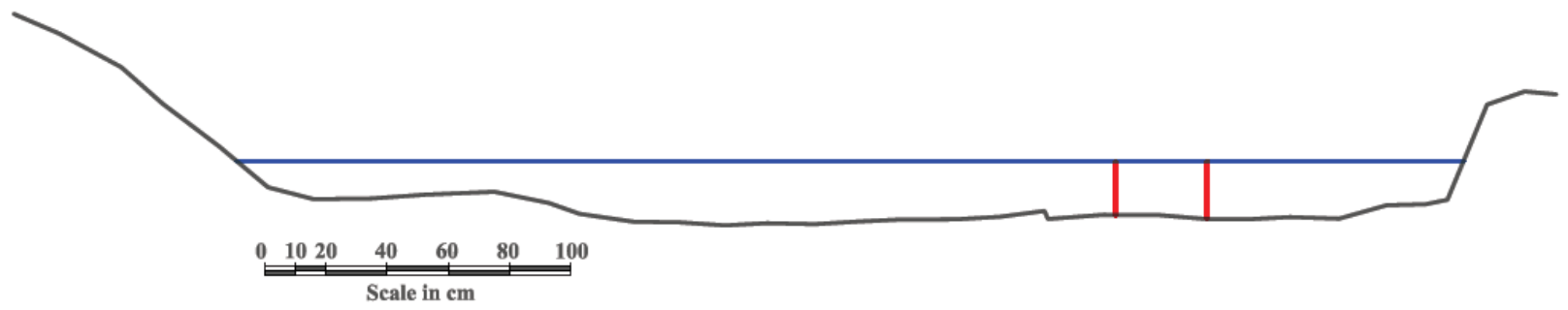

Figure 17: Cross section of location two in reach two (R2L2) with the water surface (blue) and the measurement area (red) marked.

Note: Scale is not distorted. 
Table 5: Grain size statistics for reach two (R2) (cattle restriction, reshaping of banks to 3:1 slope, and planting vegetation).

\begin{tabular}{lcccc}
\hline & \multicolumn{2}{c}{ R2L1 } & \multicolumn{2}{c}{ R2L2 } \\
& Sample 1 & Sample 2 & Sample 1 & Sample 2 \\
\hline D16 (mm) & 7.2 & 6.9 & 6.1 & 8 \\
D50 (mm) & 24 & 29 & 12 & 12 \\
D84 (mm) & 76 & 90 & 19 & 23 \\
\hline
\end{tabular}

\subsubsection{Reach 3 (R3): Designed and installed a two-stage channel with inset floodplains and re-vegetated}

The restoration techniques applied to this reach involved designing and installing a two-stage channel with inset floodplains and re-vegetating $(0.3 \mathrm{~km})$. An inset flood plain was integrated into the main channel to reduce stream velocities during storm events. The elevation of the flood plain was based on the shear stress required to move the streambed material. Natural floodplain wetlands line the stream and natural levees keep this floodplain from draining. The width of the inset flood plain was restricted in order to avoid affecting these natural levees. For this design, the channel slope and baseflow widths were not changed (Thompson et al. 2012). Location one (R3L1) is downstream of location two (R3L2). The time of samples in this reach are labeled on the discharge plot in Figure 18. Data from pebble counts conducted after each velocity sample are presented in Table 6. 


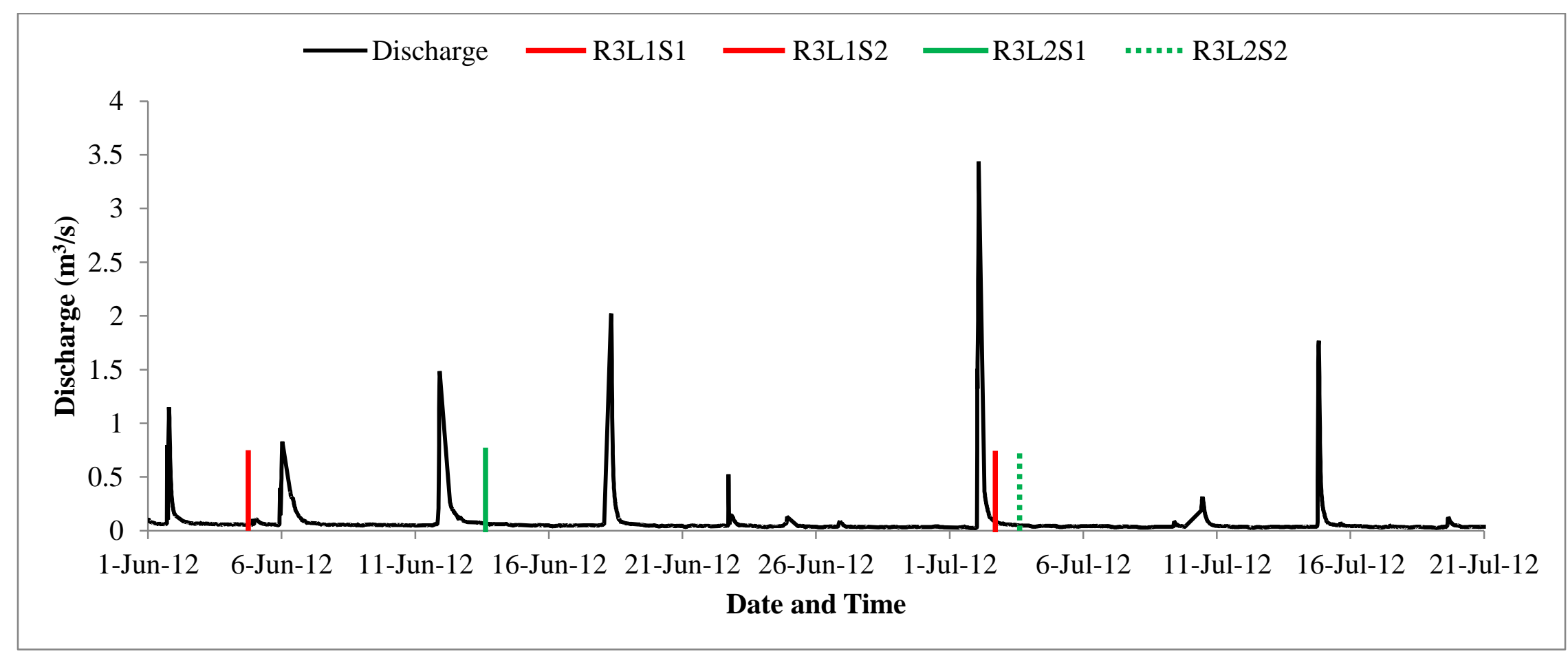

Figure 18: Continuous discharge measurements for the two month sample period with vertical lines indicating time of velocity sampling.

Note: $R, L$, and S indicate reach number, location number, and sample time, respectively. R3: cattle restriction, two-stage channel design with in-set floodplain. 


\section{R3L1:}

Approximately $6 \mathrm{~m}$ upstream of the measurement area the stream widened and was split by a small island with vegetation in the center of the stream (Figure 19a). Downstream was a straight section of stream $(\sim 10 \mathrm{~m})$ with thick grassy vegetation on both banks (Figure 19b). The right and left banks at the measurement area were covered with thick grassy vegetation (Figure 19c, d). $\mathrm{D}_{50}$ at this location was $10 \mathrm{~mm}$ and $11 \mathrm{~mm}$ for sample one and sample two, respectively (Table 6). The location of the velocity measurement area is identified in Figure 20.

a

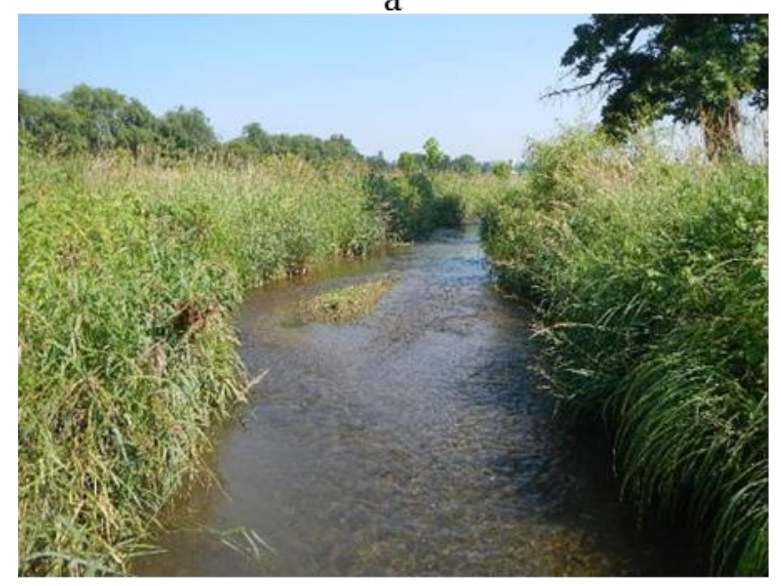

$\mathrm{C}$

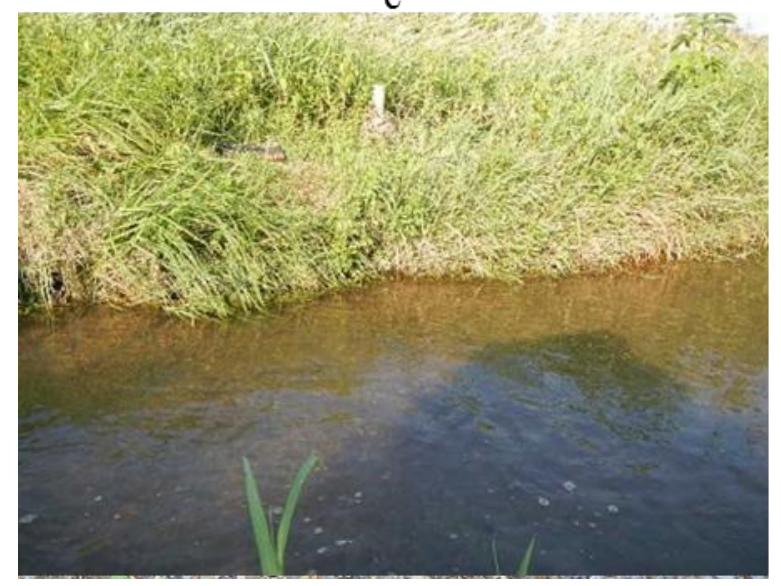

$\mathrm{b}$

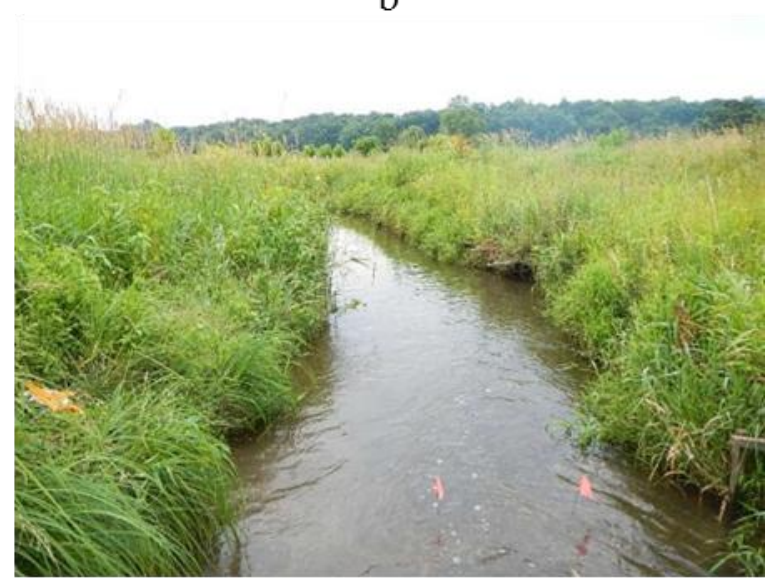

d

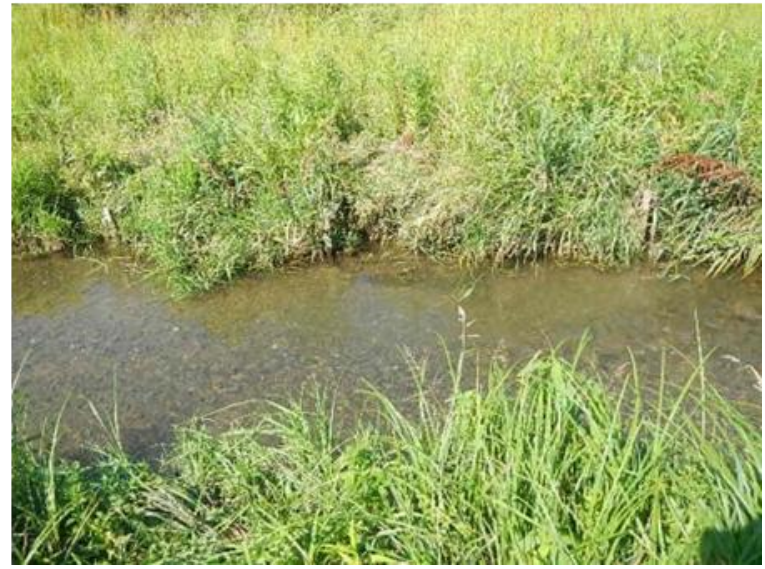

Figure 19: a) Upstream, b) downstream, c) left bank, and d) right bank of sample location 1 within reach 3 (R3L1): cattle restriction, two-stage channel design with in-set floodplain and re-vegetated. 


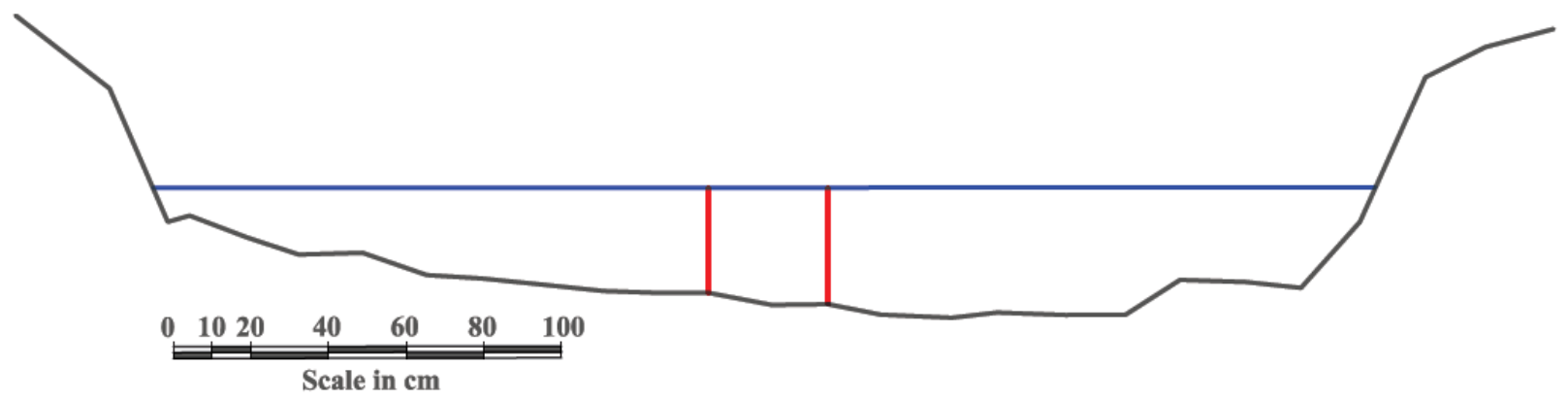

Figure 20: Cross section of location one in reach three (R3L1) with the water surface (blue) and the measurement area (red) marked.

Note: Scale is not distorted.

\section{$\underline{\text { R3L2: }}$}

Upstream of the sample area was a straight reach of stream. A patch of mossy vegetation in a shallow section in the center of the stream approximately $3 \mathrm{~m}$ upstream of the measurement area effectively split the stream flow (Figure 21a). The flow depth and width increased at the measurement area. Downstream of the measurement area the channel was straight and slightly wider (Figure 21b). All banks were gradually sloped and covered with thick grassy vegetation (Figure 21c, d). $D_{50}$ at this location was $17 \mathrm{~mm}$ and $15 \mathrm{~mm}$ for sample one and sample two, respectively (Table 6). The location of the velocity measurement area is identified in Figure 22. 
a

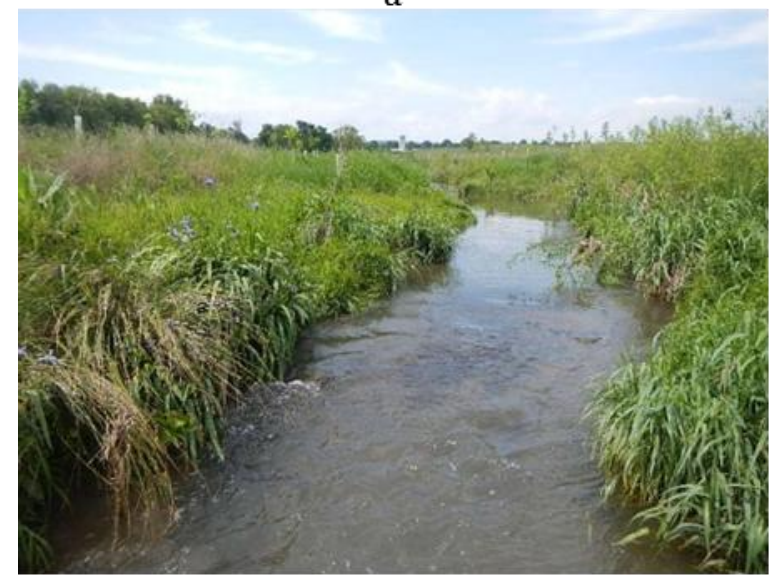

$\mathrm{c}$

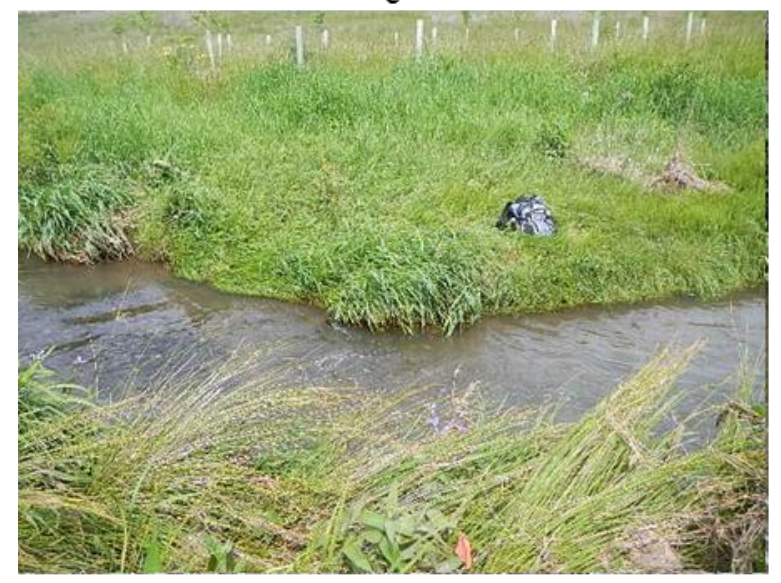

b

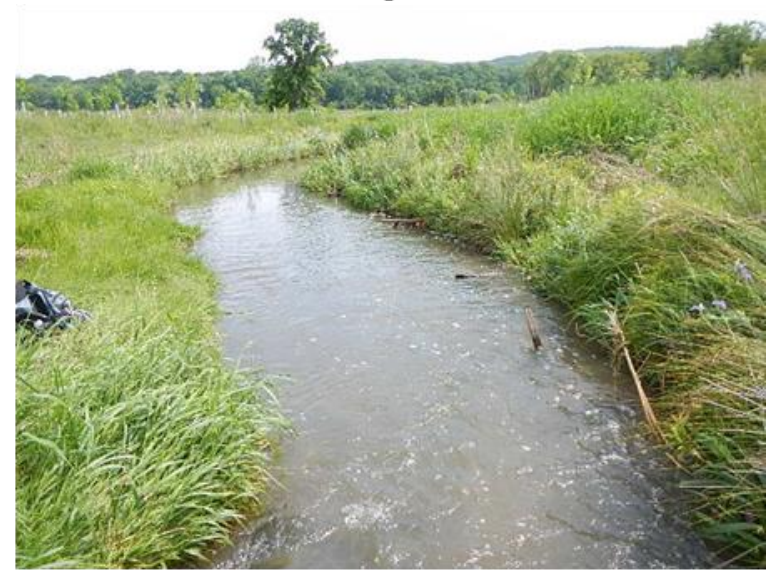

d

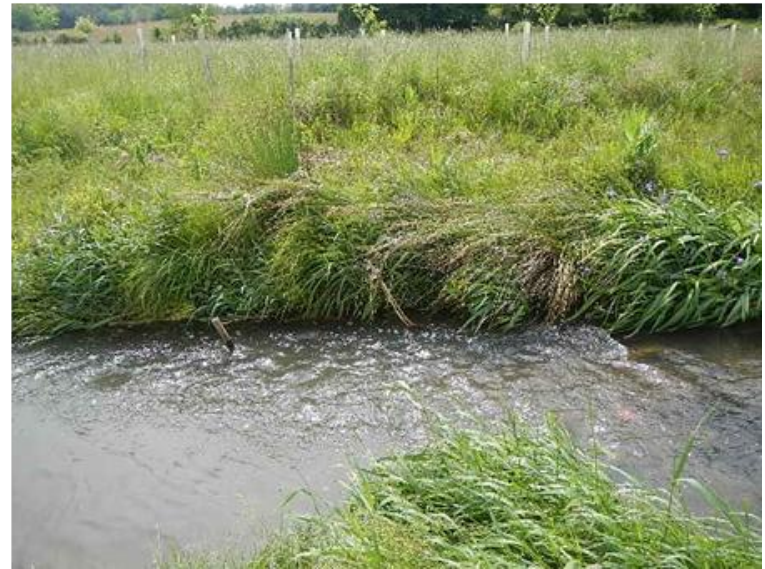

Figure 21: a) Upstream, b) downstream, c) left bank, and d) right bank of sample location 2 within reach 3 (R3L2): cattle restriction, two-stage channel design with in-set floodplain and re-vegetated.

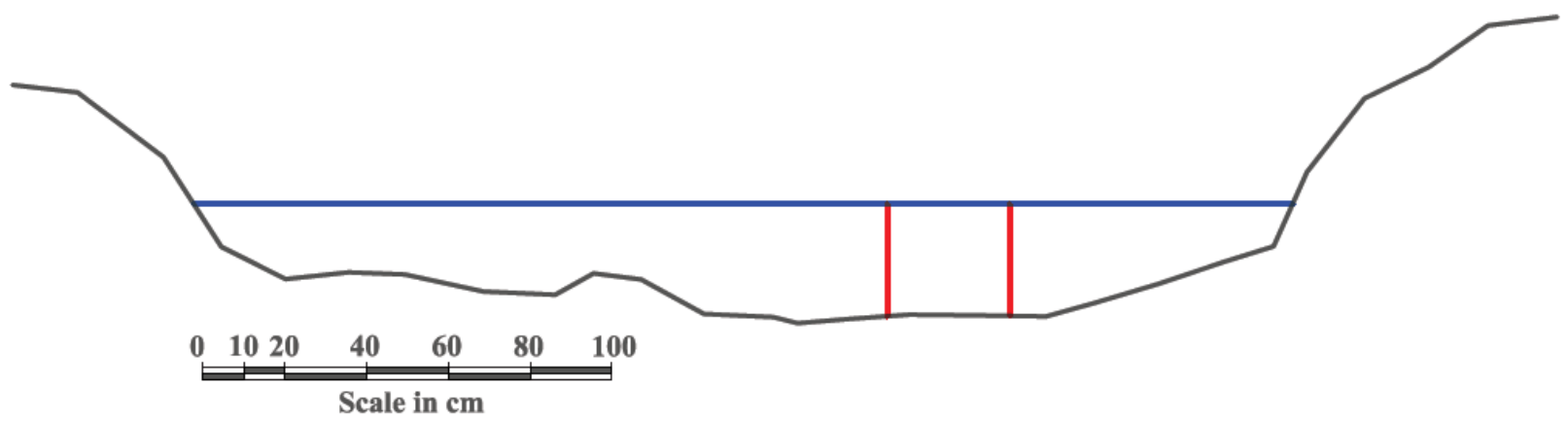

Figure 22: Cross section of location two in reach three (R3L2) with the water surface (blue) and the measurement area (red) marked.

Note: Scale is not distorted. 
Table 6: Grain size statistics for reach three (R3) (cattle restriction and two-stage channel with inset floodplain).

\section{R3L1 R3L2}

Sample 1 Sample 2 $\quad$ Sample 1 Sample 2

\begin{tabular}{lcccc}
\hline D16 (mm) & 6.4 & 6.4 & 7.8 & 6.7 \\
D50 (mm) & 10 & 11 & 17 & 15 \\
D84 (mm) & 16 & 18 & 31 & 29 \\
\hline
\end{tabular}

\subsection{Velocity Measurements}

Velocity was measured with an acoustic Doppler velocimeter (ADV) at each experimental location at baseflow as described in the following sections.

\subsubsection{Mount Description}

A custom mount was designed to hold the ADV during sampling which allowed for quick and accurate movement and stabilization of the ADV at each sampling location. The mount consisted of four legs, which could be anchored into the streambed or streambank; two braces, which connected the legs and braced the mount in the streamwise direction; one streamwise beam which allowed the ADV to be moved in the streamwise direction; two lateral beams which supported the streamwise beam and allowed the ADV to be moved in the lateral direction; and one vertical bar which held the ADV and allowed for vertical movement of the ADV to set the correct distance from the streambed (Figure 23 and Figure 24). 


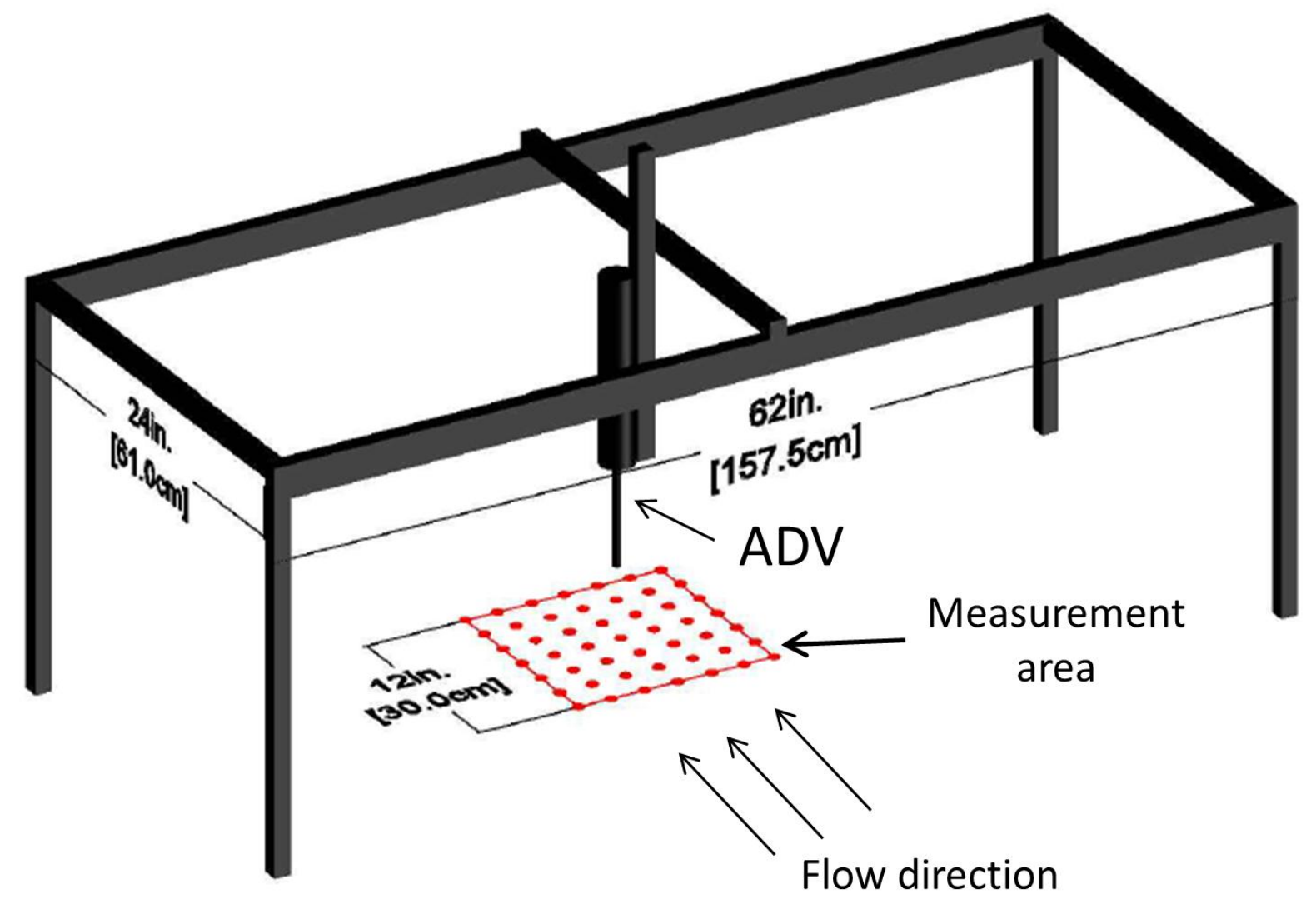

Figure 23: ADV mount with location of measurement area $(n=49)$.

The legs, braces, and vertical bar were made of 1 in. $x 1$ in. $(2.54 \mathrm{~cm} \times 2.54 \mathrm{~cm})$ extruded aluminum t-slot sections and the two lateral beams of 1 in. $x 2$ in. $(2.54 \mathrm{~cm} \times 5.08 \mathrm{~cm})$ extruded aluminum t-slot sections. This design allowed for the mount to be anchored, leveled and stabilized before the ADV was attached.

The mount setup procedure began with placing and orienting the mount perpendicular to the main flow direction. Streamers were used to identify the main stream flow direction. The legs were then anchored in the streambed with galvanized spikes. The lateral beams were then leveled via adjustable bolted connections at the legs with the assistance of a pipe leveler, an instrument which allows for leveling in two directions. The vertical bar was attached to the streamwise beam. This connection consisted of four coaster wheels which were bolted to the vertical beam and clamped the streamwise bar at the top and bottom. One bolt connecting the streamwise beam and the vertical bar allowed for this connection to be tightened after the vertical position was secured. This assembly was then connected to the lateral beams with four 
wheels (two on the upstream beam and two on the downstream beam) which ran on the lateral beams. One bolt secured this connection once the lateral position was selected. Once the mount was aligned and leveled the ADV was attached to the vertical bar using two bolted clamp connections. The pipe leveler was used to check the alignment of the vertical bar during measurements. The ADV could then be moved in the lateral, streamwise, and vertical directions within $0.5 \mathrm{~cm}$ precision using the rulers which were attached to each beam. Figure 24 shows the ADV mount and ADV setup in the field. All velocity measurements were taken at a single vertical location of $7 \mathrm{~cm}$ from the bed. This distance was set using a tool with a pin which measured the distance from the streambed to the measurement location. This same tool had a ruler which was used to measure the flow depth at each point on the measurement grid.

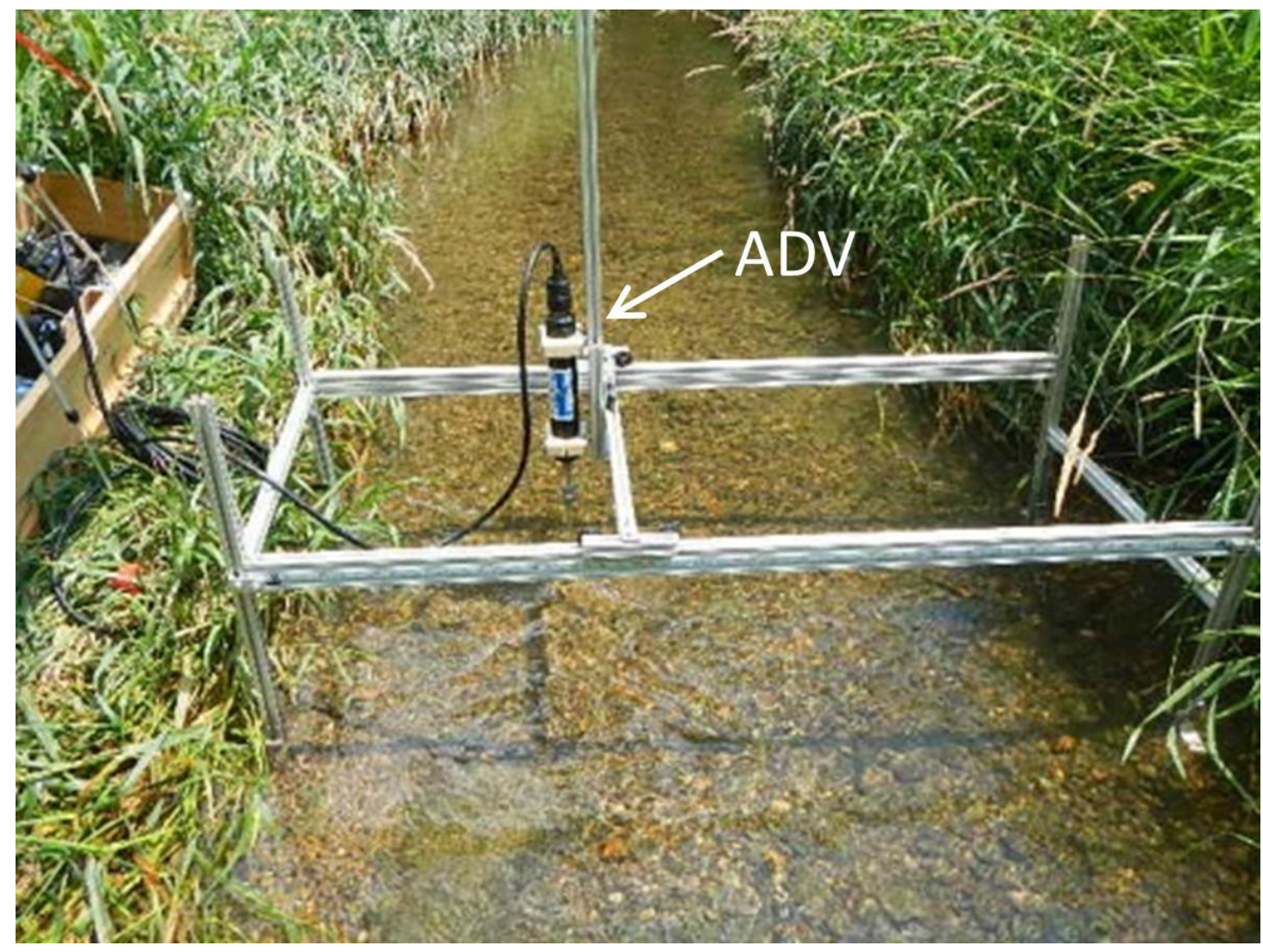

Figure 24: ADV mount deployed with ADV.

\subsubsection{ADV Measurements}

A Sontek 16-MHz micro acoustic Doppler velocimeter (MicroADV) (Sontek, San Diego, CA, USA) was used to measure three-dimensional velocities at one vertical location $7 \mathrm{~cm}$ from the boundary. The ADV was accurate within $1 \%$ of the measured velocity range. For all 
measurements in this study the measured range was $\pm 100 \mathrm{~cm} / \mathrm{s}$, therefor the range of error was $\pm 1 \mathrm{~cm} / \mathrm{s}$. A grid system was established in each of the eight measurement locations (see section 3.3 Description of measurement sites). This grid was $30 \mathrm{~cm}$ x $30 \mathrm{~cm}$ with measurements taken every $5 \mathrm{~cm}$ for a total of 49 measurements in each location (Figure 23). Location of measurement areas for specific cross sections are identified in Figure 5, Figure 7, Figure 10, Figure 12, Figure 15, Figure 17, Figure 20, and Figure 22. Velocity measurements were collected for 120 seconds at $50 \mathrm{~Hz}$. This allowed for a total of 6000 individual velocity measurements at each measurement point. These sampling parameters meet the minimum sample requirements suggested by Buffin-Belanger and Roy (2005). Flow depth was also measured and recorded at each measurement point.

All ADV data were filtered using WinADV32 software program. Data were removed which had less than $70 \%$ average correlation or signal-noise-ratio (SNR) less than 5. Data were also filtered for phase-space threshold despiking (Goring and Nikora 2002, as modified by Wahl 2000) which removes spikes which occur when the phase shift between outgoing and incoming pulse lie outside the range between $-180^{\circ}$ and $+180^{\circ}$.

\subsection{Data Analysis and Statistical Methods}

Turbulent kinetic energy, and Reynolds stresses were evaluated for each velocity time series. TKE will be presented with units $\mathrm{N} / \mathrm{m}^{2}$ and Reynolds shear stresses with units $\mathrm{Pa}$. It is worth noting that these units are equivalent to the units $\mathrm{J} / \mathrm{m}^{3}$ as TKE is sometimes presented.

Turbulent kinetic energy (TKE) estimates the average turbulence and was calculated with the following equation (Bradshaw 1971):

$$
T K E=\frac{\rho\left(\overline{u^{\prime 2}+v^{\prime 2}+w^{\prime 2}}\right)}{2}
$$

where $\overline{u^{\prime 2}+v^{\prime 2}+w^{\prime 2}}=\overline{u^{\prime 2}}+\overline{v^{\prime 2}}+\overline{w^{\prime 2}}, T K E$ is turbulent kinetic energy $\left(\mathrm{N} / \mathrm{m}^{2}\right), u^{\prime}$ is the fluctuation component of the time averaged streamwise velocity $(\mathrm{m} / \mathrm{s}), v^{\prime}$ is the fluctuation component of the time averaged lateral velocity $(\mathrm{m} / \mathrm{s}), w^{\prime}$ is the fluctuation component of the time averaged vertical velocity $(\mathrm{m} / \mathrm{s})$, and $\rho^{\prime}$ is the density of water taken to be $998 \mathrm{~kg} / \mathrm{m}^{3}$ for all measurements. The fluctuation components of velocity are as follows: 


$$
\begin{gathered}
u=\bar{u}+u^{\prime} \\
v=\bar{v}+v^{\prime} \\
w=\bar{w}+w^{\prime}
\end{gathered}
$$

where $u, v$ and $w$ are the instantaneous streamwise, lateral, and vertical velocities, respectively; $\bar{u}, \bar{v}$ and $\bar{w}$ are the streamwise, lateral, and vertical velocities, respectively, averaged over the sample time series.

Reynolds stress is the shear stress tensor on a given face which represents turbulent shear stresses and is found with the following equations (Bradshaw 1971):

$$
\begin{aligned}
& \tau_{x z}=-\rho \overline{u^{\prime} w^{\prime}} \\
& \tau_{x y}=-\rho \overline{u^{\prime} v^{\prime}}
\end{aligned}
$$

Where $\tau_{x y}$ and $\tau_{x z}$ are the vertical and lateral components of the Reynolds shear stress (Pa), respectively.

Statistical $t$ tests were performed to analyze the turbulence characteristics mentioned in the previous section. A two sample t-test of "unpaired" of "independent" samples is a statistical hypothesis test of the null hypothesis that the means of two normally distributed populations are equal. Comparisons were made between the two sample times at a common sample location; between the two sample locations within a common reach; and between the experimental reaches. An $\alpha$ value of 0.05 was used for all $t$ tests. 


\section{Results and Discussion}

While efforts were taken to align the measurement grid perpendicular to the stream flow, this positioning was difficult to verify in the field. Streamers attached to the mount were used to identify flow direction and the mount was placed accordingly. The WinADV software allows for correction of probe alignment error by adjusting the XYZ coordinate system for plane rotation. Based on recommendations from Strom and Papanicolaou (2007), and Roy et al. (1996) this correction was not implemented. Research shows that, when measuring complex flows such as those in a meandering stream, the coordinate correction can often lead to more ambiguity and uncertainty. Coordinate rotation is only recommended when sensor misalignment is certain (Strom and Papanicolaou 2007).

Several box plots are presented in this section. The box represents the median value, the $25^{\text {th }}$ percentile, and the $75^{\text {th }}$ percentile. The upper and lower tails of these boxes include data which fall within:

$$
L T=P_{25}-1.5\left(P_{75}-P_{25}\right)
$$

and

$$
U T=P_{75}+1.5\left(P_{75}-P_{25}\right)
$$

where LT and UT are the upper and lower tail limits, respectively and $\mathrm{P}_{25}$ and $\mathrm{P}_{75}$ are the values

corresponding to the $25^{\text {th }}$ percentile and the $75^{\text {th }}$ percentile, respectively. The outliers are all data which fall outside the range from LT to UT.

The results related to the bed roughness are presented first then the results related to the timeaveraged velocity measurements. The analysis of the turbulence statistics, Reynolds stresses and turbulent kinetic energy follows the velocity discussion.

\subsection{Bed Roughness}

From pebble counts completed after each velocity measurement the bed roughness characteristics: D16, D50, and D84 were calculated (Table 7). These characteristics show little change between sample times for some locations, such as R3L1 (two-stage channel) where the 
percent increases in grain sizes were $0 \%, 10 \%$, and $13 \%$ for D16, D50, and D84, respectively (Table 7). Other locations show large changes in these values, such as R1L2 (cattle restriction) where the percent decrease in grain sizes were 34\%, 36\%, and 40\% for D16, D50, and D84, respectively (Table 7). Several storm events occurred between the sample times (Figure 25). These fluctuations could indicate movement of the bed material during these large storm events. Because the banks in reach one are steep and the channel was characterized by large incisions, the flow velocities during these storm events will cause greater movement of material. The twostage channel design implemented in reach three was designed to reduce flow velocities during a storm event to prevent the movement of bed material. The relatively low change in bed roughness between sample one and two indicates this design was successful. Trends were also seen between bed roughness and turbulence characteristics and will be explained in more detail in sections 4.3 Turbulent Kinetic Energy and 4.4 Shear Stresses $\left(\tau_{\mathrm{xy}}\right.$ and $\left.\tau_{\mathrm{xz}}\right)$. 
Table 7: Bed roughness information collected from pebble counts after each velocity measurement and percent change between sample time one and sample time two.

\begin{tabular}{|c|c|c|c|c|c|c|c|c|}
\hline \multirow{5}{*}{ R0 } & \multirow{3}{*}{ L1 } & \multicolumn{3}{|c|}{ D16 (mm) } & D50 (mm) & \multicolumn{3}{|c|}{ D84 (mm) } \\
\hline & & S1 & 4.8 & NA & 9.4 & & 16 & $\mathbf{N A}$ \\
\hline & & S2 & $\mathrm{NA}^{*}$ & INA & NA & NA & NA & NA \\
\hline & \multirow{2}{*}{ L2 } & S1 & 4.9 & \multirow{2}{*}{$25 \%$} & 12 & \multirow{2}{*}{$8.3 \%$} & 26 & \multirow{2}{*}{$0.0 \%$} \\
\hline & & S2 & 6.1 & & 11 & & 26 & \\
\hline \multirow{4}{*}{ R1 } & \multirow{2}{*}{ L1 } & S1 & 7.1 & \multirow{2}{*}{$37 \%$} & 15 & \multirow{2}{*}{$20 \%$} & 28 & \multirow{2}{*}{$21 \%$} \\
\hline & & S2 & 4.5 & & 12 & & 34 & \\
\hline & \multirow{2}{*}{ L2 } & S1 & 10 & \multirow{2}{*}{$34 \%$} & 28 & \multirow{2}{*}{$36 \%$} & 73 & \multirow{2}{*}{$40 \%$} \\
\hline & & S2 & 6.6 & & 18 & & 44 & \\
\hline \multirow{4}{*}{$\mathbf{R} 2$} & \multirow{2}{*}{$\mathbf{L 1}$} & S1 & 7.2 & \multirow{2}{*}{$4.2 \%$} & 24 & \multirow{2}{*}{$21 \%$} & 76 & \multirow{2}{*}{$18 \%$} \\
\hline & & S2 & 6.9 & & 29 & & 90 & \\
\hline & \multirow{2}{*}{ L2 } & S1 & 6.1 & \multirow{2}{*}{$31 \%$} & 12 & \multirow{2}{*}{$0.0 \%$} & 19 & \multirow{2}{*}{$21 \%$} \\
\hline & & S2 & 8.0 & & 12 & & 23 & \\
\hline \multirow{4}{*}{ R3 } & \multirow{2}{*}{ L1 } & S1 & 6.4 & \multirow{2}{*}{$0.0 \%$} & 10 & \multirow{2}{*}{$10 \%$} & 16 & \multirow{2}{*}{$13 \%$} \\
\hline & & S2 & 6.4 & & 11 & & 18 & \\
\hline & \multirow{2}{*}{ L2 } & S1 & 7.8 & \multirow{2}{*}{$14 \%$} & 17 & \multirow{2}{*}{$12 \%$} & 31 & \multirow{2}{*}{$6.5 \%$} \\
\hline & & S2 & 6.7 & & 15 & & 29 & \\
\hline
\end{tabular}

Note: $\mathrm{R}, \mathrm{L}$, and $\mathrm{S}$ indicate reach number, location number, and sample time, respectively. R0: reference reach, cattle restriction; $R 1$ : cattle restriction; $R 2$ : cattle restriction and reshape banks to 3:1 slope; $R 3$ : cattle restriction, two-stage channel design with in-set floodplain.

*A second sample of ROL1 could not be taken due to low water depths and instrument limitations. 


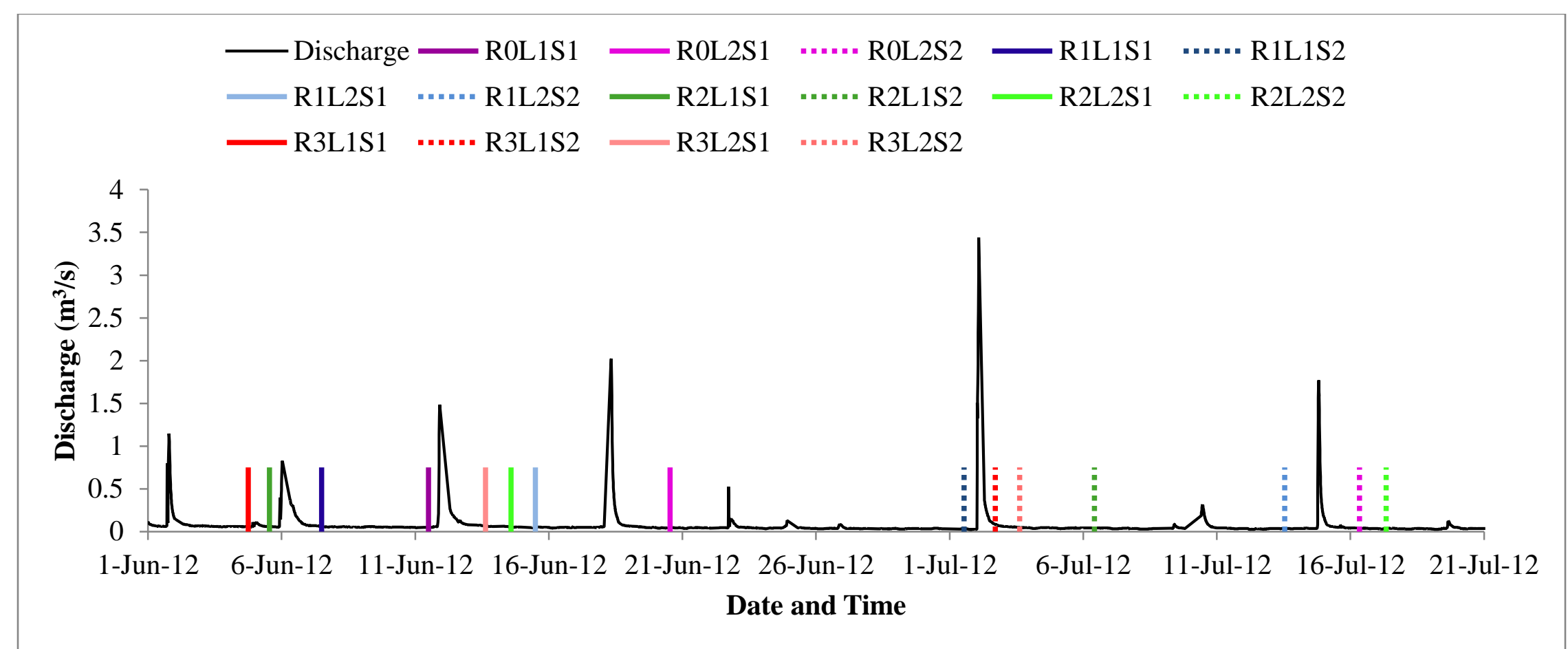

Figure 25: Continuous discharge measurements for the two month sample period with vertical lines indicating time of velocity sampling.

Note: $R, L$, and $S$ indicate reach number, location number, and sample time, respectively. R0: reference reach, cattle

restriction; $R 1$ : cattle restriction; $R 2$ : cattle restriction and reshape banks to 3:1 slope; R3: cattle restriction, two-stage channel design with in-set floodplain. A second sample of ROL1 could not be taken due to low water depths and instrument limitations. 


\subsection{Velocity}

The overall velocity vector magnitudes ranged from $24.9 \mathrm{~cm} / \mathrm{s}$ (R1L2S1; cattle restriction) to $82.7 \mathrm{~cm} / \mathrm{s}$ (R0L1S1; cattle restriction for 17 years). In all locations the overall velocity vector magnitude was substantially influenced by the streamwise component of velocity. In most locations the second greatest influence comes from the lateral velocity component and the smallest influence from the vertical velocity vector component. For all three-dimensional velocity measurements the streamwise component, $\bar{u}$, was the largest contributor to velocity magnitude $\left(\bar{V}=\sqrt{\bar{u}^{2}+\bar{v}^{2}+\bar{w}^{2}}\right)$, contributing up to $99.8 \%$ to the overall velocity vector magnitude (Table 8). Spatially averaged streamwise velocities, $\bar{u}$, ranged from $24.3 \mathrm{~cm} / \mathrm{s}$ (R1L2S1) to $81.8 \mathrm{~cm} / \mathrm{s}$ (R0L1S1). The ADV was accurate within $1 \%$ of the measured velocity range $( \pm 1 \mathrm{~cm} / \mathrm{s})$.

The streamwise velocity was influenced by the flow depth and the channel width of the stream cross section at the time of the sample. At R0L1, the flow was concentrated at the sample location as can be seen in Figure 5. The channel width at R0L1 was the smallest of all sample locations, and the mean flow depth was below the average for all sample locations (Table 9). While there were tributary inputs to Stroubles Creek, the contribution of these tributaries at base flow was negligible. Because the experimental reaches were consecutive, all locations had similar watershed characteristics. Given this information, it was expected for this location to have a larger velocity magnitude than the other locations. At R1L2 the channel width (3.2 m) is $8 \%$ greater than the average for all sample locations (Table 9). The mean flow depths at this location ( $25.6 \mathrm{~cm}$ and $24.5 \mathrm{~cm}$ for samples one and two, respectively) were at least $12 \%$ greater than the average for all sample locations (Table 9). The mean streamwise velocities for R1L2S1 and R1L2S1 were $24.3 \mathrm{~cm} / \mathrm{s}$ and $27.3 \mathrm{~cm} / \mathrm{s}$, respectively, the lowest of all samples (Table 8). The standard deviations of the streamwise velocity components, $\bar{u}$, range from $1.2 \mathrm{~cm} / \mathrm{s}$ (R3L1S1; two-stage channel) to $13.4 \mathrm{~cm} / \mathrm{s}$ (R2L1S1; banks sloped and re-vegetated) (Table 8). The large variability for both samples at R2L1 may be due to the variability of the streambed. The standard deviation of flow depth over the measurement area was $1.7 \mathrm{~cm}$ and $1.9 \mathrm{~cm}$ for sample one and sample two, respectively, which is $45 \%$ greater than the mean of all sample locations (Table 8). Similar correlations between channel properties and streamwise velocity can be seen for all other locations as well. 
The vertical component of velocity, $\bar{w}$, contributed $<0.1 \%$ (several locations) to $0.9 \%$ (R3L2S1) of the overall velocity vector magnitude (Table 8 ). The standard deviations of vertical velocities ranged from $0.4 \mathrm{~cm} / \mathrm{s}$ (R0L2S2) to $2.4 \mathrm{~cm} / \mathrm{s}$ (R3L2S2) (Table 8). With the exception of R1L1S2, the contribution of vertical velocity, $\bar{w}$, was less than or equal to the contribution of the lateral velocity, $\bar{v}$ (Table 8). The two samples taken at R1L2 recorded large contributions of vertical velocity, $\bar{w}$, to the overall velocity vector magnitude compared to the other sample locations (Table 8 ). These contributions were $0.7 \%$ and $0.8 \%$ for sample one and sample two, respectively, while the average contribution was $0.28 \%$ for all sample locations (Table 8 ). These locations had standard deviations of flow depth of $1.8 \mathrm{~cm}$ and $1.4 \mathrm{~cm}$ for sample one and sample two, respectively. These were greater than the mean of all locations which was $1.2 \mathrm{~cm}$ (Table 9). This variance in flow depth can often cause non-zero vertical velocity of near boundary flow.

Mean lateral velocities, $\bar{v}$, ranged from $-11.1 \mathrm{~cm} / \mathrm{s}$ (R0L1S1) to $8.0 \mathrm{~cm} / \mathrm{s}$ (R1L2S2) (Table 8). The standard deviations of lateral velocities ranged from $0.7 \mathrm{~cm} / \mathrm{s}$ (R3L1S1) to $3.6 \mathrm{~cm} / \mathrm{s}$ (R0L1S1) (Table 8). The lateral velocity vector component, $\bar{v}$, contributed $0.1 \%$ (R2L1S1) to $7.8 \%$ (R1L2S2) to the overall velocity vector magnitude (Table 8 ). The lateral velocity component contributed $3.8 \%$ and $7.8 \%$ of the overall velocity vector magnitude for R1L2S1 and R1L2S2, respectively. The large lateral velocities at R1L2 (Table 8) could be due to the path of the stream at the measurement location. This measurement location was about one meter downstream of a bend which directs the stream flow toward the right bank (Figure 11 a). As discussed in section 2.5.2 Turbulence analysis techniques, these lateral velocities could be due to the secondary circulation which often occurs at the bends of a stream. In contrast, the samples taken at R2L2 (banks reshaped and re-vegetated) had lateral velocity which contributed less than $0.2 \%$ of the overall velocity vector magnitude (Table 8 ). This measurement location was located in a straight section of the stream where flow was parallel to the streambanks (Figure 16). Lateral velocities were influenced by the stream path at the location. Similar relationships between site characteristics and lateral velocities can be seen at other sample locations as well. 
Table 8: Means and standard deviations (in italics) of streamwise $(\bar{u})$, lateral $(\bar{v})$, and vertical $(\bar{w})$ velocities for all samples and percent contribution to the velocity magnitude.

\begin{tabular}{|c|c|c|c|c|c|c|c|c|c|c|}
\hline & & & $\begin{array}{c}\bar{u} \\
(\mathrm{~cm} / \mathrm{s})\end{array}$ & & $\begin{array}{c}\bar{v} \\
(\mathrm{~cm} / \mathrm{s})\end{array}$ & & $\begin{array}{c}\bar{W} \\
(\mathrm{~cm} / \mathrm{s})\end{array}$ & & $\begin{array}{c}\bar{V} \\
(\mathrm{~cm} / \mathrm{s})\end{array}$ & $\mathrm{Q}\left(\mathrm{m}^{3} / \mathrm{s}\right)$ \\
\hline \multirow{8}{*}{ R0 } & \multirow{4}{*}{ L1 } & \multirow{2}{*}{ S1 } & 81.8 & $97.9 \%$ & -11.1 & $1.8 \%$ & -4.6 & $0.3 \%$ & 82.7 & 0.049 \\
\hline & & & 9.0 & & 3.6 & & 1.8 & & & \\
\hline & & \multirow{2}{*}{$\mathbf{S 2}$} & NA* & NA & NA & NA & NA & NA & NA & NA \\
\hline & & & $N A$ & & $N A$ & & $N A$ & & & \\
\hline & \multirow{4}{*}{ L2 } & \multirow{2}{*}{ S1 } & 31.8 & $98.7 \%$ & 3.5 & $1.2 \%$ & -1.3 & $0.2 \%$ & 32.0 & 0.046 \\
\hline & & & 2.1 & & 1.2 & & 0.5 & & & \\
\hline & & \multirow{2}{*}{ S2 } & 33.1 & $99.4 \%$ & 2.5 & $0.6 \%$ & -0.9 & $0.1 \%$ & 33.2 & 0.041 \\
\hline & & & 2.2 & & 0.9 & & 0.4 & & & \\
\hline \multirow{8}{*}{ R1 } & \multirow{4}{*}{ L1 } & \multirow{2}{*}{ S1 } & 43.6 & $98.5 \%$ & 4.5 & $1.0 \%$ & -2.9 & $0.4 \%$ & 43.9 & 0.060 \\
\hline & & & 9.1 & & 3.2 & & 2.0 & & & \\
\hline & & \multirow{2}{*}{$\mathbf{S 2}$} & 42.0 & $99.4 \%$ & 2.0 & $0.2 \%$ & -2.4 & $0.3 \%$ & 42.1 & 0.040 \\
\hline & & & 5.6 & & 2.5 & & 1.8 & & & \\
\hline & \multirow{4}{*}{ L2 } & \multirow{2}{*}{ S1 } & 24.3 & $95.5 \%$ & 4.8 & $3.8 \%$ & -2.1 & $0.7 \%$ & 24.9 & 0.048 \\
\hline & & & 6.4 & & 1.6 & & 1.5 & & & \\
\hline & & \multirow{2}{*}{ S2 } & 27.3 & $91.3 \%$ & 8.0 & $7.8 \%$ & -2.6 & $0.8 \%$ & 28.5 & 0.036 \\
\hline & & & 5.8 & & 1.8 & & 2.1 & & & \\
\hline \multirow{8}{*}{$\mathbf{R} 2$} & \multirow{4}{*}{ L1 } & \multirow{2}{*}{ S1 } & 40.5 & $99.8 \%$ & -1.4 & $0.1 \%$ & 1.1 & $0.1 \%$ & 40.6 & 0.058 \\
\hline & & & 13.4 & & 3.4 & & 1.8 & & & \\
\hline & & \multirow{2}{*}{$\mathbf{S 2}$} & 36.5 & $98.7 \%$ & 4.1 & $1.3 \%$ & -1.1 & $0.1 \%$ & 36.7 & 0.042 \\
\hline & & & 13.3 & & 2.4 & & 2.8 & & & \\
\hline & \multirow{4}{*}{ L2 } & \multirow{2}{*}{ S1 } & 41.6 & $99.5 \%$ & -2.8 & $0.5 \%$ & 0.7 & $0.0 \%$ & 41.7 & 0.052 \\
\hline & & & 4.9 & & 1.1 & & 0.6 & & & \\
\hline & & \multirow{2}{*}{ S2 } & 28.2 & $99.1 \%$ & -2.6 & $0.9 \%$ & -0.7 & $0.1 \%$ & 28.4 & 0.035 \\
\hline & & & 1.4 & & 0.9 & & 0.4 & & & \\
\hline \multirow{8}{*}{ R3 } & \multirow{4}{*}{ L1 } & \multirow{2}{*}{ S1 } & 31.2 & $95.5 \%$ & -6.7 & $4.4 \%$ & 0.6 & $0.0 \%$ & 31.9 & 0.055 \\
\hline & & & 1.2 & & 0.7 & & 0.6 & & & \\
\hline & & \multirow{2}{*}{$\mathbf{S 2}$} & 50.0 & $99.1 \%$ & -4.6 & $0.8 \%$ & -0.8 & $0.0 \%$ & 50.2 & 0.083 \\
\hline & & & 5.6 & & 2.2 & & 0.6 & & & \\
\hline & \multirow{4}{*}{ L2 } & \multirow{2}{*}{ S1 } & 41.7 & $97.6 \%$ & 5.1 & $1.5 \%$ & -4.0 & $0.9 \%$ & 42.2 & 0.066 \\
\hline & & & 3.6 & & 3.1 & & 1.9 & & & \\
\hline & & S? & 41.2 & $98.9 \%$ & 3.9 & $0.9 \%$ & -1.9 & $0.2 \%$ & 41.5 & 0.047 \\
\hline & & $\mathrm{N} 2$ & 2.9 & & 1.4 & & 2.4 & & & \\
\hline
\end{tabular}

Note: $\mathbf{R}, \mathrm{L}$, and $\mathrm{S}$ indicate reach number, location number, and sample time, respectively. R0: reference reach, cattle restriction; R1: cattle restriction; R2: cattle restriction and reshape banks to 3:1 slope; $R 3$ : cattle restriction, two-stage channel design with in-set floodplain.

*A second sample of ROL1 could not be taken due to low water depths and instrument limitations. 
Table 9: Minimum, maximum, mean and standard deviations of water depth in sample area for each sample and baseflow channel width measurements of each location.

\begin{tabular}{|c|c|c|c|c|c|c|c|}
\hline & & & & wat & & & $\begin{array}{c}\text { baseflow } \\
\text { channel }\end{array}$ \\
\hline & & & $\begin{array}{l}\min \\
(\mathbf{c m})\end{array}$ & $\begin{array}{l}\max \\
(\mathbf{c m})\end{array}$ & $\begin{array}{c}\text { mean } \\
(\mathrm{cm})\end{array}$ & $\begin{array}{l}\text { stdv } \\
(\mathbf{c m})\end{array}$ & \\
\hline & $\mathbf{J} 1$ & S1 & 17.0 & 21.5 & 18.5 & 1.1 & 2 \\
\hline & LI & $\mathbf{S 2}$ & $\mathrm{NA}^{*}$ & NA & NA & NA & 2.1 \\
\hline RU & I? & S1 & 15.5 & 18.5 & 17.4 & 0.64 & 14 \\
\hline & $\mathbf{L} 2$ & $\mathbf{S 2}$ & 14.0 & 16.5 & 15.3 & 0.51 & 2.4 \\
\hline & $\mathbf{I} 1$ & S1 & 13.5 & 19.0 & 16.5 & 1.3 & \\
\hline P1 & LI & S2 & 11.5 & 18.0 & 16.2 & 1.4 & 2.1 \\
\hline 11 & & S1 & 22.0 & 30.5 & 25.6 & 1.8 & 32 \\
\hline & $\mathbf{L 2}$ & S2 & 22.0 & 28.0 & 24.5 & 1.4 & 3.2 \\
\hline & L 1 & S1 & 18.5 & 24.5 & 22.0 & 1.7 & 33 \\
\hline R2 & Li & S2 & 15.5 & 22.5 & 18.8 & 1.9 & 3.3 \\
\hline - & L2 & S1 & 15.5 & 20.5 & 18.4 & 1.1 & 10 \\
\hline & $\mathbf{L}$ & S2 & 13.0 & 16.0 & 14.9 & 0.84 & 4.0 \\
\hline & I 1 & S1 & 30.0 & 33.5 & 31.8 & 0.9 & 32 \\
\hline $\mathbf{R}$ & LI & S2 & 28.0 & 32.5 & 29.9 & 1.2 & 3.2 \\
\hline N. & 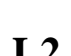 & S1 & 28.0 & 32.5 & 30.8 & 1.0 & 27 \\
\hline & $\mathbf{L}$ & S2 & 25.0 & 29.0 & 27.8 & 0.80 & 2.1 \\
\hline
\end{tabular}

Note: $\mathbf{R}, \mathbf{L}$, and $\mathrm{S}$ indicate reach number, location number, and sample time, respectively. R0: reference reach, cattle restriction; $R 1$ : cattle restriction; $R 2$ : cattle restriction and reshape banks to 3:1 slope; $R 3$ : cattle restriction, two-stage channel design with in-set floodplain.

*A second sample of ROL1 could not be taken due to low water depths and instrument limitations.

\subsection{Turbulent Kinetic Energy}

The mean values of TKE for measurement locations range from $2.6 \mathrm{~N} / \mathrm{m}^{2}$ (R0L2S2; cattle restriction for 17 years) to $11.4 \mathrm{~N} / \mathrm{m}^{2}$ (R2L1S2; banks reshaped and re-vegetated) (Table 10). For all restoration treatments, excluding R1L1 (cattle restriction), TKE varied by sample date (pvalue $\leq 0.0355$, Table 10). This observed variability is highlighted in the boxplot (Figure 26) and spatial distribution plots (Figure 27 and Figure 28). 
Table 10: Mean values of TKE, $\tau_{\mathrm{xy}}$, and $\tau_{\mathrm{xz}} ; \mathrm{p}$-values for $\mathrm{t}$-tests between each sample time for a given location are italicized.

\begin{tabular}{|c|c|c|c|c|c|c|c|c|}
\hline & & \multicolumn{2}{|c|}{ TKE } & \multicolumn{2}{|c|}{$\overline{\tau_{\mathrm{xy}}}$} & \multicolumn{2}{|c|}{$\bar{\tau} \tau_{\mathrm{xz}}$} \\
\hline & & & $\begin{array}{l}\text { mean } \\
\left(\mathrm{N} / \mathrm{m}^{2}\right)\end{array}$ & p-value & $\begin{array}{c}\text { mean } \\
(\mathbf{P a})\end{array}$ & p-value & $\begin{array}{c}\text { mean } \\
(\mathrm{Pa})\end{array}$ & p-value \\
\hline \multirow{4}{*}{ R0 } & $\mathbf{I}$ & S1 & 8.4 & \multirow{2}{*}{$N A$} & 1.28 & \multirow{2}{*}{$N A$} & 2.2 & \multirow{2}{*}{$N A$} \\
\hline & LI & S2 & NA & & NA & & NA & \\
\hline & \multirow{2}{*}{ L2 } & S1 & 3.3 & \multirow{2}{*}{$<0.0001$} & 0.16 & \multirow{2}{*}{0.2288} & 0.75 & \multirow{2}{*}{$<0.0001$} \\
\hline & & S2 & 2.6 & & 0.21 & & 0.57 & \\
\hline \multirow{4}{*}{ R1 } & I & S1 & 10.5 & \multirow{2}{*}{0.1905} & -0.35 & \multirow{2}{*}{0.3126} & 3.1 & \multirow{2}{*}{0.0084} \\
\hline & LI & S2 & 9.4 & & -0.04 & & 2.0 & \\
\hline & \multirow{2}{*}{ L2 } & S1 & 5.3 & \multirow{2}{*}{$<0.0001$} & 0.30 & \multirow{2}{*}{0.6667} & 1.2 & \multirow{2}{*}{0.0000} \\
\hline & & S2 & 9.3 & & 0.22 & & 2.1 & \\
\hline \multirow{4}{*}{ R2 } & \multirow{2}{*}{ L1 } & S1 & 9.7 & \multirow{2}{*}{0.0355} & -0.65 & \multirow{2}{*}{0.8677} & 2.3 & \multirow{2}{*}{0.6068} \\
\hline & & S2 & 11.4 & & -0.58 & & 2.5 & \\
\hline & & S1 & 5.6 & \multirow{2}{*}{$<0.0001$} & 0.27 & \multirow{2}{*}{0.2811} & 0.90 & \multirow{2}{*}{$<0.0001$} \\
\hline & $\mathbf{L 2}$ & S2 & 2.7 & & 0.13 & & 0.49 & \\
\hline \multirow{4}{*}{ R3 } & & S1 & 4.7 & \multirow{2}{*}{$<0.0001$} & -0.31 & \multirow{2}{*}{$<0.0001$} & 0.40 & \multirow{2}{*}{0.0368} \\
\hline & LI & S2 & 9.4 & & 1.23 & & 0.23 & \\
\hline & & S1 & 7.0 & \multirow{2}{*}{$<0.0001$} & 0.56 & \multirow{2}{*}{0.6167} & 1.2 & \multirow{2}{*}{0.0368} \\
\hline & $\mathbf{L} 2$ & S2 & 9.7 & & 0.48 & & 0.33 & \\
\hline
\end{tabular}

Note: $R, L$, and $S$ indicate reach number, location number, and sample time, respectively. R0: reference reach, cattle restriction; R1: cattle restriction; R2: cattle restriction and reshape banks to 3:1 slope; R3: cattle restriction, two-stage channel design with in-set floodplain.

*A second sample of R0L1 could not be taken due to low water depths and instrument limitations.

Both samples taken at ROL2 had mean TKE less than half of the average for all locations (Table 10) and also had the lowest standard deviations of flow depth of all locations (Table 9). The box plot (Figure 26) shows that R2L2S2, R0L2S1, and R0L2S2 had small ranges of TKE compared to other locations; this is true for values of $\tau_{x y}$ and $\tau_{x z}$ and will be discussed in the following section. The correlation between standard deviation of flow depth and mean TKE holds for many other locations as well and is plotted in Figure 29. The data have a correlation coefficient of 0.62. The relationship between bed heterogeneity and TKE can also be seen in the TKE box plots (Figure 26). Both samples at R0L2 have low standard deviations in flow depth and the distributions reflect a low variance in TKE as well (Figure 26). The distribution indicates large variance in R1L1S1. This variance was due to the high TKE values on the left bank side of the 
measurement area as seen in the contour plot (Figure 27b). Most outliers found on the distributions, such as those found in R2L1S1, correspond to spikes in TKE due to sudden changes in flow depths as explained earlier.

Table 11: Mean values and results of t-tests comparing TKE, $\tau_{\mathrm{xy}}$, and $\tau_{\mathrm{xz}}$ between two locations within a common reach. p-values of $t$-tests are in parenthesis.

\begin{tabular}{|c|c|c|c|c|c|c|c|c|}
\hline & \multicolumn{2}{|c|}{ R0 } & \multicolumn{2}{|c|}{ R1 } & \multicolumn{2}{|c|}{$\mathbf{R 2}$} & \multicolumn{2}{|c|}{ R3 } \\
\hline & L1 & $\mathbf{L} 2$ & L1 & $\mathbf{L} 2$ & L1 & $\mathbf{L} 2$ & L1 & $\mathbf{L} 2$ \\
\hline \multirow[t]{2}{*}{$\begin{array}{c}\text { TKE } \\
\left(\mathrm{N} / \mathbf{m}^{2}\right)\end{array}$} & $8.4^{*}$ & 3.0 & 10.0 & 7.3 & 10.6 & 4.2 & 7.0 & 8.3 \\
\hline & \multicolumn{2}{|c|}{$(<0.0001)$} & \multicolumn{2}{|c|}{$(<0.0001)$} & \multicolumn{2}{|c|}{$(<0.0001)$} & \multicolumn{2}{|c|}{$(0.0002)$} \\
\hline \multirow[t]{2}{*}{$\begin{array}{c}\tau_{\mathbf{x y}} \\
(\mathbf{P a})\end{array}$} & $1.3 *$ & 0.18 & -0.194 & 0.26 & -0.61 & 0.20 & 0.46 & 0.52 \\
\hline & \multicolumn{2}{|c|}{$(<0.0001)$} & \multicolumn{2}{|c|}{$(0.0100)$} & \multicolumn{2}{|c|}{$(0.0002)$} & \multicolumn{2}{|c|}{$(0.7386)$} \\
\hline $\begin{array}{c}\tau_{\mathrm{xz}} \\
(\mathbf{P a})\end{array}$ & $\begin{array}{r}2.2 * \\
(<\end{array}$ & $\begin{array}{l}0.66 \\
01)\end{array}$ & $\begin{array}{l}2.5 \\
(0.0\end{array}$ & 1.7 & $\begin{array}{l}2.4 \\
(<0\end{array}$ & $\begin{array}{l}0.70 \\
1)\end{array}$ & $\begin{array}{r}0.32 \\
\quad(<0\end{array}$ & $\begin{array}{l}0.78 \\
1)\end{array}$ \\
\hline
\end{tabular}

Note: $R$ and $L$ indicate reach number and location number, respectively. R0: reference reach, cattle restriction; $R 1$ : cattle restriction; $R 2$ : cattle restriction and reshape banks to 3:1 slope; R3: cattle restriction, two-stage channel design with in-set floodplain.

* Values for R0L1 are based on only one sample; A second could not be taken due to low water depths and instrument limitations. 


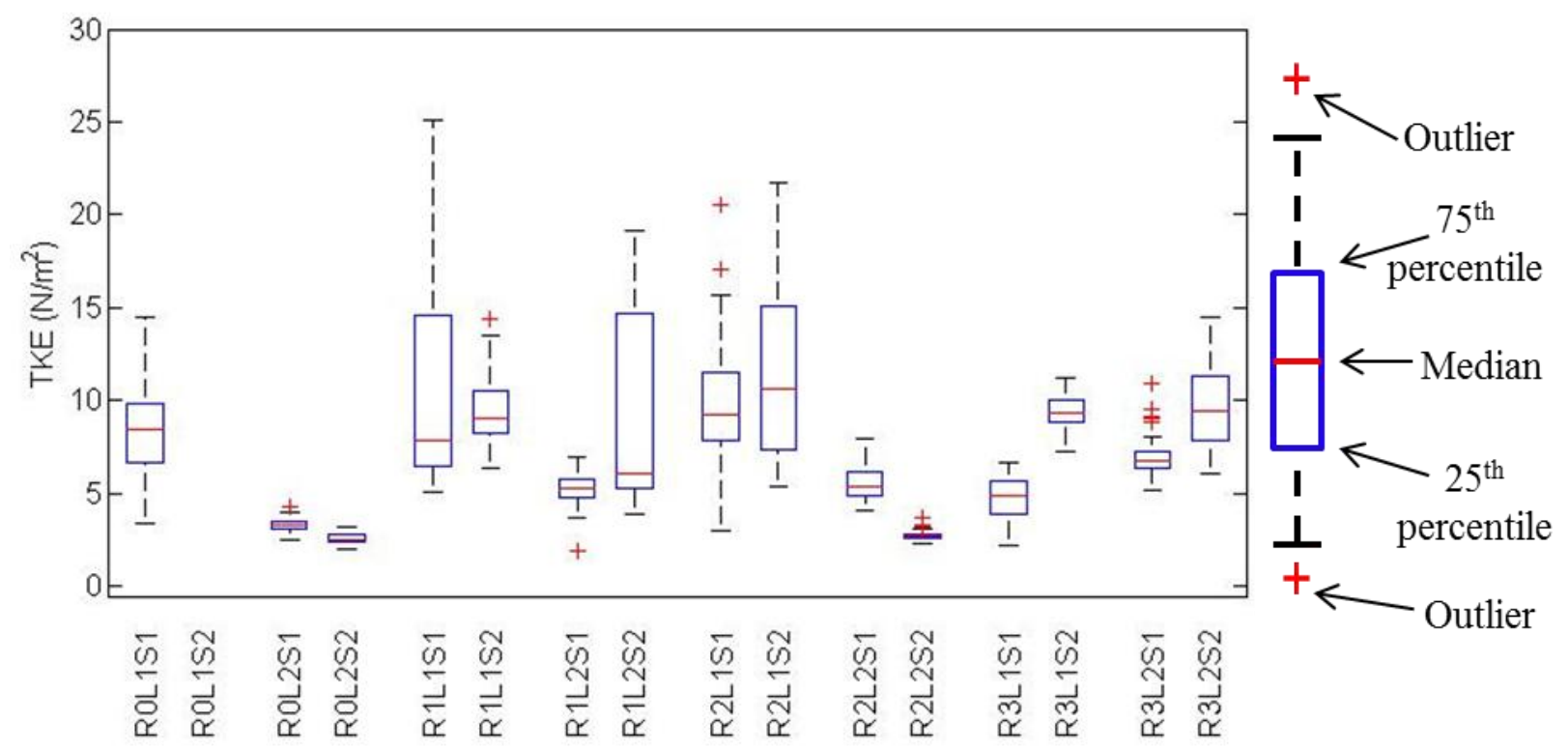

Figure 26: Distributions of TKE values for all samples.

Note: $R, L$, and $S$ indicate reach number, location number, and sample time, respectively. R0: reference reach, cattle restriction; $R 1$ : cattle restriction; $R 2$ : cattle restriction and reshape banks to 3:1 slope; $R 3$ : cattle restriction, two-stage channel design with in-set floodplain. A second sample of ROL1 could not be taken due to low water depths and instrument limitations. 

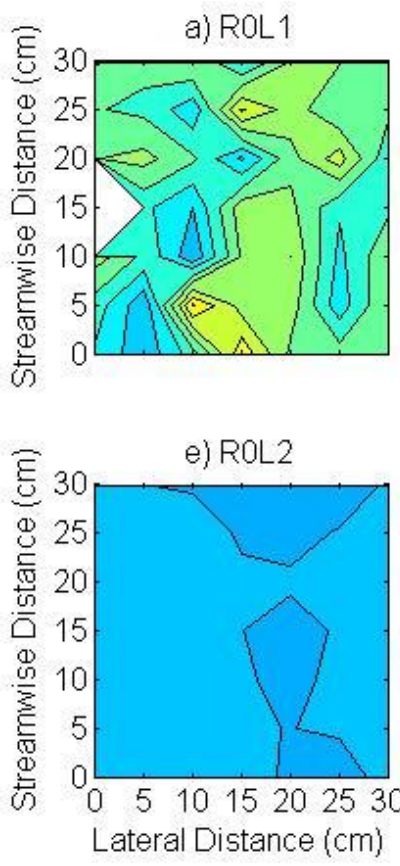

b) R1L1

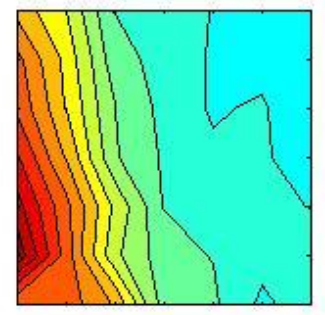

f) R1L2

c) R2L1

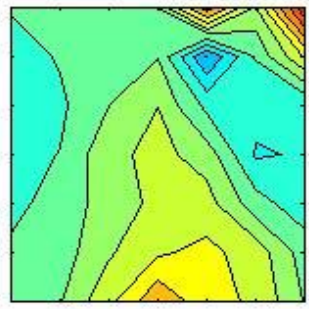

g) R2L2

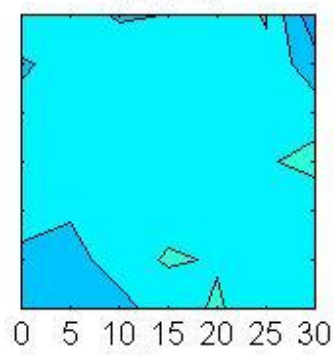

Lateral Distance $(\mathrm{cm})$

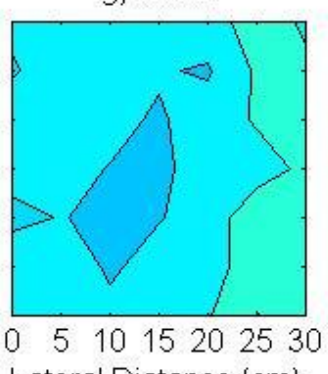

ateral Distance $(\mathrm{cm})$ d) R3L1

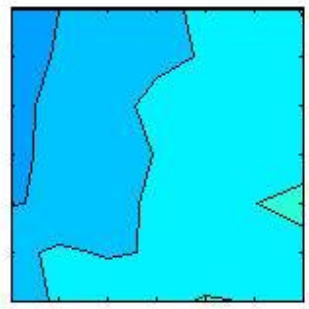

h) R3L2

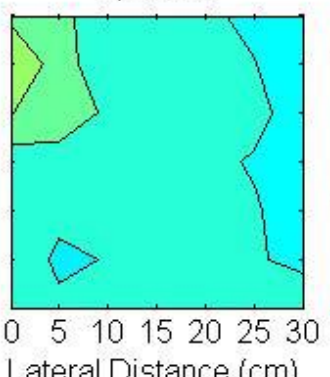

Figure 27: Spatial distributions of TKE for the first sample time at all locations. Note: $R$ and $L$ indicate reach number and location number, respectively. $R 0$ : reference reach, cattle restriction for 17 years; $R 1$ : cattle restriction; $R 2$ : cattle restriction and banks reshaped to 3:1 slope and re-vegetated; R3: cattle restriction, two-stage channel design with in-set floodplain and re-vegetated. One measurement is missing within ROL1 due to low correlation values. Flow is in positive streamwise direction. 


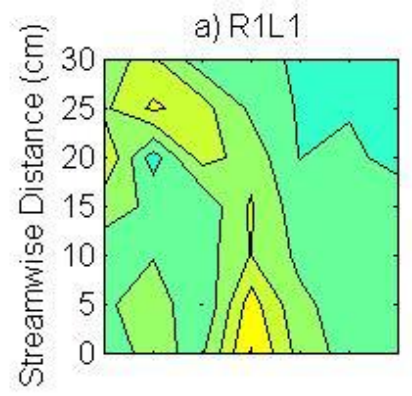

b) R2L1
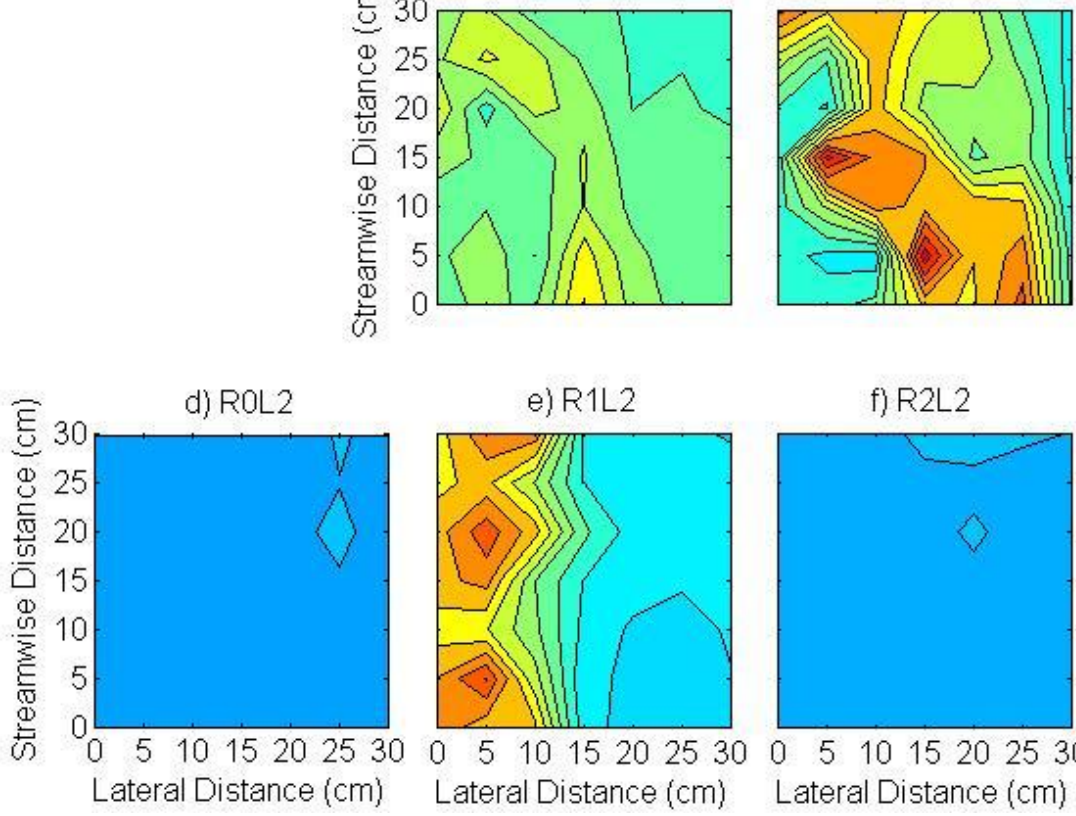

e) R1L2

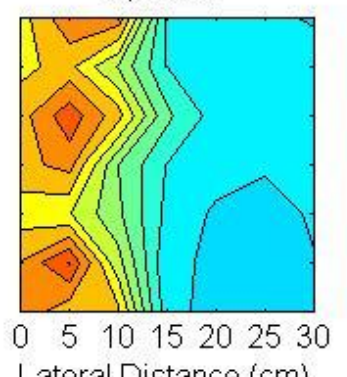

f) $R 2 L 2$

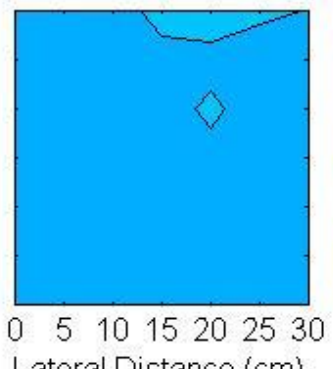

c) R3L1

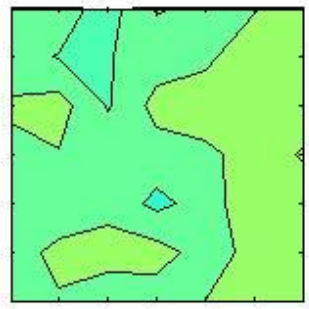

g) R3L2

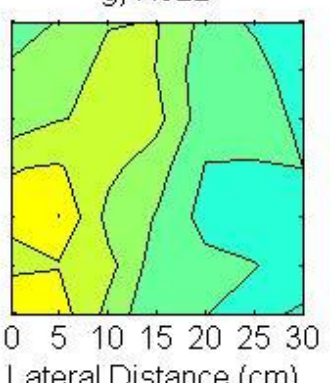

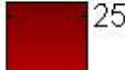

20

$15 \stackrel{\widetilde{\mathcal{E}}}{\underset{\mathrm{E}}{\mathrm{E}}}$

10

$-5$

Figure 28: Spatial distributions of TKE for the second sample time at all locations. Note: $R$ and $L$ indicate reach number and location number, respectively. $R 0$ : reference reach, cattle restriction for 17 years; $R 1$ : cattle restriction; $R 2$ : cattle restriction and banks reshaped to 3:1 slope and re-vegetated; R3: cattle restriction, two-stage channel design with in-set floodplain and re-vegetated. A second sample of ROL1 could not be taken due to low water depths and instrument limitations. Flow is in positive streamwise direction.

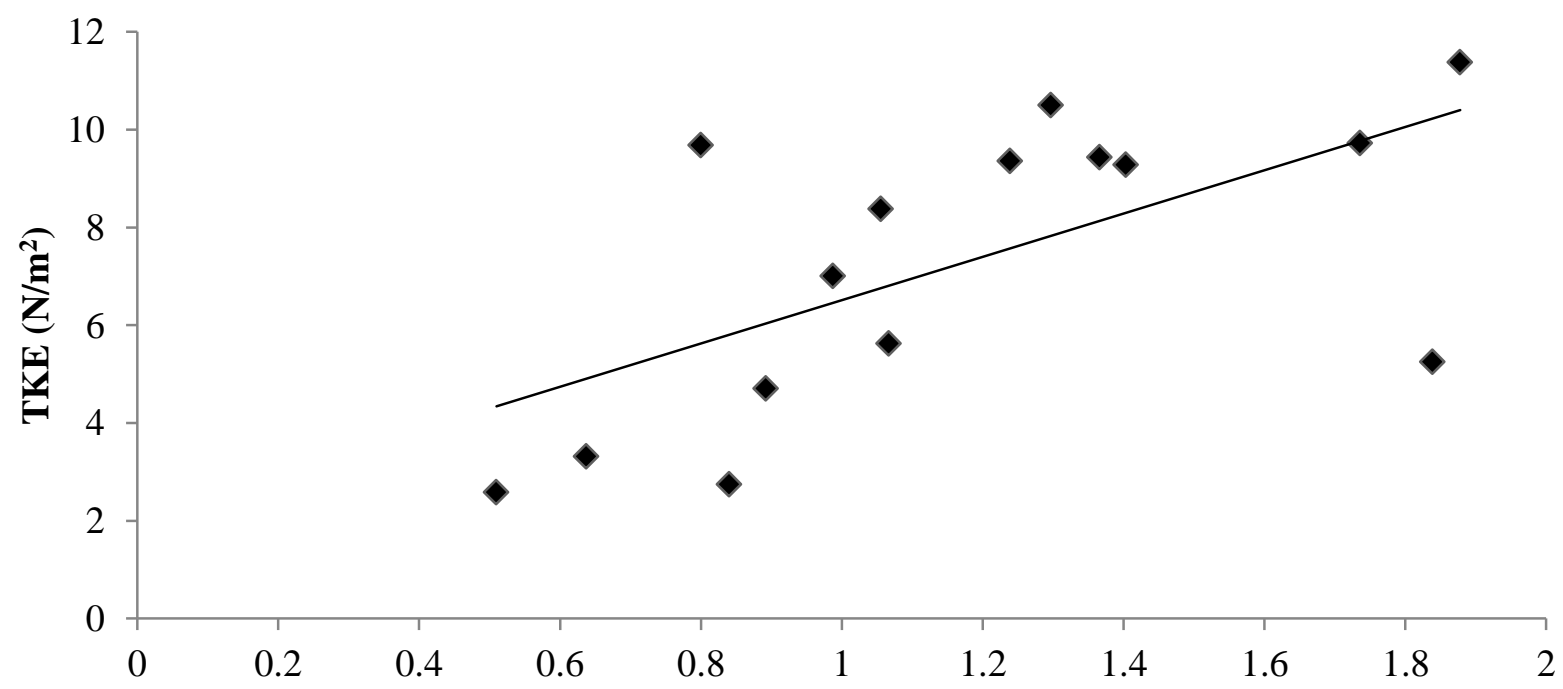

Standard Deviation of Flow Depth (cm)

Figure 29: Mean TKE versus standard deviations of flow depths for each sample. Note: A second sample of R0Ll could not be taken due to low water depths and instrument limitations. 
A correlation between flow depth and TKE can also be seen in R3L1S2 (two-stage channel). The values of TKE increase gradually toward the right bank side of the measurement area (Figure 28c) which corresponds to a gradual increase in flow depth. This trend could be due to an increase in flow in the deeper section of the measurement area causing an increase in turbulence. The spatial distribution of TKE and flow depth also shows this relationship. The spatial distribution plot of TKE for R2L1S2 is presented in Figure 28b. The spike in TKE seen at location $(5,15)$ correlates with a sudden decrease in flow depth which occurs at location $(5$, 10). Inversely, a drop in TKE at location $(10,25)$ correlates with an increase in flow depth which occurs at location $(10,20)$. A correlation between flow depth and TKE indicates that the streambeds with greater variability cause greater near bed turbulence.

A correlation can also be seen when comparing bed material characteristics (Table 7) and the box plots (Figure 26) as presented in Figure 30. The boxplots show a large variance for R1L2S1, and both R2L1S1 and R2L1S2 (Figure 30). The pebble counts for these locations also indicate a large spread of bed material from very coarse sand or very fine gravel to medium, large or very large cobble. Inversely, samples with small variances in TKE values such as R3L1S1 and R3L1S2 also have low variability of bed material ranging from very coarse sand or very fine gravel to very coarse gravel. The TKE values at measurement locations were influenced by bed heterogeneity. Similar trends can be seen for values of $\tau_{x z}$ as explained in the next section. 


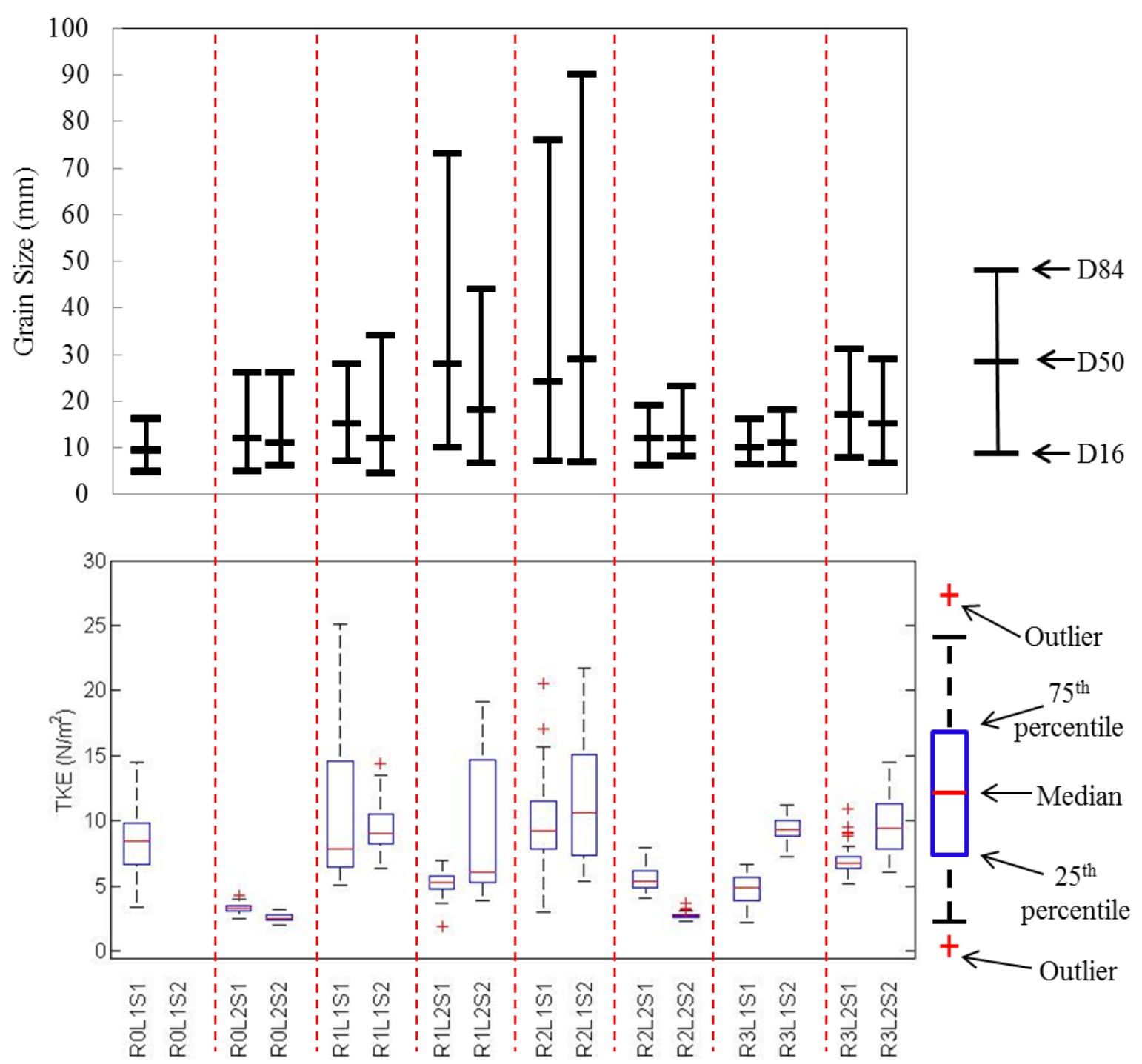

Figure 30: Comparison of grain size distributions to distributions of TKE values for all samples.

Note: $R, L$ and $S$ indicate reach number, location number and sample time, respectively. R0: reference reach, cattle restriction for 17 years; R1: cattle restriction; R2: cattle restriction and banks reshaped to 3:1 slope and re-vegetated; R3: cattle restriction, twostage channel design with in-set floodplain and re-vegetated. A second sample of ROL1 could not be taken due to low water depths and instrument limitations.

In summary, TKE was substantially influenced by measurement location, water depth, bed heterogeneity and the date of the sample. TKE was not substantially influenced by restoration technique at baseflow. Differences between restoration reaches would most likely be more significant at greater flows where bank vegetation roughness and cross section shape would be more significantly different. 


\subsection{Shear Stresses $\left(\tau_{\mathrm{xy}}\right.$ and $\left.\tau_{\mathrm{xz}}\right)$}

Reynolds shear stresses represent a value of momentum exchange. $\tau_{\mathrm{xz}}$ quantifies vertical exchange of streamwise momentum while $\tau_{\mathrm{xy}}$ quantifies lateral exchange of streamwise momentum. As with values of TKE, $t$-tests were performed between sample times and among reach locations for values of $\tau_{\mathrm{xy}}$ and $\tau_{\mathrm{xz}}$ (Table 10 and Table 11).

Mean values of $\tau_{\mathrm{xy}}$ ranged from $-0.65 \mathrm{~Pa}$ (R2L1S1; banks reshaped and re-vegetated) to $1.28 \mathrm{~Pa}$ (R0L1S1; cattle restriction for 17 years) (Table 10). With the exception of R3L1 (two-stage channel), values of $\tau_{\mathrm{xy}}$ were statistically similar between sample time one and sample time two (p-value $\geq 0.2288$, Table 10, Figure 31 ). Mean values of $\tau_{x y}$ fluctuate between positive and negative but the absolute values for most samples were $\leq 0.65 \mathrm{~Pa}$. The exceptions to this are R0L1S1 where $\tau_{x y}$ was $1.28 \mathrm{~Pa}$, and R3L1S2 where $\tau_{x y}$ was $1.23 \mathrm{~Pa}$ (Table 10). These values are greater than $270 \%$ of the mean magnitude of $\tau_{\mathrm{xy}}$ of all samples (Table 10). As explained in 3.3 Description of measurement sites, in R0L1 the flow was directed toward the right bank which causes the negative mean velocity shown in Table 8 . This shift of flow could also cause the flux of momentum causing the high value of lateral shear stress, $\tau_{\mathrm{xy}}$. At this location only one sample could be taken due to low flow depth during the time the second sample was to be taken so the statistical similarity between the two samples could not be analyzed. R3L1 was the only location where the values of $\tau_{\mathrm{xy}}$ were not statistically similar between the two samples (Table 10 and Figure 31). The box plot (Figure 31) shows that, as with TKE, R2L2S2, R0L2S1 and R0L2S2 have small ranges of $\tau_{\mathrm{xy}}$ compared to other locations. A correlation between bed characteristics and $\tau_{\mathrm{xy}}$ is more difficult to characterize than the correlation between the bed characteristics and TKE and $\tau_{\mathrm{xz}}$ (Figure 32 and Figure 33 ). 


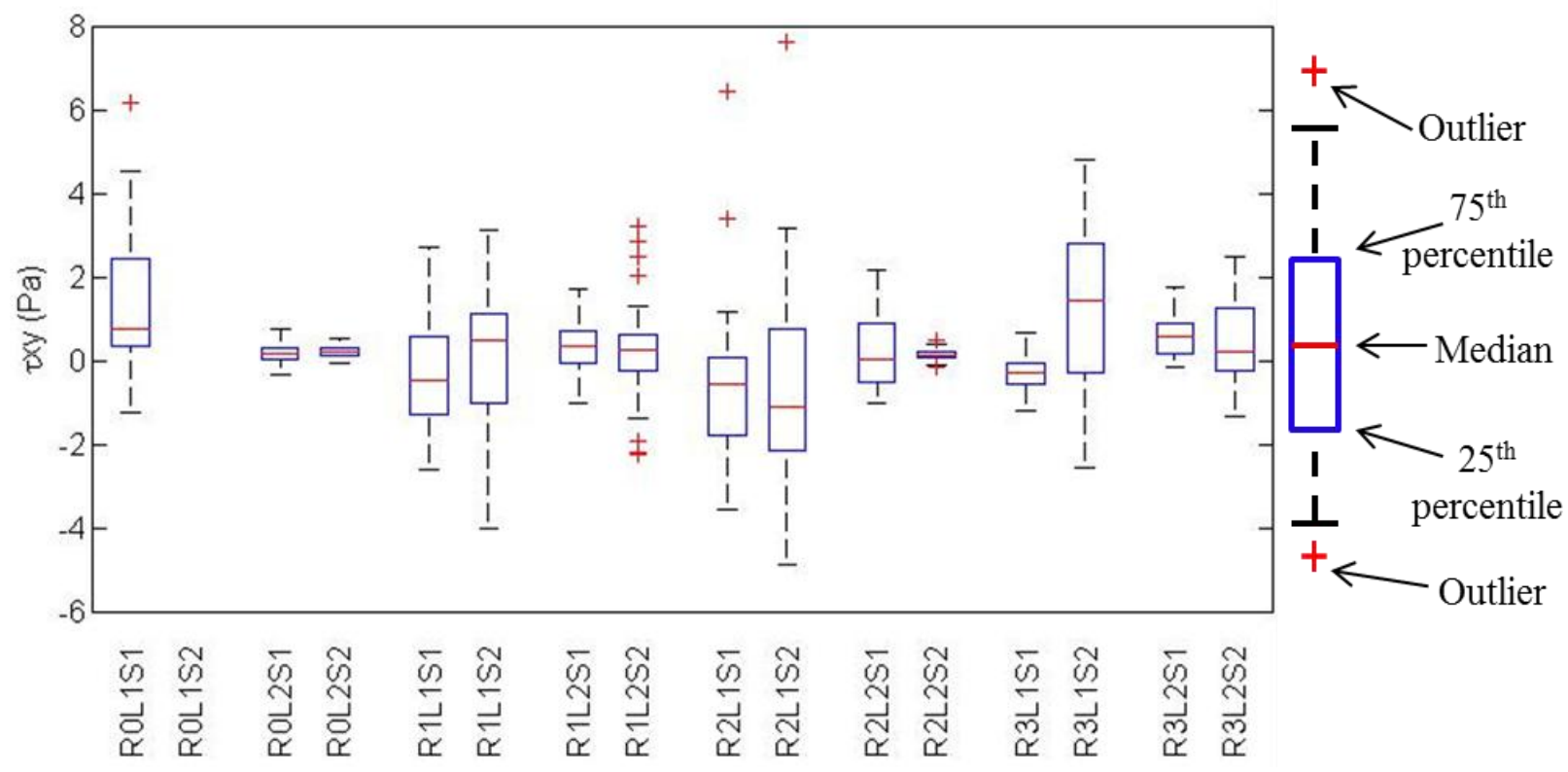

Figure 31: Distributions of $\tau_{\mathrm{xy}}$ values for all samples.

Note: $R, L$ and $S$ indicate reach number, location number and sample time, respectively. R0: reference reach, cattle restriction for 17 years; R1: cattle restriction; R2: cattle restriction and banks reshaped to 3:1 slope and re-vegetated; R3: cattle restriction, twostage channel design with in-set floodplain and re-vegetated. A second sample of R0L1 could not be taken due to low water depths and instrument limitations. 


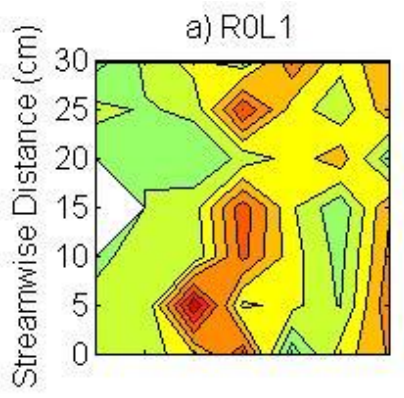

b) R1L1

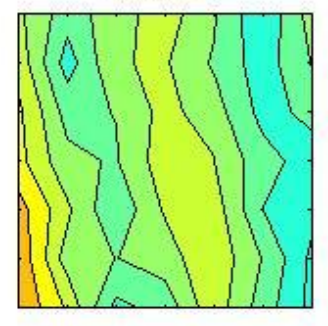

e) ROL2

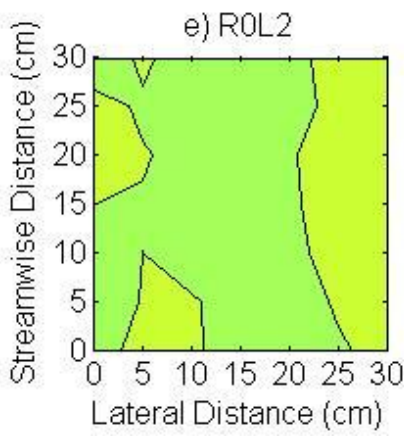

f) R1L2

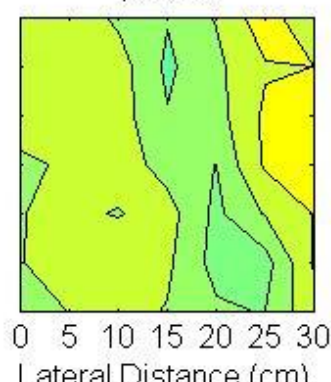

c) R2L1

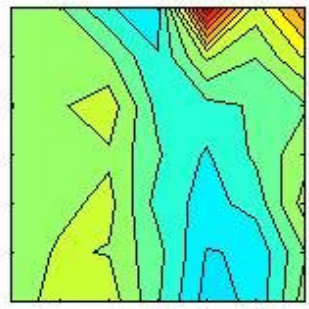

g) R2L2

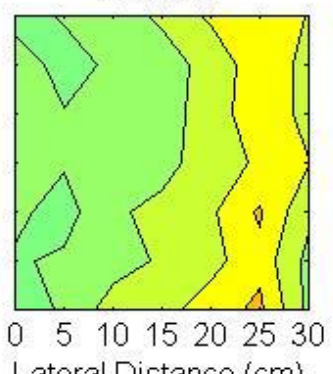

d) R3L1

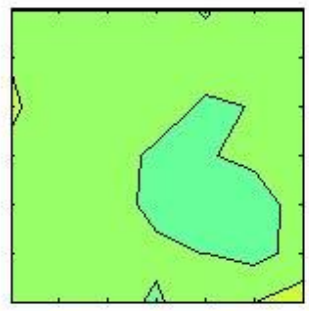

h) R3L2

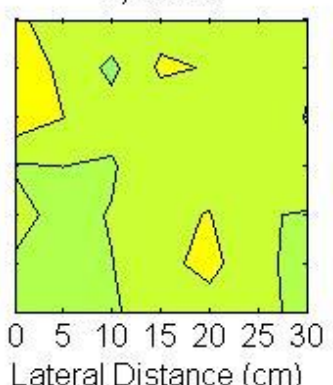

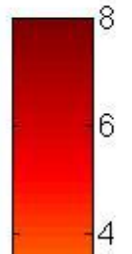

Figure 32: Spatial distributions of $\tau_{\mathrm{xy}}$ for the first sample time at all locations.

Note: $R$ and $L$ indicate reach number and location number, respectively. $R 0$ : reference reach, cattle restriction for 17 years; $R 1$ : cattle restriction; $R 2$ : cattle restriction and banks reshaped to 3:1 slope and re-vegetated; R3: cattle restriction, two-stage channel design with in-set floodplain and re-vegetated. One measurement is missing within ROL1 due to low correlation values. Flow is in positive streamwise direction. 


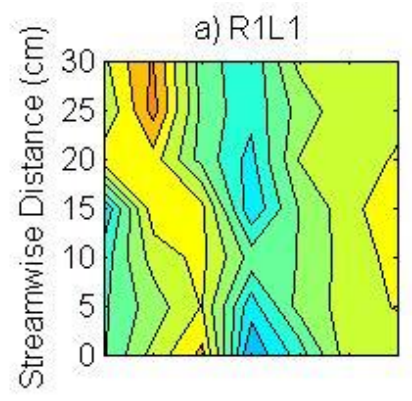

b) R2L1

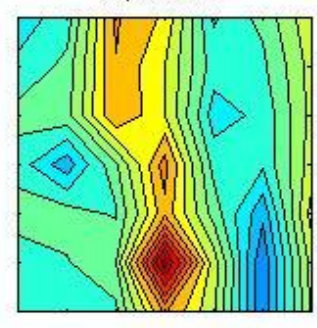

e) R1L2

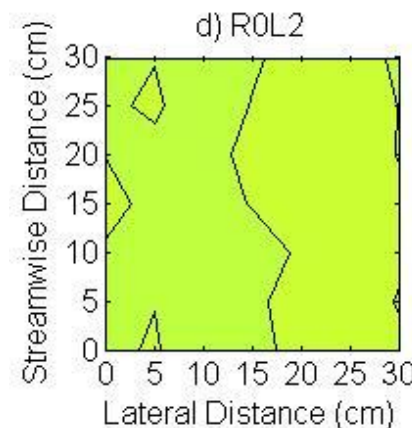

Lateral Distance $(\mathrm{cm})$

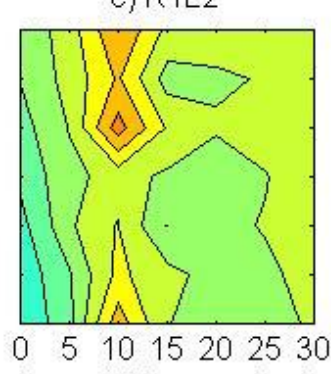

Lateral Distance $(\mathrm{cm})$

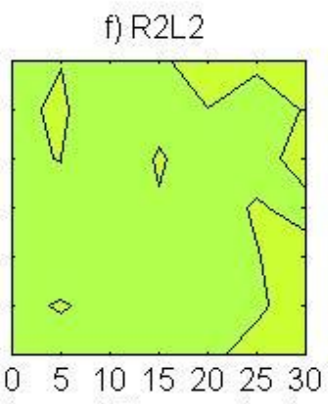

Lateral Distance (cm)

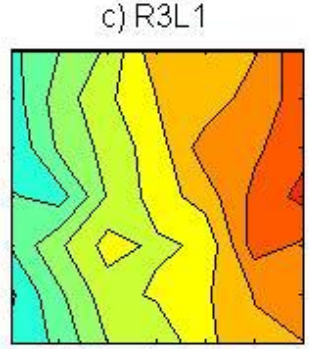

g) R3L2

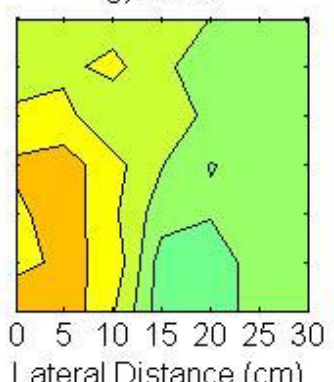

Lateral Distance $(\mathrm{cm})$

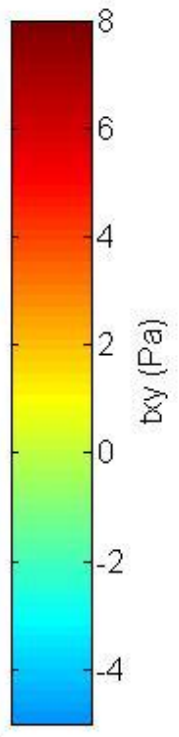

Figure 33: Spatial distributions of $\tau_{x y}$ for the second sample time at all locations.

Note: $R$ and $L$ indicate reach number and location number, respectively. R0: reference reach, cattle restriction for 17 years; $R 1$ : cattle restriction; $R 2$ : cattle restriction and banks reshaped to 3:1 slope and re-vegetated; R3: cattle restriction, two-stage channel design with in-set floodplain and re-vegetated. A second sample of ROL1 could not be taken due to low water depths and instrument limitations. Flow is in positive streamwise direction.

Mean values of the component of Reynolds shear stress, $\tau_{\mathrm{xz}}$, for each sample range from $0.23 \mathrm{~Pa}$ (R3L1S2) to 3.1 Pa (R1L1S1; cattle restriction) (Table 10). R2L1 showed statistical similarity between $\tau_{\mathrm{xz}}$ values of sample one and sample two (p-value=0.6068,Table 10). All other locations showed $\tau_{\mathrm{xz}}$ values were statistically different between sample times (p-value $\leq$ 0.0368, Table 10). Values of $\tau_{\mathrm{xz}}$ were statistically different between the two sample locations in a common reach (p-value $\leq 0.0004$, Table 11).

Similar to TKE, a correlation can be seen between the standard deviations of flow depth and the average $\tau_{\mathrm{xz}}$ of the sample area. R0L2S1 and R0L2S2 have mean $\tau_{\mathrm{xz}}$ values of $0.75 \mathrm{~Pa}$ and 0.57 $\mathrm{Pa}$, respectively (Table 10). These values are less than $60 \%$ of the mean of all locations (Table 10). The standard deviations of flow depth during these samples were $0.64 \mathrm{~cm}$ and $0.51 \mathrm{~cm}$, respectively, which are less than $60 \%$ of the mean for all samples (Table 9). This relationship is shown in Figure 37 where mean $\tau_{\mathrm{xz}}$ values for each sample were plotted against the standard deviation of flow depths. The correlation coefficient for these data was 0.63 . The contour plot of $\tau_{\mathrm{xz}}$ for R2L1S2 is presented in Figure 35. The spike in $\tau_{\mathrm{xz}}$ seen at location $(5,15)$ correlates 
with a sudden decrease in flow depth which occurs at location $(5,10)$. Conversely, a drop in $\tau_{\mathrm{xz}}$ at location $(10,25)$ correlates with an increase in flow depth which occurs at location $(10,20)$. Similar correlations are seen in the contour plots for the second set of samples (Figure 36).

The box plots of $\tau_{\mathrm{xz}}$ show the similarities in distributions to those of TKE (Figure 34 and Figure 26). The box plot (Figure 34) shows that, as with TKE and $\tau_{\mathrm{xy}}, \mathrm{R} 2 \mathrm{~L} 2 \mathrm{~S} 2$, R0L2S1 and R0L2S2 have small ranges of $\tau_{\mathrm{xz}}$ compared to other locations. As with TKE values, large distributions of $\tau_{\mathrm{xz}}$ are seen in R1L1S1, R1L2S2, R2L1S1 and R2L1S2 (Figure 34). The pebble counts for these locations also indicate a large spread of bed material from very coarse sand or very fine gravel to medium, large or very large cobble (Table 7). Inversely, samples with small variances in $\tau_{\mathrm{xz}}$ values such as R3L1S1 and R3L1S2 also have low variability of bed material ranging from very coarse sand or very fine gravel to very coarse gravel (Table 7). These correlations are highlighted in Figure 38. The $\tau_{\mathrm{xz}}$ values at measurement locations were influenced by bed heterogeneity.

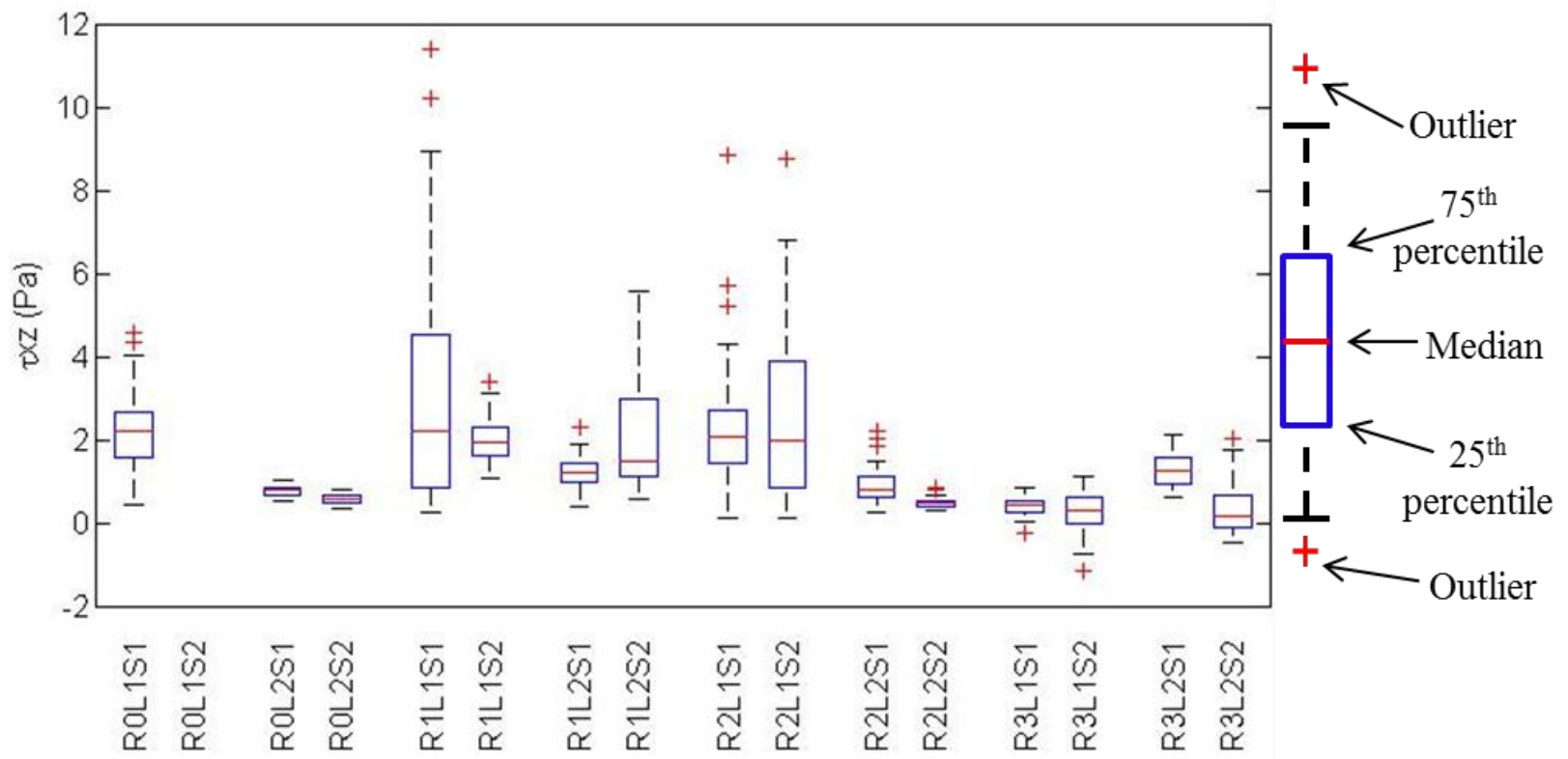

Figure 34: Distributions of $\tau_{\mathrm{xz}}$ values for all samples.

Note: $R, L$ and $S$ indicate reach number, location number and sample time, respectively. R0: reference reach, cattle restriction for 17 years; R1: cattle restriction; R2: cattle restriction and banks reshaped to 3:1 slope and re-vegetated; R3: cattle restriction, twostage channel design with in-set floodplain and re-vegetated. A second sample of ROL1 could not be taken due to low water depths and instrument limitations. 


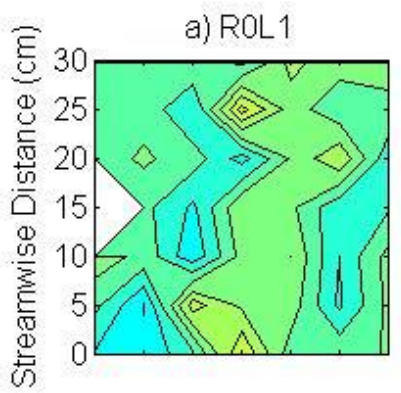

e) ROL2

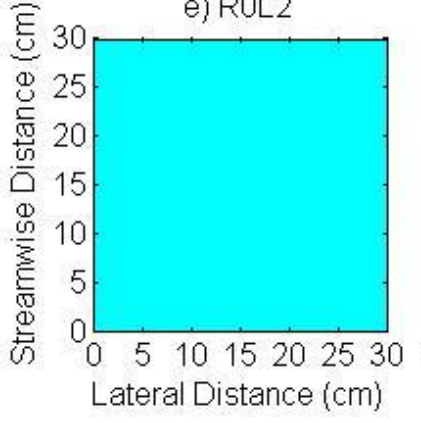

b) R1L1

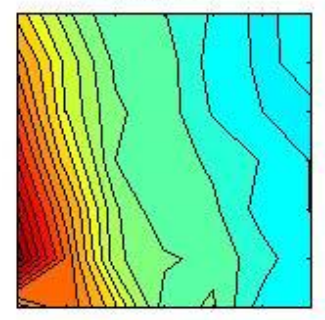

c) R2L1

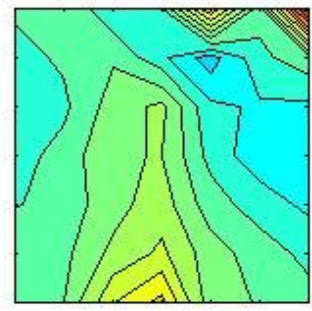

g) R2L2

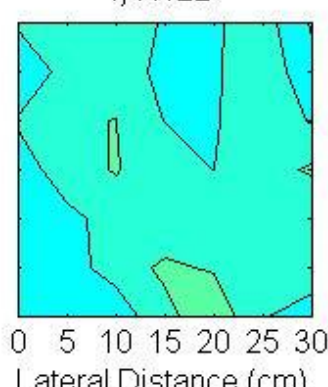

d) R3L1

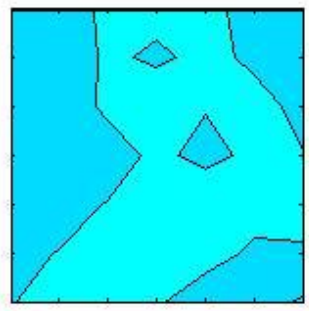

h) R3L2

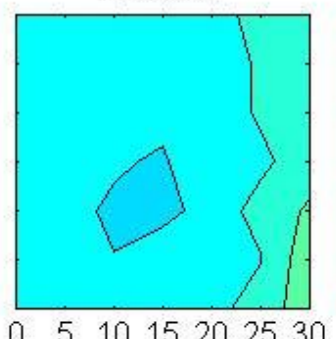

Lateral Distance $(\mathrm{cm})$ Lateral Distance $(\mathrm{cm})$

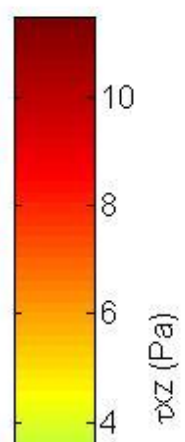

Figure 35: Spatial distributions of $\tau_{\mathrm{xz}}$ for the first sample time at all locations.

Note: $R$ and $L$ indicate reach number and location number, respectively. R0: reference reach, cattle restriction for 17 years; $R 1$ : cattle restriction; $R 2$ : cattle restriction and banks reshaped to 3:1 slope and re-vegetated; R3: cattle restriction, two-stage channel design with in-set floodplain and re-vegetated. One measurement is missing within ROL1 due to low correlation values. Flow is in positive streamwise direction. 


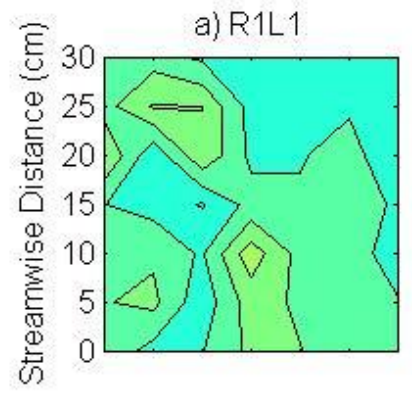

b) R2L1

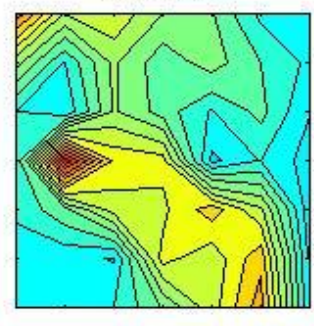

e) R1L2

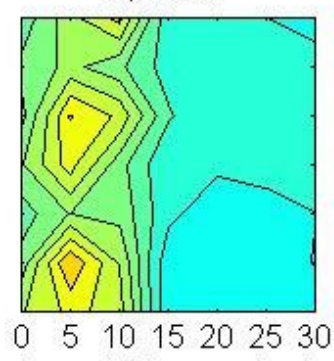

Lateral Distance $(\mathrm{cm})$ f) R2L2

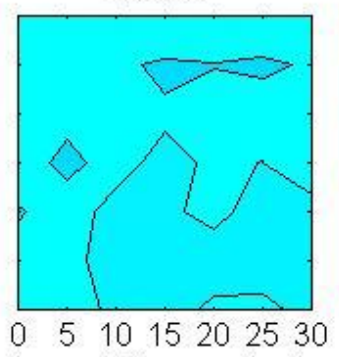

Lateral Distance $(\mathrm{cm})$ d) ROL2

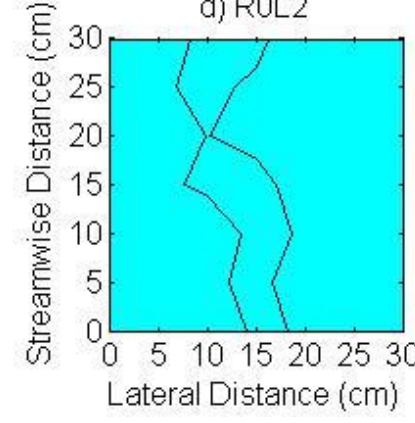

c) R3L1

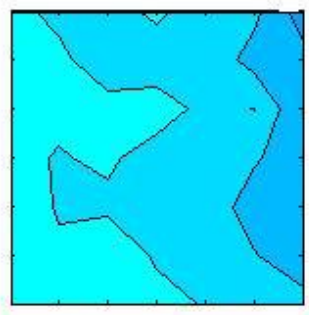

g) $R 3 L 2$

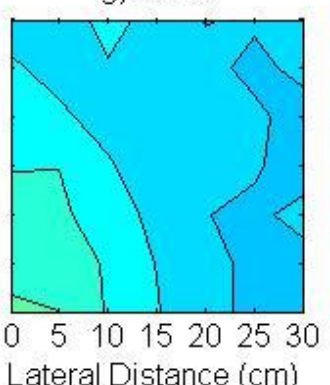

Figure 36: Spatial distributions of $\tau_{\mathrm{xz}}$ for the second sample time at all locations.

Note: $R$ and $L$ indicate reach number and location number, respectively. R0: reference reach, cattle restriction for 17 years; $R 1$ : cattle restriction; $R 2$ : cattle restriction and banks reshaped to 3:1 slope and re-vegetated; R3: cattle restriction, two-stage channel design with in-set floodplain and re-vegetated. A second sample of ROL1 could not be taken due to low water depths and instrument limitations. Flow is in positive streamwise direction.

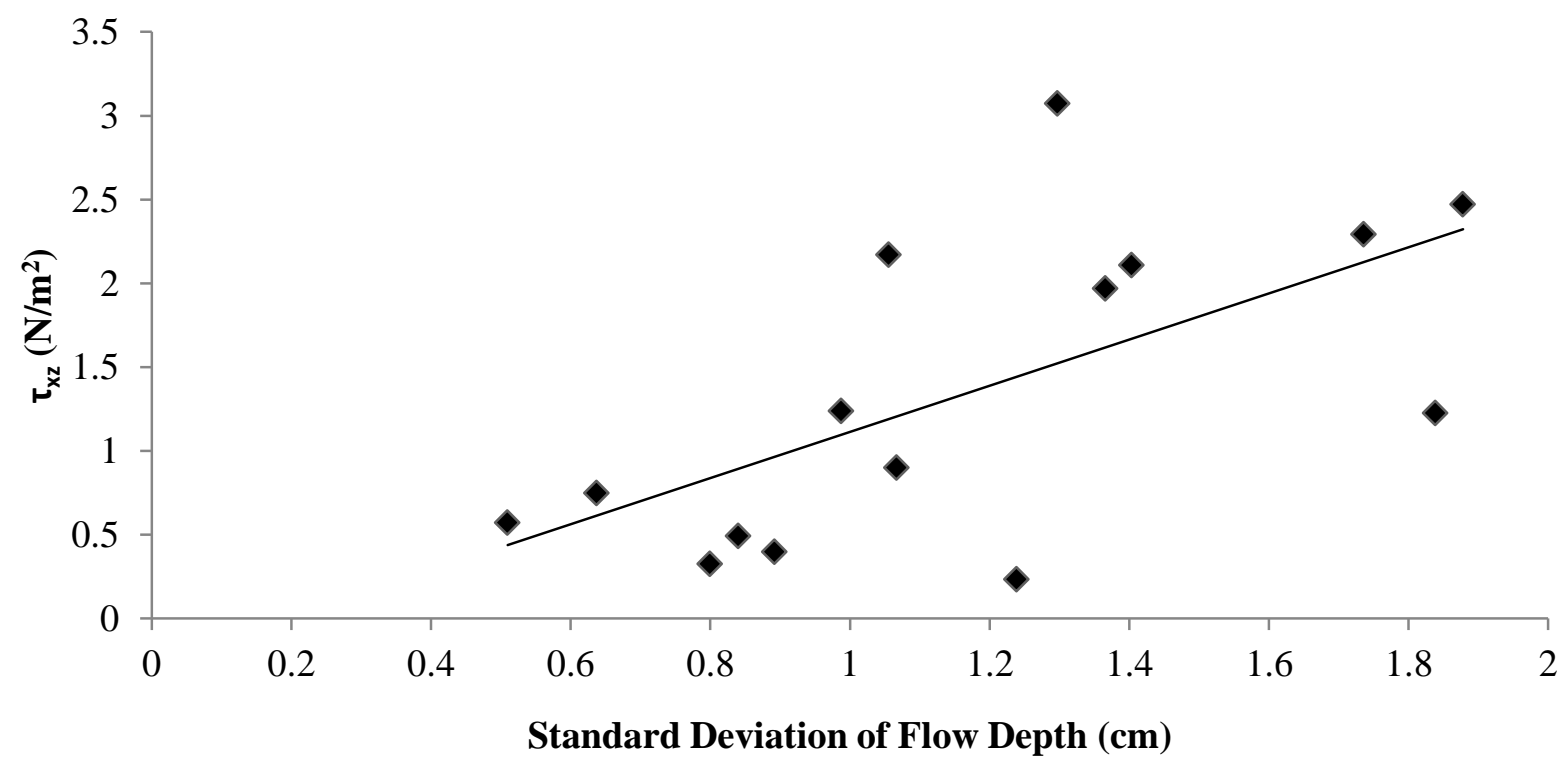

Figure 37: Mean $\tau_{\mathrm{xz}}$ versus standard deviations of flow depths for each sample with linear trend line shown with a correlation coefficient of 0.63 .

Note: A second sample of ROL1 could not be taken due to low water depths and instrument limitations. 


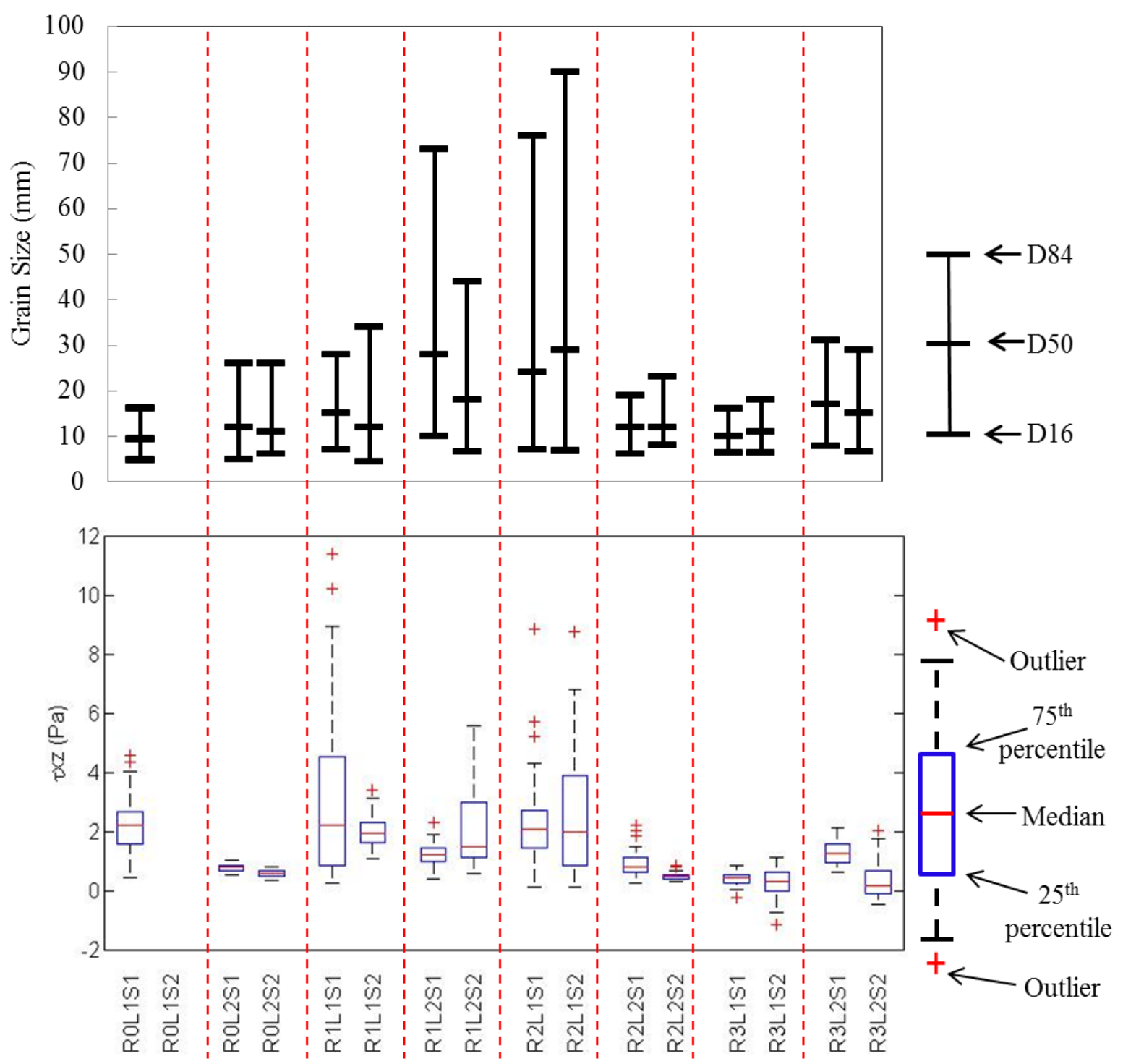

Figure 38: Comparison of grain size distributions to distributions of $\tau_{\mathrm{xz}}$ values for all samples.

Note: $R, L$ and $S$ indicate reach number, location number and sample time, respectively.

R0: reference reach, cattle restriction for 17 years; R1: cattle restriction; R2: cattle restriction and banks reshaped to 3:1 slope and re-vegetated; R3: cattle restriction, twostage channel design with in-set floodplain and re-vegetated. A second sample of R0L1 could not be taken due to low water depths and instrument limitations.

TKE values and $\tau_{\mathrm{xz}}$ show similar trends as explained in the earlier sections. This correlation is confirmed when plotting the mean TKE values against mean $\tau_{\mathrm{xz}}$ values (Figure 39). This plot has a correlation coefficient of 0.64 . 


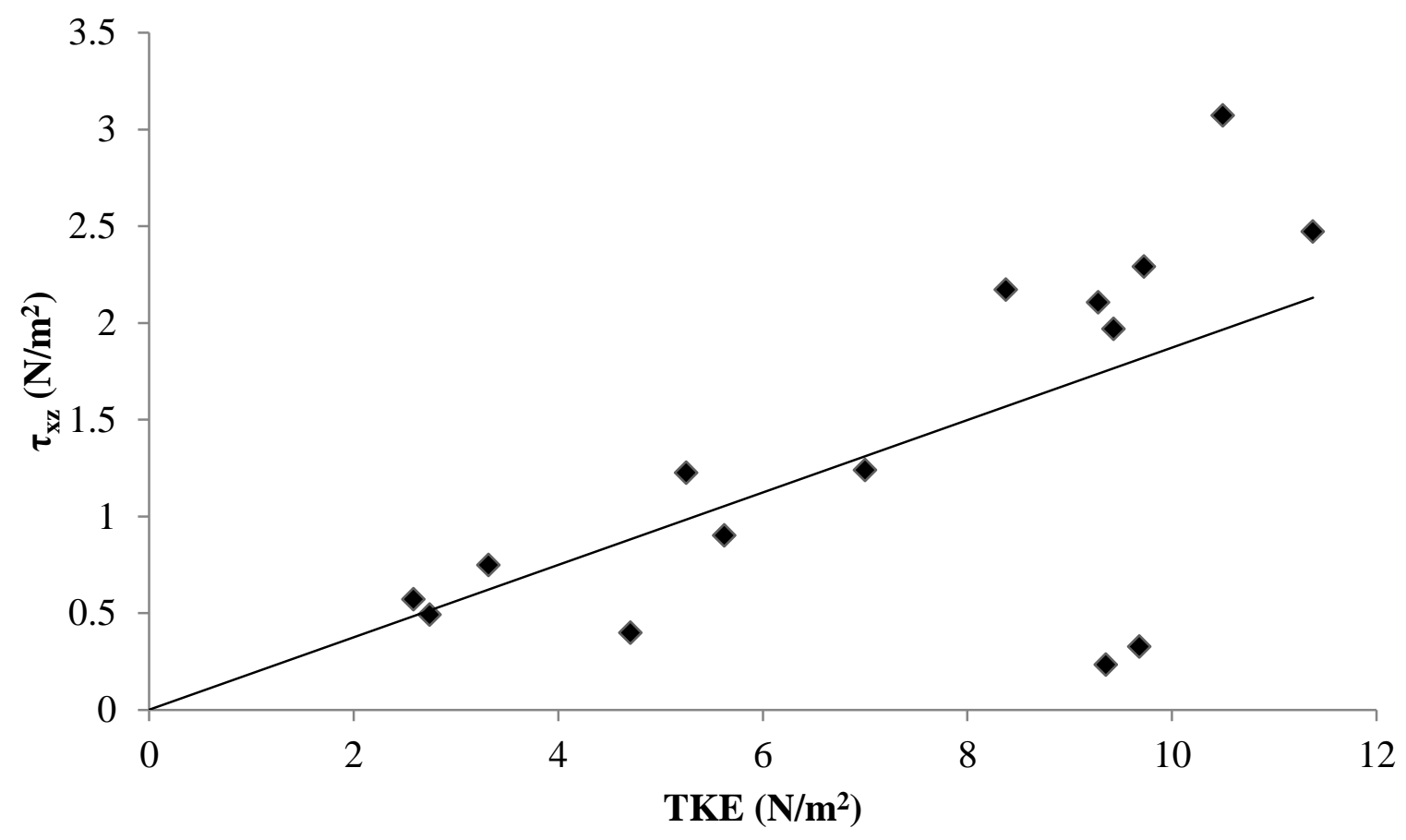

Figure 39: Mean TKE versus mean $\tau_{\mathrm{xz}}$ for each sample. Note: A second sample of ROL1 could not be taken due to low water depths and instrument limitations.

Values of $\tau_{\mathrm{xy}}$ were statistically similar between sample time one and sample time two with the exception of one location. The location of the measurement in the meander of the stream may have caused larger values of $\tau_{\mathrm{xy}}$. It is more difficult to identify trends in $\tau_{\mathrm{xy}}$ than with TKE and $\tau_{\mathrm{xz}}$. With the exception of one location, all sample locations showed TKE values were statistically different between sample times. A correlation can be seen between the standard deviations of flow depth within a sample area and the average $\tau_{\mathrm{xz}}$ of the sample area.

\subsection{Comparison of Restoration Treatments}

Differences were observed among experimental reaches when considering local, physical channel characteristics. The reference reach (cattle restriction for 17 years) typically had a baseflow channel width smaller than those of the restoration reaches (Table 9). The two locations within the reference reach have the smallest channel widths at baseflow ( $2.1 \mathrm{~m}$ and 2.4 $\mathrm{m}$ for location one and location two, respectively) (Table 9). One cause for this could be the bank protection by vegetation during large storm events which reduces bank erosion. Vegetation in this location has been allowed to establish for 17 years. The locations sampled within reach 
two (banks reshaped and re-vegetated) have the largest channel widths (3.3 $\mathrm{m}$ and $4.0 \mathrm{~m}$ for location one and location two, respectively) (Table 9). While reaches one (cattle restriction) and three (two-stage channel) had similar channel widths at base flow, the bankfull widths had differences. It can be seen in the channel cross sections (Figure 10, Figure 12, Figure 20, Figure 22) that reach one had much steeper banks than reach three. These steep banks prevent the flow from distributing over a large area during higher flows.

The physical differences between experimental reaches also include the vegetation growth on the banks and floodplains. The reference reach was surrounded by dense vegetation including grass, shrubs and large trees (Figure 4a and Figure 4b). Reaches one, two, and three were only surrounded with grass and shrubs with few exceptions due to historical cattle access. Trees have been planted around reaches two and three but are only 2-3 years old and offer no shade.

The most visually obvious difference between the physical conditions of the experimental reaches was the condition of the banks. The reference reach had steep banks in some sections but these banks have full vegetation coverage. The physical conditions of the banks in reach one were indicative of bank erosion. The banks in this reach were steep and void of vegetation which reduces the channel roughness. There were several locations where indications of recent bank failure were apparent (Figure 40). The banks in reaches two and three were visibly more stable than those in reach one. Banks had gradual slope and, with few exceptions, were completely covered with grassy vegetation. The difference between reaches two and three were mainly in the stream flow path. Reach two was generally straighter and contained few riffles while reach three contained many riffles and follows a meandering path as seen in Figure 2. 
a

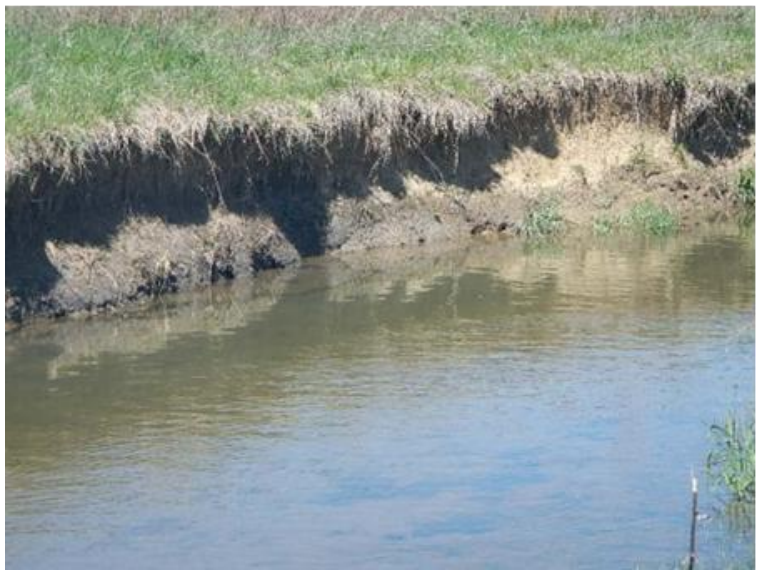

$\mathrm{b}$

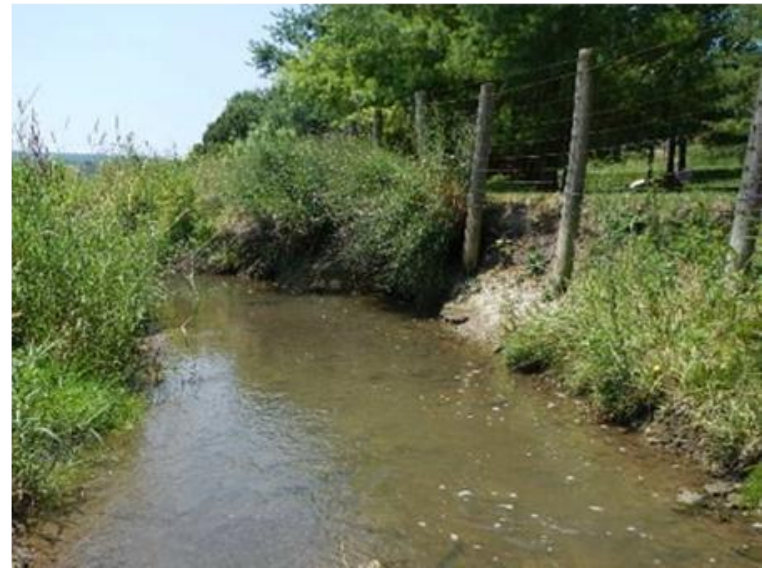

Figure 40: Examples of bank failure in reach one (cattle restriction).

A comparison of TKE values for each reach showed a few differences as well. The mean TKE within the reference reach was $4.8 \mathrm{~N} / \mathrm{m}^{2}$ which was less than $70 \%$ the average TKE of all four reaches $\left(7.1 \mathrm{~N} / \mathrm{m}^{2}\right.$ ) (Table 12). This lower mean is reflected in the box plot (Figure 41). The outliers on the plot for the reference reach are from the first sample of location one (R0L1S1). Since only one sample was collected from this location, the statistics are most affected by the samples taken at location two (R0L2). The mean TKE values of the two samples taken at location two were $3.3 \mathrm{~N} / \mathrm{m}^{2}$ and $2.6 \mathrm{~N} / \mathrm{m}^{2}$ for samples and two, respectively (Table 10). These means are less than half the mean TKE at location one $\left(8.4 \mathrm{~N} / \mathrm{m}^{2}\right)$ which explains the skewed box plot (Figure 41). The mean TKE for reach one, reach two, and reach three were $8.6 \mathrm{~N} / \mathrm{m}^{2}$, $7.4 \mathrm{~N} / \mathrm{m}^{2}$, and $7.7 \mathrm{~N} / \mathrm{m}^{2}$, respectively (Table 12). The boxplots for TKE of reach one and reach two also contain outliers. These indicate spikes in TKE explained in section 4.3Turbulent Kinetic Energy. No outliers are present in the plot of TKE for reach three and the TKE values are more evenly distributed. Values of TKE were statistically similar between reach two and reach three (Table 12). The statistical similarity between reach two and three could be due to similar channel characteristics in these two restoration reaches. In both reaches the channel has been altered and vegetation has been planted on the streambanks. Some similar trends are seen in distributions of $\tau_{\mathrm{xz}}$. 


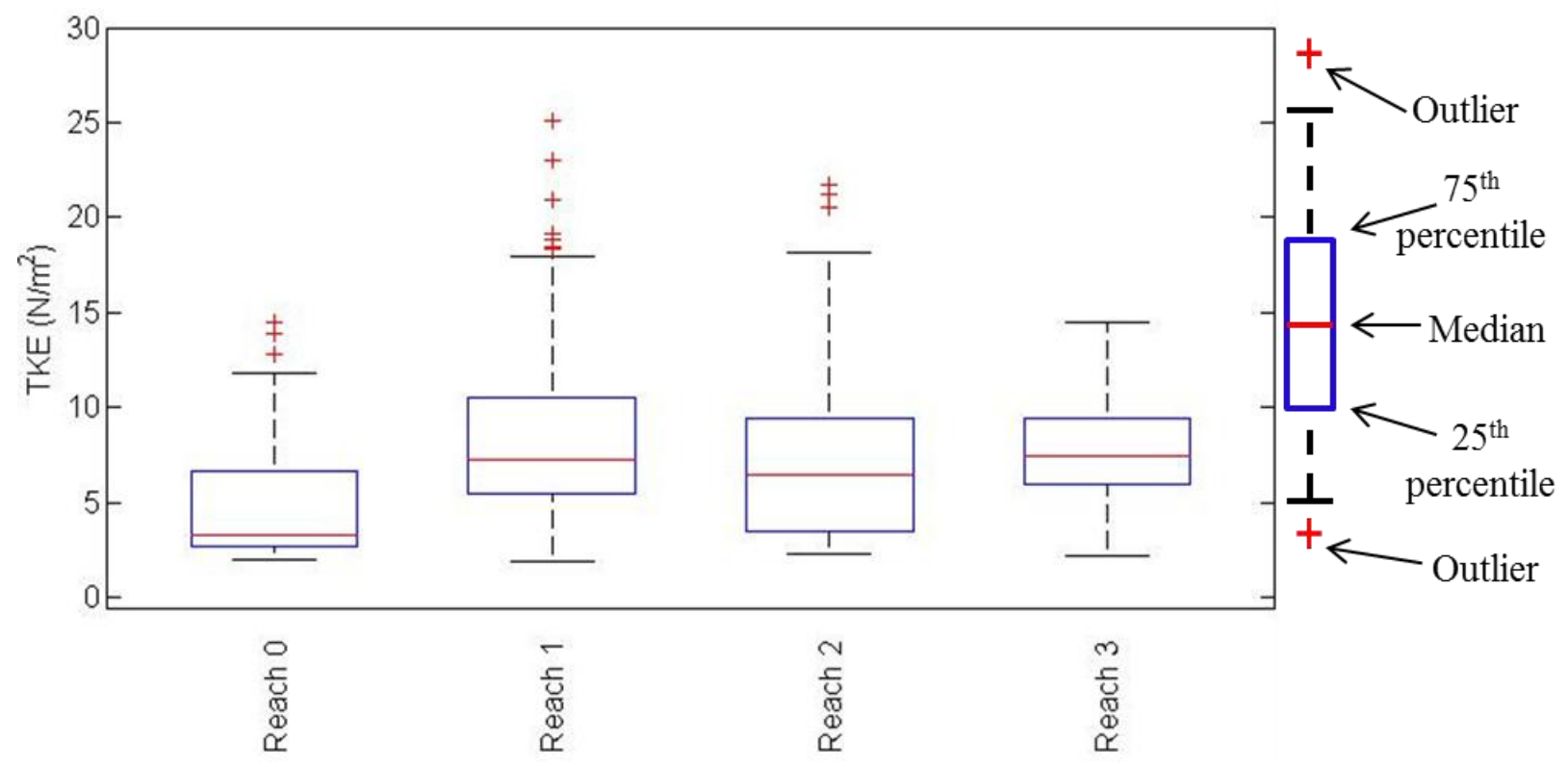

Figure 41: Distributions of TKE values for all experimental reaches.

Note: Reach zero: reference reach, cattle restriction for 17 years; reach one: cattle restriction; reach two: cattle restriction and banks reshaped to 3:1 slope and re-vegetated; reach three: cattle restriction, two-stage channel design with in-set floodplain and revegetated. Values for reach zero are based on only three samples; a second sample at location one could not be taken due to low water depths and instrument limitations.

The mean $\tau_{x y}$ was lowest for reach two $(-0.21 \mathrm{~Pa})$ and highest for the reference reach $(0.55 \mathrm{~Pa})$ (Table 12). The values of $\tau_{x y}$ were statistically similar between reach one and reach two (Table 12). The distributions of $\tau_{x y}$ for each restoration reach are shown in Figure 42. 


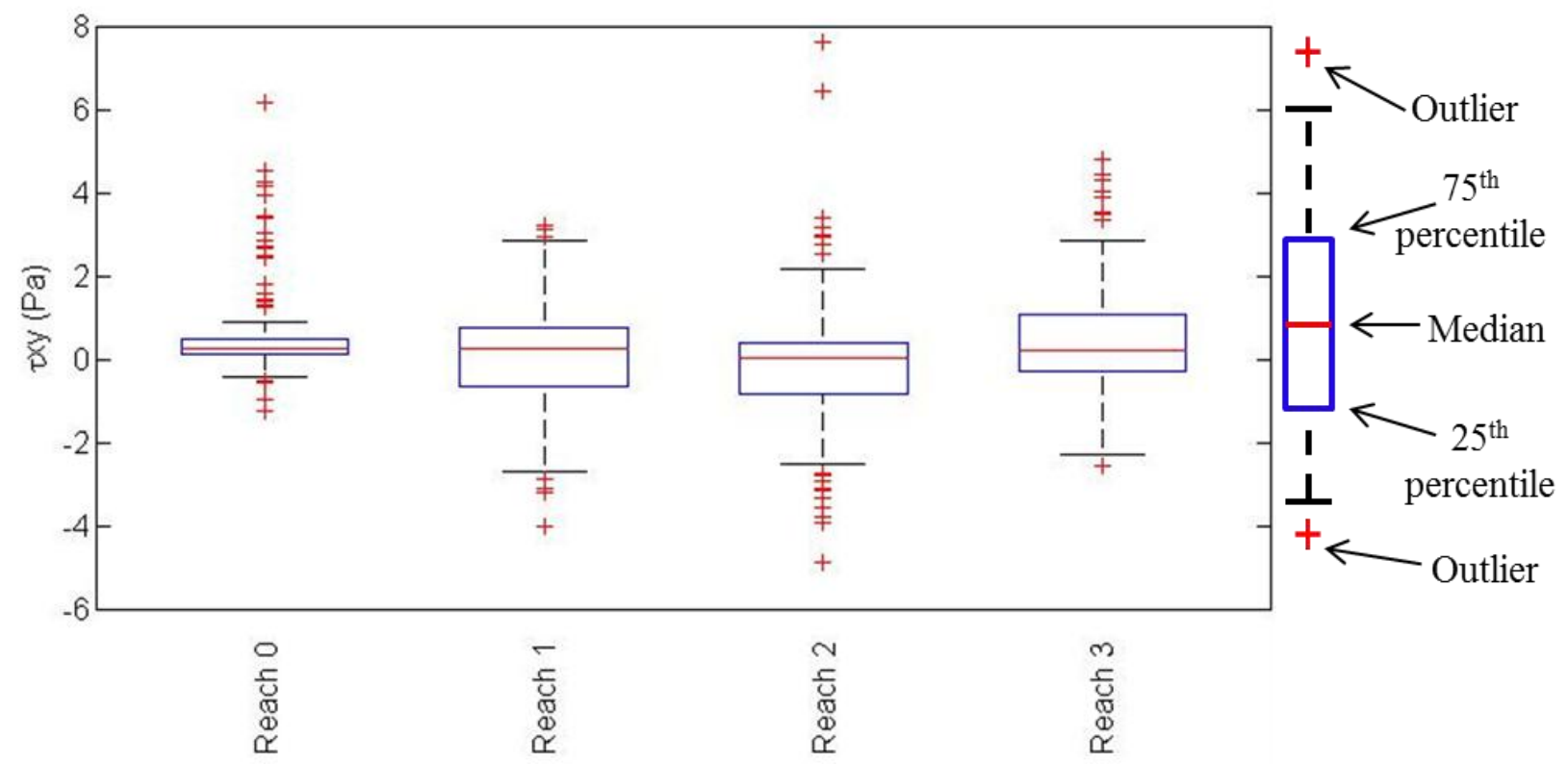

Figure 42: Distributions of $\tau_{\mathrm{xy}}$ values for all experimental reaches.

Note: Reach zero: reference reach, cattle restriction for 17 years; reach one: cattle restriction; reach two: cattle restriction and banks reshaped to 3:1 slope and re-vegetated; reach three: cattle restriction, two-stage channel design with in-set floodplain and revegetated. Values for reach zero are based on only three samples; a second sample at location one could not be taken due to low water depths and instrument limitations.

The mean $\tau_{x z}$ was lowest for reach $3(0.55 \mathrm{~Pa})$ and highest for reach one (2.09 Pa) which also had the highest mean TKE (Table 12). The values of $\tau_{x z}$ were statistically different for all experimental reaches (Table 12 and Figure 43). For box plots of $\tau_{x z}$ for the reference reach (Reach 0), reach one, and reach two outliers are found (Figure 43). These outliers, as with TKE, correspond to the spikes mentioned in section 4.4 Shear Stresses $\left(\tau_{\mathrm{xy}}\right.$ and $\left.\tau_{\mathrm{xz}}\right)$. As with the plot of TKE, the box plot of $\tau_{x z}$ for the reference reach is skewed due to the low values of $\tau_{x z}$ at location two and the lack of a second sample in location one (Figure 43). Again, similar to the TKE plot, the plot of $\tau_{\mathrm{xz}}$ for reach three is less skewed than the other plots and only contains two outliers which indicate a more even distribution. A more even distribution is likely due to the more stable conditions of the channel in this reach. 


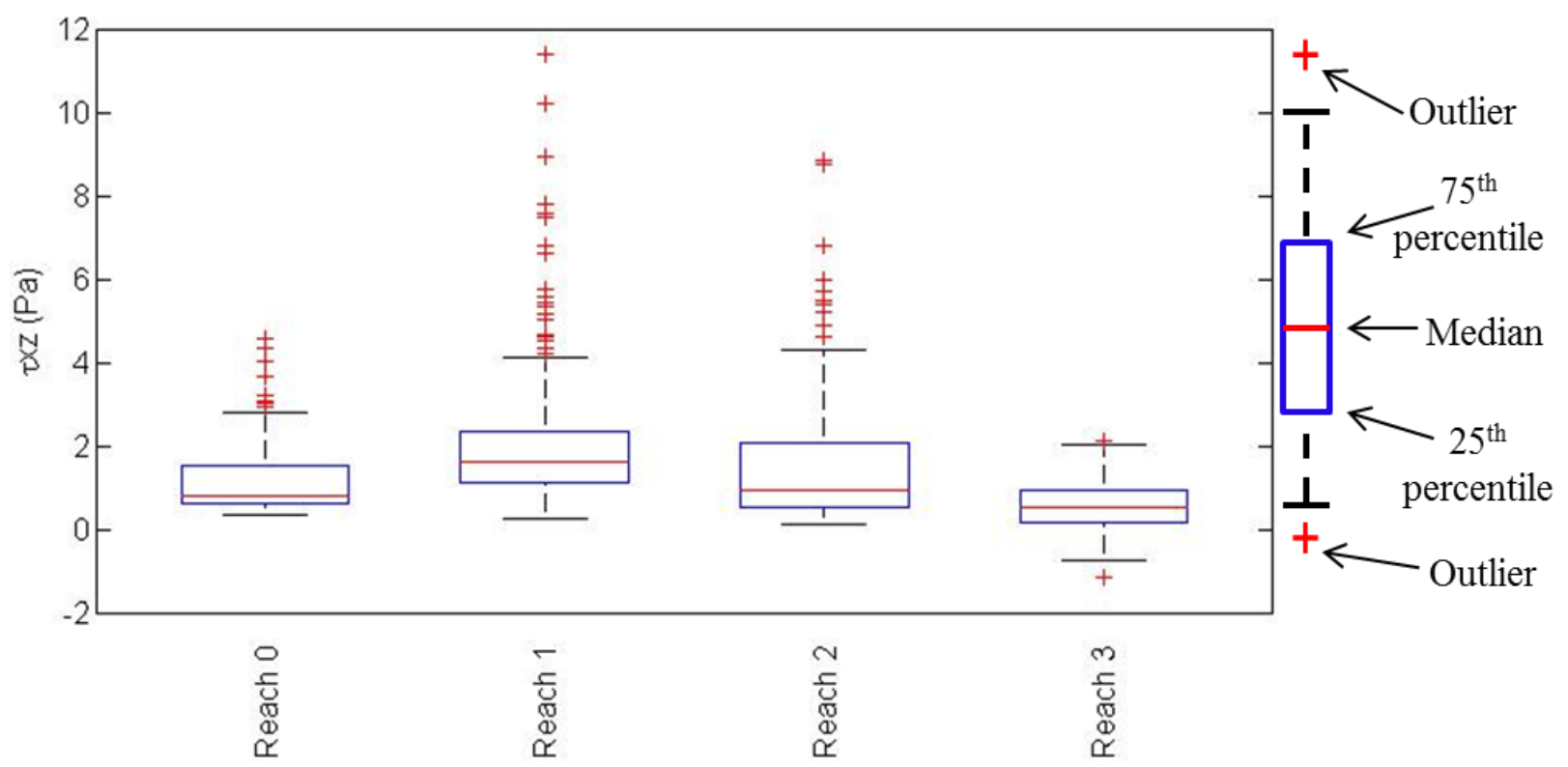

Figure 43: Distributions of $\tau_{\mathrm{xz}}$ values for all experimental reaches.

Note: Reach zero: reference reach, cattle restriction for 17 years; reach one: cattle restriction; reach two: cattle restriction and banks reshaped to 3:1 slope and re-vegetated; reach three: cattle restriction, two-stage channel design with in-set floodplain and revegetated. Values for reach zero are based on only three samples; a second sample at location one could not be taken due to low water depths and instrument limitations.

The Stroubles Creek watershed was affected by several large storms during the two month experimental data collection. While velocity data were only recorded at baseflow, Figure 25 (Appendix A) shows flow data for the full two months. The storms are identified by the large spikes in volumetric flow but these spikes do not reach over the bankfull flow of Stroubles Creek which is $5.66 \mathrm{~m}^{3} / \mathrm{s}$ (Stroubles Creek IP Steering Committee et al. 2006). These storms seem to have effectively moved sediment through the stream channel as many pebble counts indicate a change in streambed material from sample period one to sample period two.

The movement of sediment during these storms can be confirmed by turbidity readings which were also constantly measured during the full two month data collection time. Figure 44 in the appendix shows these turbidity data where the spikes in turbidity correlate with spikes in flow presented in Figure 25 (Appendix A). During the times of data collection the turbidity was generally between three and seven NTUs. 
Table 12: Mean values of TKE, $\tau_{\mathrm{xy}}$, and $\tau_{\mathrm{xz}}$ for each experimental reach.

\begin{tabular}{cccc}
\hline & TKE $\left(\mathbf{N} / \mathbf{m}^{\mathbf{2}}\right)$ & $\boldsymbol{\tau}_{\mathbf{x y}}(\mathbf{P a})$ & $\boldsymbol{\tau}_{\mathbf{x z}}(\mathbf{P a})$ \\
\hline $\mathbf{R 0}$ & $4.8[\mathrm{a}]$ & $0.55[\mathrm{a}]$ & $1.16[\mathrm{a}]$ \\
$\mathbf{R 1}$ & $8.6[\mathrm{~b}]$ & $0.03[\mathrm{~b}]$ & $2.09[\mathrm{~b}]$ \\
$\mathbf{R 2}$ & $7.4[\mathrm{c}]$ & $-0.21[\mathrm{~b}]$ & $1.54[\mathrm{c}]$ \\
$\mathbf{R 3}$ & $7.7[\mathrm{c}]$ & $0.49[\mathrm{a}]$ & $0.55[\mathrm{~d}]$ \\
\hline
\end{tabular}

Note: Letters indicate statistical correlations based on unpaired t-tests with $\alpha=0.05$. Values of turbulence characteristics within reaches labeled with common letters were statistically similar. $R$ indicates the reach number. $R 0$ : reference reach, cattle restriction for 17 years; R1: cattle restriction; R2: cattle restriction and banks reshaped to 3:1 slope and re-vegetated; R3: cattle restriction, two-stage channel design with in-set floodplain and re-vegetated. Values for reach zero are based on only three samples; a second sample at location one could not be taken due to low water depths and instrument limitations. 


\section{Conclusions}

Near boundary turbulence characteristics were analyzed among reaches of Stroubles Creek where stream restoration of varying intensity has been implemented. Two sample locations were chosen within each reach. Measurements were taken at 49 points within a $30 \mathrm{~cm}$ x $30 \mathrm{~cm}$ grid at a vertical distance of $7 \mathrm{~cm}$ from the streambed. Three-dimensional velocity measurements were recorded with an ADV for two minutes at $50 \mathrm{~Hz}$. Detailed cross section surveys were taken for each sample location. Modified Wolman pebble counts were conducted after each velocity measurement to analyze bed roughness. Velocity data were used to determine TKE and Reynolds shear stresses at each measurement. Student's t-tests were used to compare turbulence characteristics between sample times, reach locations, and restoration reaches.

At baseflow the differences among restoration treatments did not directly result in differences in turbulence statistics. Several major findings include:

- Streamwise velocity and overall velocity vector magnitude were influenced by the flow depth and the channel width of the stream cross section at the location and time of the sample.

- With the exception of R1L1S2 (cattle restriction) the contribution of vertical velocity, $\bar{w}$, was less than or equal to the contribution of the lateral velocity, $\bar{v}$.

- Lateral velocities were influenced by the sample location with respect to the stream meander.

- For all restoration treatments, excluding R1L1, TKE varied by sample date; likely due to redistribution of bed sediment following storm events.

- For all restoration treatments, excluding R2L1 (banks reshaped and re-vegetated), $\tau_{\mathrm{xz}}$ varied by sample date; likely due to redistribution of bed sediment following storm events.

- Values of TKE and $\tau_{\mathrm{xz}}$ were statistically different among sample locations for each treatment.

- A correlation can be seen between the variances of flow depth and turbulence characteristics. This correlation indicates that the streambeds with greater variability cause greater TKE and $\tau_{\mathrm{xz}}$. 
- TKE and $\tau_{\mathrm{xz}}$ had similar spatial distributions.

- Within reach three (two-stage channel) the TKE and $\tau_{\mathrm{xz}}$ values were more evenly distributed.

\subsection{Study Limitations and Future Research}

Limitations of the study were attributed to instrumentation, site characteristics, and time restrictions. The instrument used to measure velocities cannot be operated during storms so no storm flow events could be captured. The time required to setup the ADV and run the sampling procedures limited the study to one sample per day. Efforts were taken to find sites which had similar flow characteristics within each reach for this comparison. There were difficulties in finding multiple sites within each reach which had suitable characteristics such as location one in the reference reach (cattle restriction) where the flow depth at the time of the second sample was too low for the instrumentation to function properly.

Several suggestions can be made for future research related to this study. All velocity measurements in this study were taken during baseflow when flow was constrained within the channel. At storm flow the conditions of the banks (i.e. slope and vegetation coverage) have an effect on the turbulence characteristics. Measurements during large storm events may show greater differences between the restoration techniques. With only two locations sampled within each reach it is difficult to represent a full reach of stream and make comparisons between the restoration techniques. For future studies, more sample locations and larger sample grids would offer a more accurate representation of each reach. 


\section{References}

Bernhardt, E. S., Palmer, M. A., Allan, J. D., Alexander, G., Barnas, K., Brooks, S., Carr, J., Clayton, S., Dahm, C., Follstad-Shah, J., Galat, D., Gloss, S., Goodwin, P., Hart, D., Hassett, B., Jenkinson, R., Katz, S., Kondolf, G. M., Lake, P. S., and Lave, R. (2005).

"Synthesizing U.S. River Restoration Efforts." Science, 308(5722), 636-637.

Bradshaw, P. (1971). An Introduction to Turbulence and its Measurement. Pergamon Press, Oxford; New York.

Buffin-Bélanger, T., and Roy, A. G. (2005). "1 Min in the Life of a River: Selecting the Optimal Record Length for the Measurement of Turbulence in Fluvial Boundary Layers." Geomorphology, 68(1), 77-94.

Crowder, D. W., and Diplas, P. (2002). "Vorticity and Circulation: Spatial Metrics for Evaluating Flow Complexity in Stream Habitats." Canadian Journal of Fisheries and Aquatic Sciences, 59(4), 633.

Dantec Dynamics A/S. (2012). "Measurement Principles of LDA." http://www.dantecdynamics.com/Default.aspx?ID=1046 $(09 / 03,2012)$.

Doll, B. A., Grabow, G. L., Hall, K. R., Halley, J., Harman, W. A., Jennings, G. D., and Wise, D. E. (2003). Stream Restoration: A Natural Channel Design Handbook. NC Stream Restoration Institute, NC State University.

Environmental Protection Agency (U.S.). (2009). "National Water Quality Inventory Report to Congress: 2004 Reporting Cycle." Rep. No. EPA 841-R-08-001, USEPA, Washington, D.C.

Franca, M., Ferreira, R. M. L., and Lemmin, U. (2008). "Parameterization of the Logarithmic Layer of Double-Averaged Streamwise Velocity Profiles in Gravel-Bed River Flows." Adv. Water Resour., 31(6), 915-925.

Goring, D., and Nikora, V. (2002). "Despiking Acoustic Doppler Velocimeter Data." J.Hydraul.Eng., 128(1), 117-126.

Harrelson, C. C., Rawlins, C. L., and Potyondy, J. P. (1994). "Stream Channel Reference Sites: An Illustrated Guide to Field Technique." Rep. No. RM-245, U.S. Department of Agriculture, Forest Service, Rocky Mountain Forest and Range Experiment Station, Fort Collins, CO.

Hassett, B. A., Palmer, M. A., and Bernhardt, E. S. (2007). "Evaluating Stream Restoration in the Chesapeake Bay Watershed through Practitioner Interviews." Restor.Ecol., 15(3), 563-572. 
Hopkinson, L., and Wynn, T. (2009). "Vegetation Impacts on Near Bank Flow." Ecohydrology, 2(4), 404-418.

Lacey, R. W. J., and Roy, A. G. (2007). "A Comparative Study of the Turbulent Flow Field with and Without a Pebble Cluster in a Gravel Bed River." Water Resour.Res., 43(5), W05502.

Lagasse, P. F., and Thompson, P. L. (1995). "Guarding against scour." Civil Engineering (08857024), 65(6), 56.

Lane, S. N., Biron, P. M., Bradbrook, K. F., Butler, J. B., Chandler, J. H., Crowell, M. D., McLelland, S. J., Richards, K. S., and Roy, A. G. (1998). "Three-dimensional measurement of river channel flow processes using acoustic doppler velocimetry." Earth Surf.Process.Landforms, 23(13), 1247-1267.

Natural Resources Conservation Service. (2007). "Part 654: Stream Restoration Design." National Engineering Handbook, United States Department of Agriculture, Washington, D.C., .

Nezu, I., and Rodi, W. (1986). "Open-channel Flow Measurements with a Laser Doppler Anemometer." J.Hydraul.Eng., 115(5), 335-355.

Pujol, D., Colomer, J., Serra, T., and Casamitjana, X. (2010). "Effect of submerged aquatic vegetation on turbulence induced by an oscillating grid." Cont.Shelf Res., 30(9), 1019-1029.

Radspinner, R. R., Diplas, P., Lightbody, A. F., and Sotiropoulos, F. (2010). "River Training and Ecological Enhancement Potential Using In-Stream Structures." J.Hydraul.Eng., 136(12), 967-980.

Rosgen, D. L. (2001). "The Reference Reach: A Blueprint for Natural Channel Design." Proceedings of the ASCE Wetlands Engineering and River Restoration Conference, ASCE, Reston, Virginia, .

Roy, A. G., Biron, P., and Serres, B.,DE. (1996). "On the necessity of applying a rotation to instantaneous velocity measurements in river flows." Earth Surf.Process.Landforms, 21(9), 817-827.

Roy, M. L., Roy, A. G., and Legendre, P. (2010). "The relations between 'standard' fluvial habitat variables and turbulent flow at multiple scales in morphological units of a gravelbed river." River Res and Applic, 26(4), 439-455.

Shields, F., Cooper, C., and Knight, S. (1995). "Experiment in Stream Restoration." J.Hydraul.Eng., 121(6), 494-502.

Simon, A., Doyle, M., Kondolf, M., Shields Jr., F. D., Rhoads, B., and McPhillips, M. (2007). "Critical Evaluation of how the Rosgen Classification and Associated "Natural 
Channel Design" Methods Fail to Integrate and Quantify Fluvial Processes and Channel Response." J.Am.Water Resour.Assoc., 43(5), 1117-1131.

SonTek. (2008). "16 MHz MicroADV."

http://www.dantecdynamics.com/Default.aspx?ID=1046 (09/02/12, 2012).

StREAM. (2011). "Stream Restoration, Education, and Management (StREAM) Lab." https://sites.google.com/site/stroublescreek/ (Sept. 18, 2011).

Strom, K., and Papanicolaou, A. (2007). "ADV Measurements around a Cluster Microform in a Shallow Mountain Stream." J.Hydraul.Eng., 133(12), 1379-1389.

Stroubles Creek IP Steering Committee, Virginia Tech Department of Biological Systems Engineering, and Virginia Water Resources Research Center. (2006). "Upper Stroubles Creek Watershed TMDL Implementation Plan Montgomery County, Virginia." Rep. No. 2005-0013, VT-BSE, .

Sukhodolov, A. N., and Sukhodolova, T. A. (2010). "Case Study: Effect of Submerged Aquatic Plants on Turbulence Structure in a Lowland River." J.Hydraul.Eng., 136(7), 434446.

Tennekes, H., and Lumley, J. L. (1972). A First Course in Turbulence. MIT Press, Cambridge, Mass.

Thompson, T. W., Hession, W. C., and Scott, D. (2012). "StREAM Lab at Virginia Tech." Resource, Special Section March/April 8.

Trowbridge, J. H., Geyer, W. R., Butman, C. A., Chapman, R. J., and Woods Hole Oceanographic Institution MA Coastal, Research Center. (1989). The 17-Meter Flume at the Coastal Research Laboratory. Part 2. Flow Characteristics. Defense Technical Information Center, .

Voulgaris, G., and Trowbridge, J. H. (1998). "Evaluation of the Acoustic Doppler Velocimeter (ADV) for Turbulence Measurements." Journal of Atmospheric \& Oceanic Technology, 15(1), 272.

Wahl, T. T. L. (2000). "Analyzing ADV data using WinADV." 2000 Joint Conference on Water Resources Engineering and Water Resources Planning and Management, American Society of Civil Engineers, Reston, Virginia, .

Wilcox, A. C., and Wohl, E. E. (2007). "Field measurements of three-dimensional hydraulics in a step-pool channel." Geomorphology, 83(3-4), 215-231.

Wolman, M. G. (1954). "A method of sampling coarse river-bed material." Transactions of the American Geophysical Union, 35(6), 951-956. 


\section{Appendix}

Table 13: Results of pebble counts taken immediately following each velocity measurement.

\begin{tabular}{|c|c|c|c|c|c|c|c|c|c|c|c|c|c|c|c|c|c|}
\hline \multirow[b]{3}{*}{ Material } & \multirow[b]{3}{*}{ Size Range (mm) } & \multicolumn{4}{|c|}{ RO } & \multicolumn{4}{|c|}{ R1 } & \multicolumn{4}{|c|}{$\mathbf{R 2}$} & \multicolumn{4}{|c|}{ R3 } \\
\hline & & \multicolumn{2}{|c|}{ L1 } & \multicolumn{2}{|c|}{$\mathbf{L 2}$} & \multicolumn{2}{|c|}{$\mathbf{L 1}$} & \multicolumn{2}{|c|}{$\mathbf{L 2}$} & \multicolumn{2}{|c|}{ L1 } & \multicolumn{2}{|c|}{$\mathbf{L} 2$} & \multicolumn{2}{|c|}{ L1 } & \multicolumn{2}{|c|}{$\mathbf{L 2}$} \\
\hline & & S1 & S2 & S1 & S2 & S1 & $\mathbf{S 2}$ & S1 & S2 & S1 & S2 & S1 & S2 & S1 & $\mathbf{S 2}$ & S1 & $\mathbf{S 2}$ \\
\hline very coarse sand & $1-2$ & 0 & NA & 0 & 0 & 0 & 1 & 2 & 2 & 0 & 0 & 0 & 0 & 1 & 0 & 0 & 0 \\
\hline very fine gravel & $2-4$ & 5 & NA & 12 & 3 & 3 & 12 & 2 & 1 & 1 & 7 & 2 & 2 & 6 & 5 & 3 & 5 \\
\hline fine gravel & $4-6$ & 5 & NA & 8 & 12 & 7 & 11 & 3 & 8 & 6 & 5 & 13 & 4 & 7 & 8 & 2 & 5 \\
\hline fine gravel & $6-8$ & 16 & NA & 15 & 21 & 10 & 12 & 4 & 16 & 14 & 8 & 16 & 10 & 9 & 14 & 12 & 16 \\
\hline medium gravel & $8-11$ & 9 & NA & 12 & 17 & 11 & 12 & 6 & 7 & 4 & 9 & 15 & 25 & 39 & 22 & 10 & 9 \\
\hline medium gravel & $11-16$ & 18 & NA & 16 & 17 & 24 & 13 & 13 & 11 & 7 & 6 & 22 & 30 & 23 & 31 & 20 & 18 \\
\hline coarse gravel & $16-22$ & 16 & NA & 14 & 12 & 21 & 15 & 12 & 16 & 14 & 8 & 27 & 11 & 8 & 13 & 15 & 16 \\
\hline coarse gravel & $22-32$ & 20 & $\mathrm{NA}$ & 16 & 13 & 12 & 6 & 13 & 13 & 14 & 10 & 3 & 13 & 6 & 6 & 24 & 20 \\
\hline very coarse gravel & $32-45$ & 2 & NA & 3 & 5 & 5 & 13 & 11 & 11 & 14 & 15 & 2 & 3 & 1 & 1 & 11 & 2 \\
\hline very coarse gravel & $45-64$ & 1 & NA & 1 & 1 & 5 & 3 & 13 & 3 & 9 & 10 & 0 & 1 & 0 & 0 & 1 & 1 \\
\hline small cobble & $64-90$ & 0 & NA & 0 & 0 & 0 & 1 & 13 & 2 & 2 & 6 & 0 & 1 & 0 & 0 & 1 & 0 \\
\hline medium cobble & $90-128$ & 3 & NA & 3 & 3 & 2 & 1 & 0 & 10 & 7 & 11 & 0 & 0 & 0 & 0 & 1 & 3 \\
\hline large cobble & $128-180$ & 5 & NA & 0 & 0 & 0 & 0 & 4 & 0 & 4 & 5 & 0 & 0 & 0 & 0 & 0 & 5 \\
\hline very large cobble & $180-256$ & 0 & NA & 0 & 0 & 0 & 0 & 4 & 0 & 4 & 0 & 0 & 0 & 0 & 0 & 0 & 0 \\
\hline
\end{tabular}

Note: $R, L$, and $S$ indicate reach number, location number, and sample time, respectively. R0: reference reach, cattle

restriction; R1: cattle restriction; R2: cattle restriction and reshape banks to 3:1 slope; $R 3$ : cattle restriction, two-stage channel design with in-set floodplain. A second sample of R0L1 could not be taken due to low water depths and instrument limitations. 


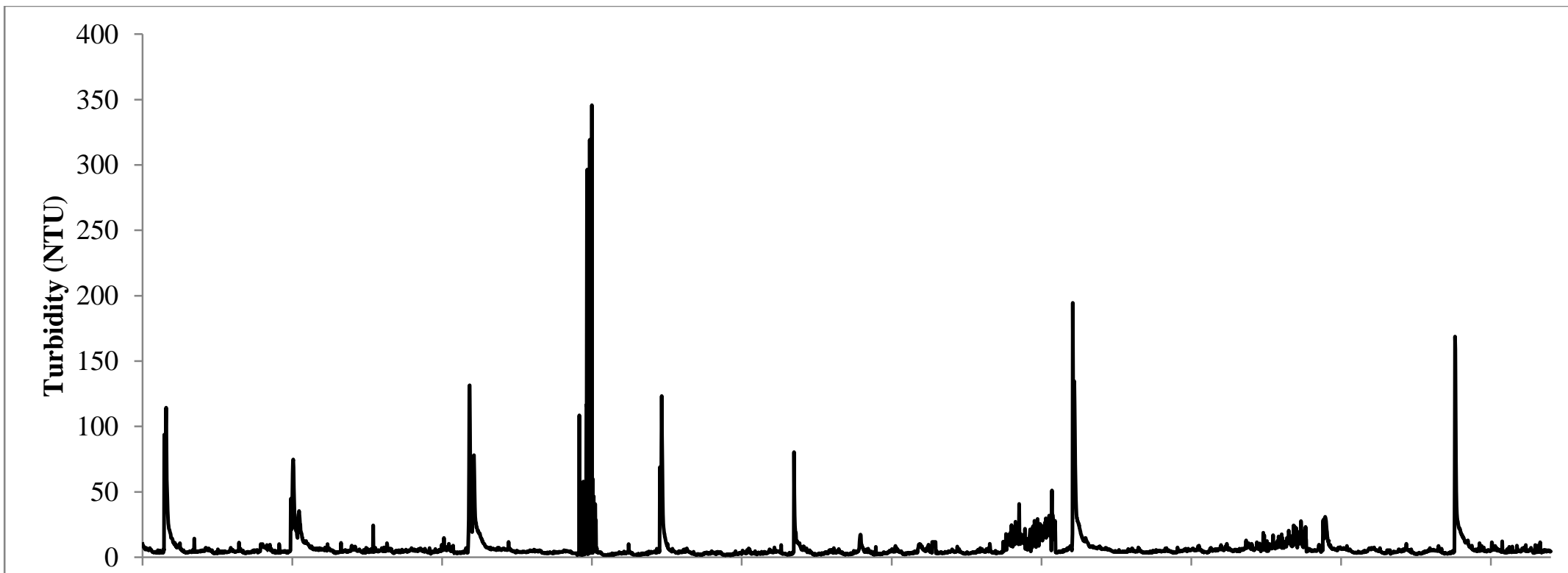

1-Jun-2012 6-Jun-2012 11-Jun-2012 16-Jun-2012 21-Jun-2012 26-Jun-2012 1-Jul-2012 6-Jul-2012 11-Jul-2012 16-Jul-2012 Date and Time

Figure 44: Continuous turbidity measurements for the two month sample period. 